\begin{tabular}{|l|l|}
\hline 2. To: (Receiving Organization) & 3. From: Coriginating Organization) \\
SST Retrieval Projects & SST Retrieval Projects \\
\hline 5. Proj./Prog./Dept./Div.: & $\begin{array}{l}\text { 6. Design Authority/ Design Agent/Cog. } \\
\text { Engr.: } \\
\text { John Bailey }\end{array}$ \\
\hline
\end{tabular}

8. Originator Remarks:

For Approval and Release

11. Receiver Remarks: 11A. Design Basel ine Document? [] Yes [X] No

4. Related EDT No.:

624378

7. Purchase Order No.:

NA

9. Equip./Component No.: POR-007/POR-008

10. System/8ldg./Facility: West Tank Farms

12. Major Assm. Dwg. No.:

H-14-102610

13. Permit/Permit Application No.:

14. Required Response Date:

July 22, 1998

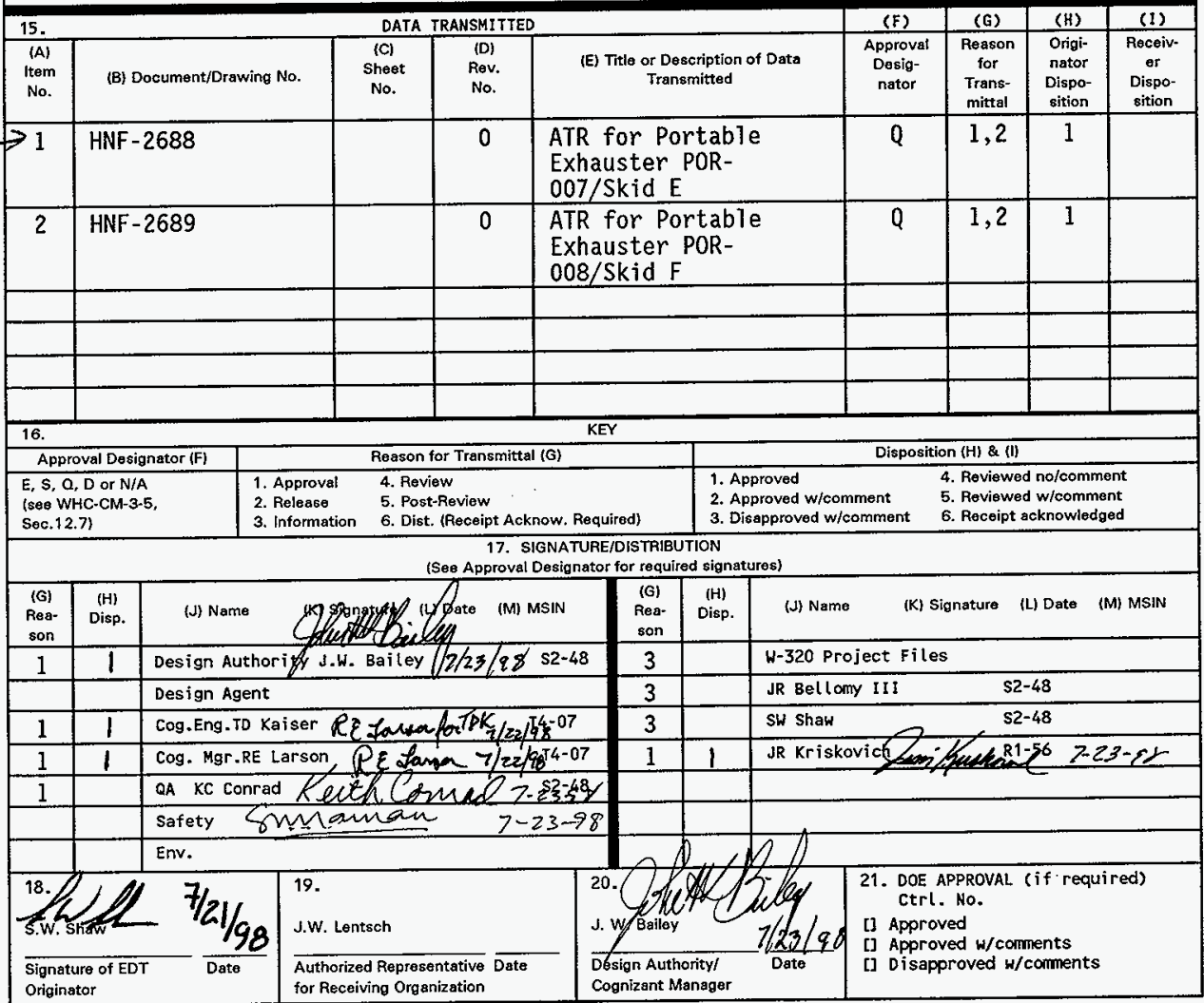

BD-7400-172-2 (05/96) GEF097 


\title{
ACCEPTANCE TEST REPORT FOR PORTABLE EXHAUSTER POR-007/SKID E
}

\author{
J.R. Kriskovich \\ Lockheed Martin Hanford Company, Richland, WA 99352 \\ U.S. Department of Energy Contract DE-AC06-96RL 13200
}

EDT/ECN: 624762

Org Code: LK400

UC: 510

B\&R Code: EW3130010

Charge Code: D2M41

Total Pages:

$15 T 160$

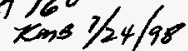

Key Words: Acceptance Test, Portable Exhauster, W320, Annulus, Ventilation

\section{Abstract:}

This document describes Acceptance Testing performed on Portable Exhauster POR-007/Skid E. It includes measurements of bearing vibration levels, pressure decay testing, programable logic controller interlocks, high vacuum, flow and pressure control functional testing.

TRADEMARK DISCLAIMER. Reference herein to any specific comerciat product, process, or service by trade name, trademark, manufacturer, or otherwise, does not necessarily constitute or imply its endorsement, recommendation, or favoring by the United States Government or any agency thereof or its contractors or subcontractors.

Printed in the United States of America. To obtain copies of this document, contact: Document Control Services, P.O. Box 950, Mailstop H6-08, Richland WA 99352 , Phone (509) 372-2420; Fax (509) 376-4989.
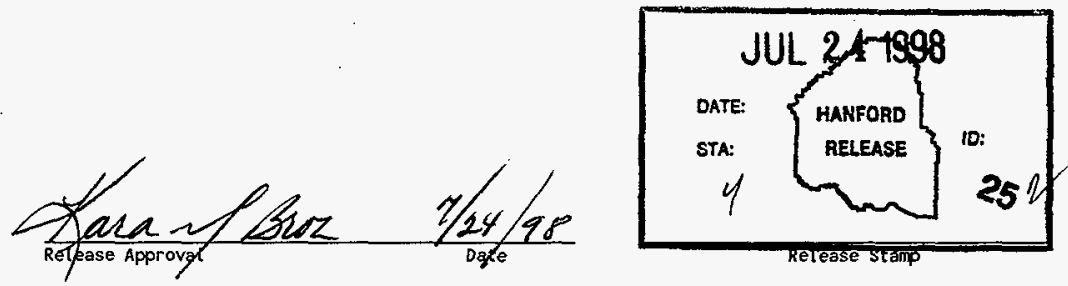

\section{Approved for Public Release}


HNF-2688

Rev. 0

\section{ACCEPTANCE TEST REPORT FOR PORTABLE \\ EXHAUSTER POR-007/SKID E}

by

S. W. Shaw

July 20, 1998

contact

J. R. Bellomy III 


\section{EXECUTIVE SUMMARY}

\section{INTRODUCTION}

Portable Exhauster POR-007 was procured via HNF-0490, "Specification for a Portable Exhauster System for Waste Tank Ventilation." Prior to taking ownership, Acceptance testing was performed at the vendors. However at the conclusion of testing a number of issues remained that required resolution before the exhausters could be used by Project W-320.

The purpose of Acceptance testing documented by this report was to demonstrate compliance of the exhausters with the performance criteria established within HNF-0490, Rev. 1 following a repair and upgrade effort at Hanford. In addition, data obtained during this testing is required for the resolution of outstanding Non-conformance Reports (NCR), and finally, to demonstrate the functionality of the associated software for the pressure control and high vacuum exhauster operating modes provided for by $\mathrm{W}-320$.

Additional testing not required by the ATP was also performed to assist in the disposition and close out of recieving inspection report and for application design information (system curve). Results of this testing are also captured within this document.

\section{OBSERVATIONS AND CONCLUSIONS}

A number of procedural deficentcies were noted in the ATP as identified by the redline/strike out comments captured in this test report. The redline comments noted have been incorporated into the ATP via ECN 647640 . A listing of exceptions encountered during the ATP begins on page 108. All exceptions were resolved during testing.

A "technical" exception observed during testing occured during efforts to operate the exhausters in flow control mode at 1000 CFM (intended to simulate operation connected to a primary tank) while attached to the inlet station and HEPA filter used for testing. When operating in this configuration, exhauster inlet vacuums exceeded the 3.5 INWC interlock value, and shut down the exhauster. Upon consideration this was resolved by removing the G-1 Filter housing cover, by-passing the HEPA filter. A roughing filter was placed over the 12" diameter opening leading to the hose connection, and the butterfly damper (EW-1) was used to establish the 3 INWC vacuum required at the exhauster inlet while operating at $1000 \mathrm{CFM}$.

Noise levels produced by the exhausters were measured during the course of testing at 1000 SCFM, and found to be below the $86 \mathrm{~dB}$ allowed by HNF-0490 at a distance of 1 meter from the stack exit. Data obtained during sound level testing is included as Attachment 17.

Although not required by the ATP, system curves were obtained for the exhauster while operating in the high vacuum mode. High efficiency mist eliminators had been removed, seal pot drain lines in the plenum had been plugged, and the exhauster was connected to a $\mathrm{G}-1$ filter housing equipped with a 1000 CFM HEPA filter by way of a 12 inch diameter hose. Using this data to plot a system curve for both the portable exhauster and the 102-AY annulus it can be shown that POR-007 should be capable of producing a flow of approximately 830 SCFM through the annulus. POR-008 appears a better fit for the 102-AY annulus, and is capable of producing

HNF-2688

Rev 0

Page ii 
approximately 880 SCFM. Both these values assume clean HEPA filters. Test data and associated graphs for each of the exhausters is included as Attachment 18.

The functionality of the Programmable Logic Controller (PLC) interlocks and message view panel alarm displays were demonstrated successfully

The ability to isolate the seal pot from the plenum using 1" test plugs was demonstrated via the pressure decay testing performed in Section 5.22. As part of that testing it was learned that the methodology to employ for leak testing when using the plugs is to first insert the plug and pressurize the seal pot. Access is then provided to the plugs via the plenum, and the plug seal can be quickly checked using a liquid leak detector. Once the integrity of the plugs within the plenum drains has been established, the plenum is then sealed (HEME and HEPA, and pre-filter covers replaced), and pressure testing of the plenum performed. For the purposes of the ATP, pressure decay testing of the plenum was performed with the seal pot open to atmosphere to ensure that any leakage would be detected. 


\section{ATP FOR PORTABLE EXHAUSTERS POR-007/SKID E}




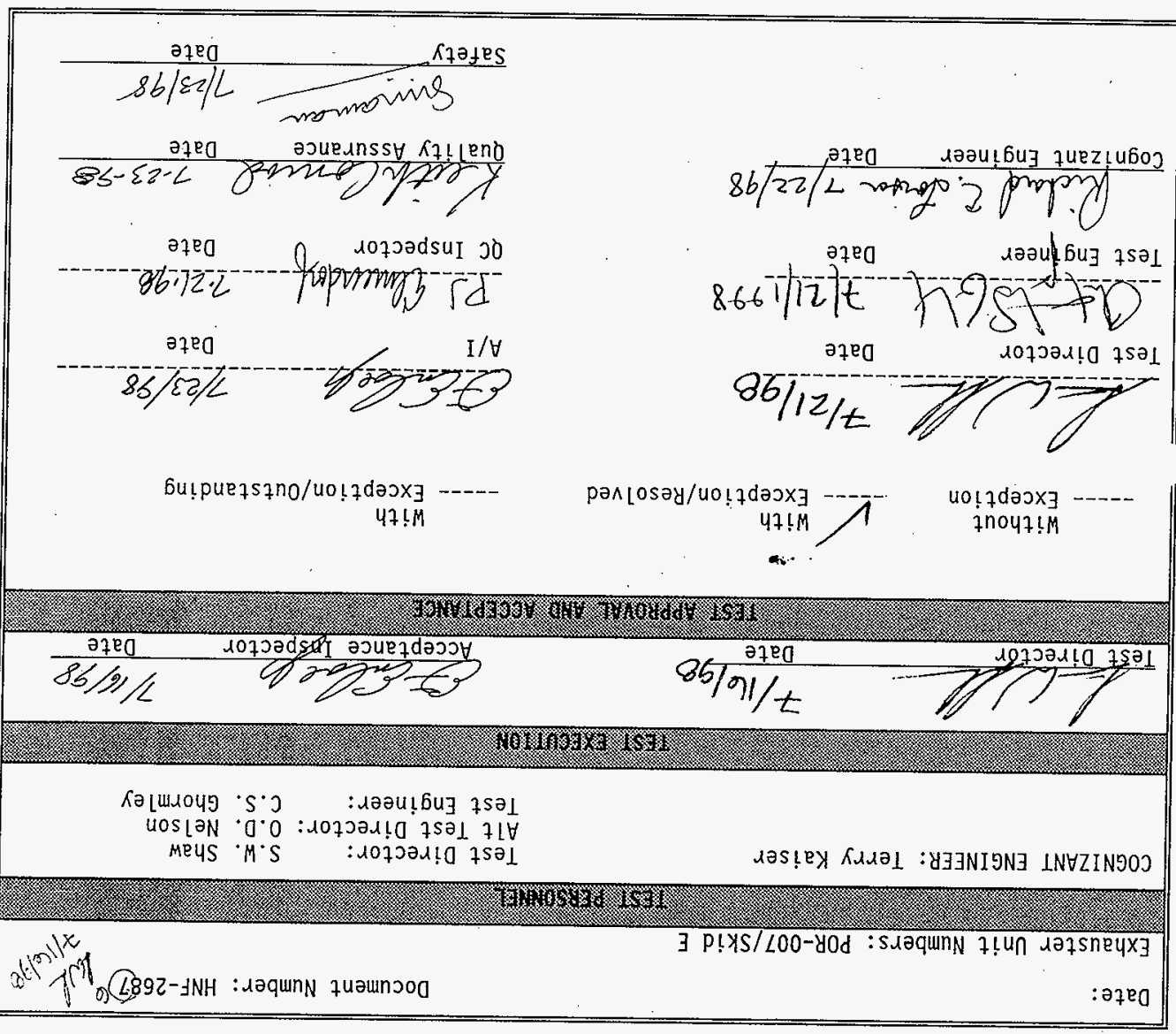

133HS NOILกJXX LSII 
TABLE OF CONTENTS

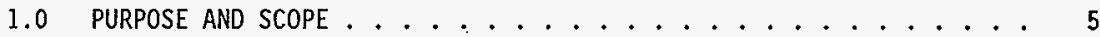

1.1 PURPOSE ........................ 5

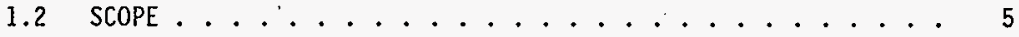

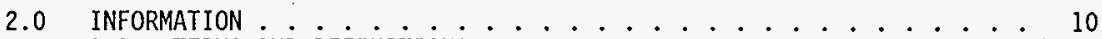

2.1 TERMS AND DEFINITIONS ...................... 10

2.2 RESPONSIBILITIES . . . . . . . . . . . . . . 10

2.3 REFERENCES ........................ 12

2.4 GENERAL INFORMATION . . . . . . . . . . . . 12

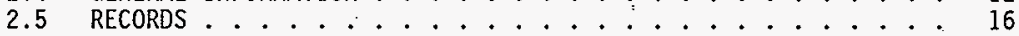

3.0 PRECAUTIONS AND LIMITATIONS . . . . . . . . . . . . . 17

3.1 PERSONNEL SAFETY $\ldots \ldots \ldots \ldots \ldots$

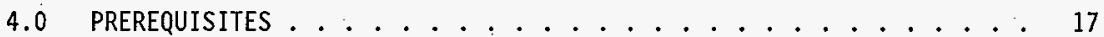

4.1 SPECIAL TOOLS, EQUIPMENT, AND SUPPLIES $\ldots 17$

4.2 PERFORMANCE DOCUMENTS . . . . . . . . . . . . . . 19

4.3 CONDITIONS AND ACTIONS ...................... 19

5.0 PROCEDURE . . . . . . . . . . . . . . . . . 22

5.1 POWER SYSTEM CHECK . . . . . . . . . . . . . 22

5.2 PRESSURE DECAY TEST . . . . . . . . . . . . . . 25

5.3 GLYCOL SYSTEM LEAK TEST . . . . . . . . . . . 29

5.4 EXHAUSTER FAN CHECK .................. 31

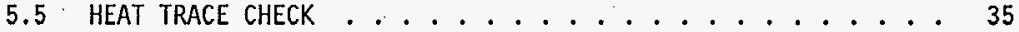

5.6 FILTER \#1 DP INTERLOCK/ALARM CHECK . . . . . . . . . 37

5.7 FILTER \#2 DP INTERLOCK/ALARM CHECK $\ldots \ldots . \ldots . \ldots 43$

5.8 FILTER \#1 \& \#2 DP INTERLOCK/ALARM CHECK . . . . . . . 48

5.9 STACK FLOW INTERLOCK/ALARM CHECK ........... 51

5.10 SEAL POT INTERLOCK/ALARM CHECK ............ . 55

5.11 GLYCOL INTERLOCK/ALARM CHECK .................... 61

5.12 THERMOCOUPLE INTERLOCK/ALARM CHECK .......... 66

5.13 PLENUM PRESSURE DP INTERLOCK/ALARM CHECK . . . . . . . . . 69

5.14 GLYCOL HEATER TEST . . . . . . . . . . . . 73

5.15 FAN INLET VACUUM INTERLOCK/ALARM CHECK-PRESSURE CONTROL $: .75$

5.16 STACK FLOW INTERLOCK/ALARM CHECK-PRESSURE CONTROL . . . . . 79

5.17 HIGH INLET VACUUM INTERLOCK CHECK-HIGH VACUUM $\ldots . . . .82$

5.18 STACK FLOW ALARM CHECK-HIGH VACUUM .......... 85

5.19. FUNCTIONAL TEST - FLOW CONTROL $(1000$ CFM) . . . . . . 87

5.20 FUNCTIONAL TEST - FLOW CONTROL (500 CFM) . . . . . . . . . 89

5.21 FUNCTIONAL TEST - PRESSURE CONTROL . . . . . . . . . . 91

5.22 FUNCTIONAL TEST - HIGH VACUUM . . . . . . . . . . 94

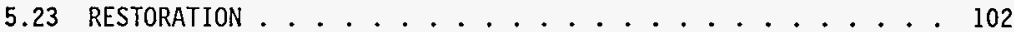

ATTACHMENT 1 - ATP TEST LOG . . . . . . . . . . 104

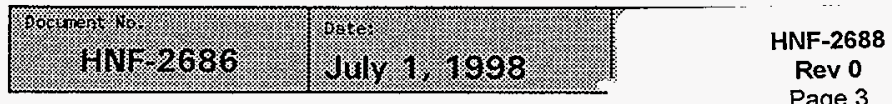

Page 3 


\section{TANK FARIM ACCEPTANCE TEST PROCEDURE}

ATTACHMENT 2 - ATP TEST EXCEPTION REPORT . . . . . . . . . 108

ATTACHMENT 3 - ATP SIGNATURE SHEET . . . . . . . . . 120

ATTACHMENT 4 - ATP INITIAL ElECTRICAL LINEUP . . . . . . . 121

ATTACHMENT 5 - ATP INITIAL VALVE LINEUP . . . . . . . . . . 122

ATTACHMENT 6 - VTP-FT-184 FIVE POINT CHECK . . . . . . . . . . . 124

ATTACHMENT 7 - VTP-PDT-170 [0-(-20) INWC] FIVE POINT CHECK . . . . . 125

ATTACHMENT 8 - OPERATING/ALARM/INTERLOCK SET POINTS . . . . . . 126

ATTACHMENT 9 - DATA ACQUISITION FOR LEAK RATE CALCULATION . . . . . . 128

ATTACHMENT 10 - LEAKAGE RATE CALCULATION . . . . . . . 132

ATTACHMENT 11 - FUNCTIONAL TEST VALVE LINEUP . . . . . . . . . 140

ATTACHMENT 12 - FUNCTIONAL TEST ELECTRICAL LINEUP . . . . . . . . 142

ATTACHMENT 13 - FUNCTIONAL TEST PRESSURE CONTROL

OPERATIONAL, ALARM, INTERLOCK SET POINTS . . . . . 143

ATTACHMENT 14 - FUNCTIONAL TEST HIGH VACUUM OPERATIONAL,

ALARM, INTERLOCK SET POINTS ........... . . 145

ATTACHMENT 15 - ATP FinAL VAlVE LINEUP . . . . . . . . . 147

ATTACHMENT 16 - ATP FINAL ELECTRICAL LINEUP . . . . . . . . . . 149

ATTACHMENT 17 - NOISE LEVEL TEST DATA . . . . . . . . . . 150

ATTACHMENT 18 - SYSTEM PERFORMANCE TEST DATA . . . . . . . . . 152

\begin{tabular}{|c|c|}
\hline \% & for \\
\hline
\end{tabular}




\subsection{PURPOSE AND SCOPE}

\subsection{PURPOSE}

This Acceptance Test Procedure will ensure that the Exhauster meets the functional, operational, and safety criteria specified in HNF-S-0490, Rev 1. The components that will be tested are listed in the scope section that follows. Fan and pressure testing shall comply with ASME N509 and N510.

\subsection{SCOPE}

1.2.1 This procedure applies to the Emergency Backup 1000 CFM Portable Exhauster (POR-007-VTP/SKID E).

NOTE: A11 component identification numbers referenced in this procedure are preceded with POR-007. These prefixes will not be repeated throughout the remainder of this document.

1.2.2 The systems/functions that will be tested are:

1.2.2.1 POWER SYSTEM CHECK

This check will verify that there is electrical power to the Exhauster systems.

\subsubsection{PRESSURE DECAY TEST}

This test demonstrates the integrity of the Exhauster train assembly air boundary, including the Seal Pot.

\subsubsection{GLYCOL SYSTEM DECAY TEST}

This test demonstrates the integrity of the glycol heater, reservoir and associated glycol piping.

\subsubsection{EXHAUSTER FAN CHECK}

This check will verify that the Exhauster Fan is rotating in the correct direction, and that fan shaft bearing vibration levels are within a) lowables defined by ANSI N-509. 


\subsection{SCOPE (Cont.)}

1.2.2.5 HEAT TRACE THERMOSTAT CHECK

This check will verify that the Heat Trace thermostat functions properiy.

\subsubsection{FILTER \# I DP INTERLOCK/ALARM TEST}

This test will verify that 1st HEPA filter high-high, low, and Rate-of-Change (ROC) differential pressure interlocks stop the exhaust fan when conditions that simulate the rupture or plugging of the 1st HEPA filter are caused.

\subsubsection{FILTER \# 2 DP INTERLOCK/ALARM TEST}

This test will verify that 2nd HEPA filter highhigh, low, and ROC differential pressure interlocks stop the exhaust fan when conditions that simulate the rupture or plugging of the 2nd HEPA filter are caused.

\subsubsection{FILTER \#1 \& \#2 DP INTERLOCK/ALARM TEST}

This test will verify that HEPA filter train high-high, low, and ROC differential pressure interlocks stop the exhaust fan when conditions that simulate the rupture or plugging of the HEPA filter train are caused.

\subsubsection{STACK FLOW INTERLOCK/ALARM TEST}

This test will verify that Stack High and Low Flow interlocks stop the exhaust fan when conditions outside operating set points exist .

\section{SEAL POT INTERLOCK/ALARM TEST}

This test will verify that Seal Pot high and low level interlocks stop the exhaust fan when conditions outside operating set points exist, and verify the operation of the seal pot pump.

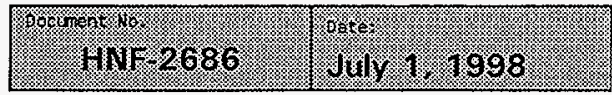




\subsection{SCOPE (Cont.)}

1.2.2.11 GLYCOL INTERLOCK/ALARM CHECK

This check wil]:

- verify that the Glycol System low coolant level interlock illuminates the rotating beacon, shuts down the glycol system recirculation pump and coolant heater when coolant levels drop below the operational set point.

- verifies operation of the glycol recirculation pump.

- verifies that the glycol system heater is correctly wired.

\subsubsection{THERMOCOUPLE INTERLOCK/ALARM TEST}

This test will verify that 1st HEPA filter high and low temperature interlocks perform as required when inlet air temperatures exceed the operational set points.

\subsubsection{PLENUM PRESSURE DP INTERLOCK/ALARM TEST}

This test will verify that plenum pressure high vacuum and high pressure interlocks shut down the exhaust fan when operational set points are exceeded.

\section{GLYCOL HEATER TEST}

This test will verify that the Heater and Glycol Circulation Pump function properly, and raise the inlet air temperature 20 degrees $F$ above ambient inlet temperature.

\section{2 .2 .15}

\section{FAN INLET VACUUM INTERLOCK/ALARM CHECK-PRESSURE CONTROL}

This check will verify that the high vacuum interlock and $70 \mathrm{w}$ vacuum alarm are actuated when alarm set points are exceeded with the exhauster operating in its pressure control mode. 


\subsection{SCOPE (Cont.)}

1.2 .2 .16

1.2 .2 .17

1.2 .2 .18

1.2.2.19

1.2 .2 .20

1.2 .2 .21

\section{STACK FLOW INTERLOCK/ALARM CHECK-PRESSURE CONTROL}

This check will verify the stack flow high interlock and stack flow low alarm function as required when alarm set points are exceeded with the exhauster in its pressure control mode.

\section{HIGH INLET VACUUM INTERLOCK CHECK - HIGH VACUUM}

This check will verify the high vacuum interlock shuts down the fan when the fan inlet al lowable vacuum is exceed when the exhauster is in its high vacuum operating mode.

\section{STACK FLOW ALARM CHECK - HIGH VACUUM}

This check will verify that the high stack flow alarm is activated when the alarm set point is exceeded with the exhauster configured in high vacuum operating mode.

\section{FUNCTIONAL TEST - FLOW CONTROL (1000 SCFM)}

This test will verify. that the exhauster is capable of maintaining steady state operation at 1000 SCFM using the exhauster's flow control logic:

\section{FUNCTIONAL TEST - FLOW CONTROL (500 SCFM).}

This test will verify that the exhauster is capable of maintaining steady state operation at 500 SCFM using the exhauster's flow control logic.

\section{FUNCTIONAL TEST - PRESSURE CONTROL}

This test will demonstrate the ability of the exhauster to ventilate the 102-AY annulus using the exhauster's programmable logic controller's pressure control algorithms. 


\subsection{SCOPE (Cont.)}

\subsubsection{FUNCTIONAL TEST - HIGH VACUUM}

This test will demonstrate the ability of the exhauster to ventilate the 102-AY annulus using the exhauster's programmable logic controller's high vacuum operation algorithms. 


\subsection{INFORMATION}

\subsection{TERMS AND DEFINITIONS}

$\begin{array}{lll}2.1 .1 & \text { DMM } & \text {-Digital Multimeter } \\ 2.1 .2 & \text { DPT } & \text {-Differential Pressure Transmitter } \\ 2.1 .3 & \text { DS } & \text {-Disconnect Switch } \\ 2.1 .4 & \text { HEPA } & \text {-High Efficiency Particulate Air } \\ 2.1 .5 & \text { MPZ } & \text {-Mini Power Zone } \\ 2.1 .6 & \text { ROC } & \text {-Rate of Change } \\ 2.1 .7 & \text { SLC } & \text {-Smal7 Logic Controller } \\ 2.1 .8 & \text { INWC } & \text {-Inches Water Column }\end{array}$

\subsection{RESPONSIBILITIES}

2.2.1 Craft:

- Provide assistance during ATP testing

- Provide equipment for performance of this ATP.

2:2.2 A/I Inspector:

- Witness Testing and review recorded test data for accuracy and completeness.

2.2.3 Quality Assurance

- Review acceptance test procedure for accuracy and completeness.

- Review acceptance test report for accuracy and completeness. 


\subsection{RESPONSIBILITIES (Cont.)}

2.2 .4

2.2 .5
LOCKHEED MARTIN QC Inspector:

- Witness Testing and review recorded test data for accuracy and completeness for resolution of items identified in Non-conformance reports.

Test Director:

- Verifies prerequisites complete prior to start of test

- Maintaining control of the testing process and change record authorization for this ATP

- Ensures all required data is collected

- Ensures Safe and productive accomplishment of testing

- Ensure safe working conditions and practices

- Ensure compliance with test documents

- Ensures review and approval of all modifications to test procedures are completed prior to return to testing

- Acts as direct line of communication and centralized point of control during normal, abnormal, and casualty situations

- Conduct pretest briefings as required

- Schedule/reschedule tests as required

- Conduct pre-job system walkdowns

- Review test documents to validate acceptance 


\subsection{RESPONSIBILITIES (Cont.)}

2.2.6 Test Engineer:

- Provide technical support during testing.

- Provide programming support during testing.

- Review test documents to validate acceptance.

- Record equipment status and data per this procedure.

- Record data exceptions and other notes as required on the ATP Data Sheets.

- Prepare post testing documents.

\subsection{REFERENCES}

- H-14-102610, "1,000 SCFM Portable Exhauster Piping and Instrumentation Schematic Diagram"

- Vendor Information VI \#50024

- FMEF-037, R-3 Standardized Energized Electrical Work Permit.

\subsection{GENERAL INFORMATION}

\subsubsection{CHANGE CONTROL}

2.4.1.1 Changes to this procedure that effect technical content shall be made in accordance with HNFPR0 -440 .

2.4.1.2 Editorial changes may be made to this procedure as required to accommodate procedural/editorial deficiencies that do not effect techinical content. Redline changes shall be entered using red ink, initialed and dated by the Test Director. Documentation of redline changes sha1? be made in the Acceptance Test Report. 


\subsection{GENERAL INFORMATION (cont)}

2.4 .2

\section{EXCEPTIONS}

2.4.2.1 Test exceptions are used to document unexpected test results and identify appropriate actions, not to circumvent performance requirements or document procedural deficiencies.

2.4.2.2 All test exceptions shall be given a sequential number and recorded on Attachment 1, ATP TEST LOG.

2.4.2.3 Attachment 2, ATP TEST EXCEPTION REPORT, sha11 be filled out to record and disposition each test exception.

2.4 .3

\section{ALARM RESPONSE}

2.4.3.1 This Acceptance Test Procedure identifies a11 a) arms expected as a result of testing and provides instructions for responding to those alarms. During testing of High-High or Low-Low set points, High and Low al arms are also anticipated.

2.4.3.2 Unexpected alarms received during testing, that are associated with this test, shall be logged as test exceptions and evaluated by the Test Director for effect on the test. 


\subsection{GENERAL INFORMATION (Cont.)}

2.4.4 If during performance of this procedure, any of the following conditions are found, IMMEDIATELY notify the assigned Test Director, his al ternate, or Test Engineer:

- Any equipment malfunction which could prevent fulfillment of functional requirements

- Personnel error or procedural inadequacy which could prevent fulfiliment of procedura? requirements

- Any other unexpected anomalies.

Test Director shall assess the effect on the equipment and the test and direct either continuation of the test in the same section, proceeding to another attachment or section of the test, or suspension of the test per step 2.4.11 and establishing a safe condition for equipment. 


\subsection{GENERAL INFORMATION (Cont.)}

2.4.5 Comply with the Hanford Site Wide Lock and Tag policy requirements, HNF-PRO-81.

2.4.6 Al1 Measuring and Test Equipment (M\&TE) used during performance of this procedure to collect qualitative data, with the exception of "timing devices", shall meet the following requirements:

- Be within its current calibration cycle as evidenced by an affixed calibration label

- Be capable of the desired range

All exhauster instrumentation shall be set-up per the direction of the cognizant engineer (calibration stickers not required).

2.4.7 Time keeping shall be made with commercially available timing devices.

2.4.8 It is recommended that the computer be connected to the SLC $500 \mathrm{CPU}$ (per vendor data) throughout the test. However, the computer may be connected and disconnected as required to facilitate exhauster access, test schedule, and changing weather conditions.

2.4.9 Testing in Sections 5.1 through 5.18 with the Reterest 5.23158 . 710 exception of Sections 5 .2 and-5.10 may be performed either by placing a force on the seal pot, or by filling the seal pot to the prescribed level as identified in Section 5.4. Sections $5,2,5.10$, and 5.19 through 5.21 must be performed with the seal pot filled. Section 5.22 may be performed with a force on the seal pot or with a filled seal pot at the discretion of the Test Director. Step 5.4.1 may be performed at any time during the test as necessary to $\rightarrow$ ijl the seal pot.

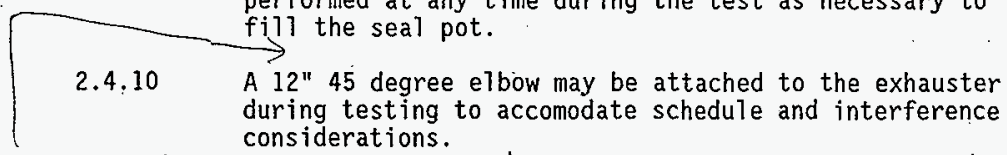
Per Ex. 9: Acknowledge alarms on mv-101 anytime .
7/81980) Whafter mpz-1 is re-energized. 


\subsection{GENERAL INFORMATION (Cont.)}

\subsubsection{SYSTEM STATUS}

2.4.11.1 Record all changes in equipment configuration, comments and observations by participants, and all other data pertinent to the test on Attachment 1, ATP TEST LOG.

\subsubsection{SUSPENSION OF TEST AND RESUMING TEST}

2.4.12.1 Test Director may unilaterally, for any reason, stop testing, and place equipment in a safe condition. All suspension of testing due to exceptions shall be documented on Attachment 1, ATP TEST LOG.

2.4.12.2 If a section of the test is suspended for any reason prior to completing all steps, the Test Director shail establish initial conditions necessary to resume testing for that section. Previously completed sections need not be repeated uniess directed by the Test Director to establish conditions required to resume the test.

2.4.12.3 Sections of this ATP may be performed out of sequence, per Test Directors instructions.

\subsection{RECORDS}

The performance copy of the ATP and all completed attachments shall be filed as a permanent test record (Acceptance Test Report). 


\subsection{PRECAUTIONS AND LIMITATIONS}

\subsection{PERSONNEL SAFETY}

Warning - Energized circuits and leads are contained inside the cabinets. Comply with HNF-PRO-088, "Electrical Work Safety" and the energized electrical work permit in the work package.

Warning - Exposed piping and valves on the glycol system may be thermally hot.

Warning - Fan shaft guard shall not be in place during testing to facilitate vibration and temperature readings. observe caution and comply with barricades per HNFPRO-101.

Caution - Heat Trace wires become Hot when energized. Use caution around Heat Trace wires and conduits.

Caution - Watch out for badgers.

\subsection{PREREQUISITES}

\subsection{SPECIAL TOOLS, EOUIPMENT, AND SUPPLIES}

The following supplies shall be available at the work place:

- Yokogawa hand held transmitter configurer BT-200

- Digital Multi-Meter: Portable, 0-600 volts $A C, \pm 5 \%$ accuracy

Cal Serial No. 646-45-08-172 Expiration Date $4 / 2 / 99$

- Vibration Instrument

Make IRD Mode 1

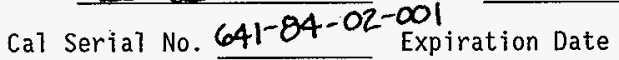
$3 / 4 / 99$ 


\subsection{SPECIAL TOOLS, EQUIPMENT, AND SUPPLIES (cont)}

- Type J Thermocouple Simulator and connection wire

Cal Serial No. 545-13-55-038

Expiration Date

wh resolutoj 2/10/99

- * Pressure measurement device, acetrate to \pm 0.1 INWC,

approximate range of -25 to +25 INWC. $\quad 10 / 8 / 98$

Cal Serial No.78-31-04-036 Expiration Date 2/23/99

\section{exceptroxd on}

$7 / 75 / 98$ (x) 然长

- Barometer (use the Hanford weather station, 373-2716)

- Compressed air source (or blower), pressure reducer (or damper), isolation valve, and safety relief mechanism (rated to relieve at $+/-20$ " w.g.)

- Vacuum source (Capable of producing -20.0 INWC) and isolation valve

- Computer (to interface SLC Logic program)

- Ice Water

- Portable Calibration System (C-Box) Model 401-18-20 by Drexe]Brook.

* See Attachment 9 for which deuice was used on any qiven pressure test.

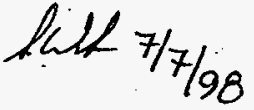




\subsection{PERFORMANCE DOCUMENTS}

The following documents may be needed to perform this procedure:

- Low Tox Antifreeze Materiat Safety Data Sheet (\#MSDSP355)

- Operating Instructions for Yokogawa hand held transmitter configurer BT-200

\subsection{CONDITIONS AND ACTIONS}

NOTE - Steps in Section 4.3 may be performed in any order.

NOTE - A daily pre-job briefing shall be performed by the Test Director and documented in Attachment 1, ATP TEST LOG.

4.3.1 CONDUCT an initial pretest briefing for all personnel involved in the performance of this ATP.

TEST DIRECTOR INITIALS/DATE: $7 / 6 / 98$

4.3 .2

PERFORH a walkdown inspection of the work area for unusual and/or hazardous conditions.

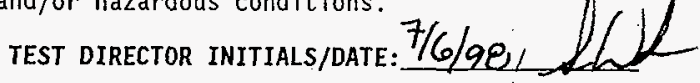

4.3.3 ENSURE the official ATP copy and al] other photocopies to be used during testing are the latest approved revision.

TEST DIRECTOR INITIALS/DATE:

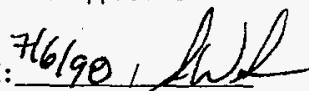




\section{TANK FARM ACCEPTANCE TEST PROCEDURE}

\subsection{CONDITIONS AND ACTIONS (Cont.)}

NOTE - Signature Sheet requirement is ongoing as new individuals become involved in the procedure.

4.3.4 ENSURE all personnel to be involved with performance of this procedure have completed Attachment 3, ATP SIGNATURE SHEET.

TEST DIRECTOR INITIALS/DATE:

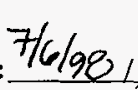

4.3.5 ENSURE the following filters are in place:

- Prefilter

- First and Second Stage HEPA Fi]ters

- Roughing Filter over Exhauster Inlet when appropriate.

TEST DIRECTOR INITIALS/DATE:

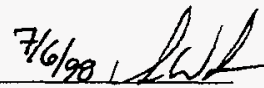

4.3.6 ENSURE "GLYCOL EXPANSION RESERVOIR TANK" VTP-TK-001 is approximately $60 \pm 5 \%$ full by observing "GLYCOL LEVEL GAUGE" VTP-LG-201.

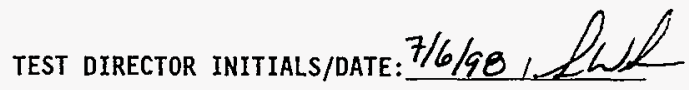

4.3.7 ENSURE exhauster valves are aligned per Attachment 5, ATP Initial Valve Lineup prior to the start of testing.

\section{TEST DIRECTOR INITIALS/DATE:}

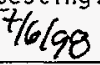

4.3.8 ENSURE NEC field inspection is complete.

TEST DIRECTOR INITIALS/DATE:

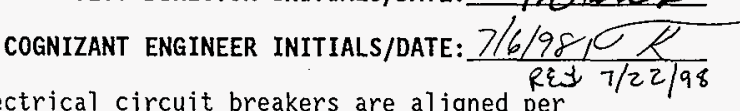

4.3.9 ENSURE electrical circuit breakers are aligned per

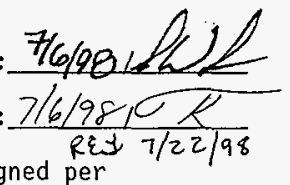

Attachment 4, ATP Initial Electrical Lineup prior to the start of testing.

TEST DIRECTOR INITIALS/DATE: 


\subsection{CONDITIONS AND ACTIONS (Cont.)}

4.3 .10

ENSURE the exhauster has been connected to a $480 \mathrm{~V}$, 3-Phase power source.

TEST DIRECTOR INITIALS/DATE: $7 / 6 / 98 / 2$

4.3.11 ENSURE that all exhauster instrumentation has been set-up for testing.

TEST DIRECTOR INITIALS/DATE: $7 / 6 / 98 / 2 / \mathrm{h} / 2$

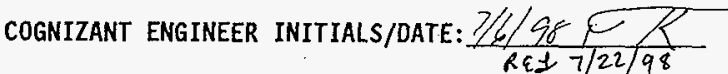

4.3.12 ENSURE that ARMAFLEX insulation pads are installed between exhauster skid pads and ground.

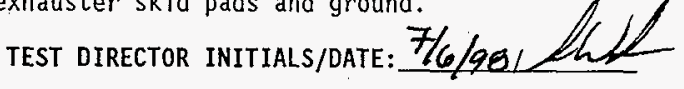

4.3.13 ENSURE 5 Point checks of VTP-FT-184 and VTP-PDT-170 are completed per Attachments 6 and 7.

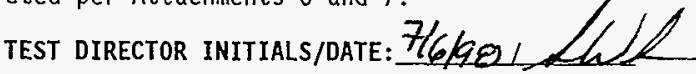
COGNIZANT ENGINEER INITIALS/DATE: $17 / 6 / 98$ Ret $7 / 22 / 98$ 


\subsection{PROCEDURE}

NOTE- For all testing completed in Section 5, if "EXHAUST

FAN MOTOR" VTP-M-001 does not start when "START PUSH

BUTTON" VTP-PB-101 is pressed, then "STOP PUSH BUTTON"

VTP-PB-102 to reset VFD and then PUSH VTP-PB-101.

\subsection{POWER SYSTEM CHECK}

Warning - Energized circuits and leads are contained inside the cabinets. Comply with HNF-PRO-088, "Electrical Work Safety" and the energized electrical work permit in the work package.

5.1.1 ENSURE all enclosure doors are closed and test personnel are clear of voltage hazard.

5.1.2 ENSURE $480 \mathrm{~V}, 3$ phase power to the Exhauster is connected and turned on.

Initial: $=$ Date: $216 / 98$

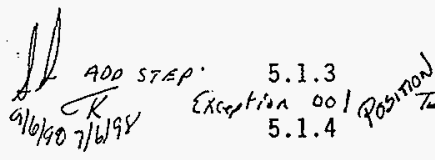

DPOSITION "480 VOLT MAIN DISCONNECT" VTP-DS-101 to ON.

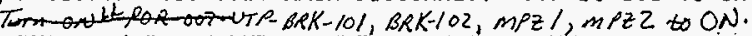
PUSH red "PUSH BUTTON EMERGENCY STOP" VTP-PB-103 (located on door of " 480 VOLT MAIN DISCONNECT" VTP-DS-101).

5.1.5 ENSURE the "480 VOLT MAIN DISCONNECT" VTP-DS-101 has tripped AND PERFORM the following using a DMM:

5.1.5.1 OPEN the "480 VOLT MAIN DISCONNECT" VTP-DS-101 cabinet door.

5.1.5.2 RECORD voltage between Terminal $L 1$ and Terminal L2.

READING

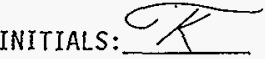

5.1.5.3 VERIFY $0 \mathrm{~V}$ between Termina] $\mathrm{L} 1$ and Termina] L2.

5.1.5.4 RECORO voltage between Terminal $L I$ and Terminal L3.

READING:

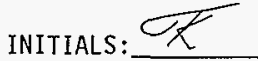

5.1.5.5 VERIFY $0 \mathrm{~V}$ between Terminal $\mathrm{LI}$ and Terminal L3. 


\section{TANK FARM ACCEPTANCE TEST PROCEDURE}

\subsection{POWER SYSTEM CHECK (Cont.)}

5.1.5.6 RECORD voltage between Termina] $L 2$ and Termina] L3.

READING: $\theta$ INITIALS:

5.1.5.7 VERIFY $0 \mathrm{~V}$ between Terminat $L 2$ and Terminat L3.

5.1.5.8 CLOSE the "480 VOLT MAIN DISCONNECT" VTP-DS-101 cabinet door.

5.1.6 RESET the "480 VOLT MAIN DISCONNECT" VTP-DS-101 by turning to OFF then to ON position.

\section{WARNING}

Energized circuits and leads are contained inside the cabinet. Comply with HNF-PR0-088, "Electrical Work Safety". Energized circuits and leads are contained inside the cabinets. Comply with HNF-PRO-088, "Electrical Work Safety" and the energized electrical work permit in the work package.

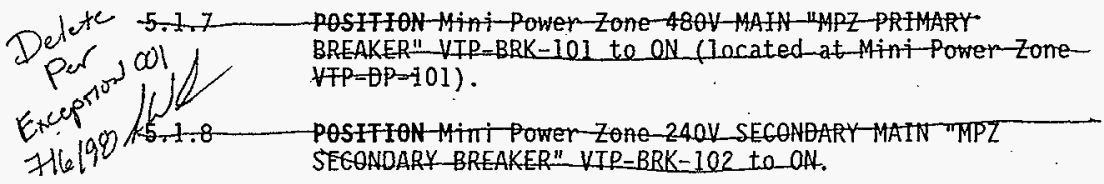

5.1.9 POSITION the following MPZ $120 \mathrm{~V}$ circuit breakers to ON:

\begin{tabular}{|c|c|c|}
\hline CIRCUIT BREAKER NUMBER & DESCRIPTION & ON 10 \\
\hline IPz & $\begin{array}{l}\text { ACTION PAR RELAYS, POWER SUPPLIES. } \\
\text { WILEERSON DISPLAY WETERS }\end{array}$ & $V$ \\
\hline $4 P^{2}=2$ & $\begin{array}{l}\text { GLYCOL PUMP, SEAL DOT PUMP, SHUNT } \\
\text { TRIP, PLOT GGGTS, ALARM BEACON }\end{array}$ & $v$ \\
\hline MPZ & $\begin{array}{l}\text { HEAT TRACE, GLYCOL CONTAGTOR, HEAT } \\
\text { TRACE LIGHT }\end{array}$ & \\
\hline$Y P z_{4}$ & CABINET HEATERS AND EANS & 2 \\
\hline $1 P Z-5$ & CONVENIENCE RECEPTACIE & $\nu$ \\
\hline
\end{tabular}




\section{TANK FARM ACCEPTANCE TEST PROCEDURE}

\subsection{POWER SYSTEM CHECK (Cont.)}

5.1.10 VERIFY the Wilkerson indicators are illuminated by visual inspection AND COMPLETE the following table.

\begin{tabular}{|c|c|c|c|c|c|c|c|}
\hline 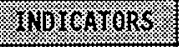 & 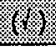 & 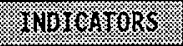 & 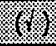 & W10MLAGORS & 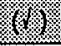 & HoYG GORS & $y=$ \\
\hline W6 P r & $\longleftarrow$ & $109.1 \%$ & 2 & y) & L & Wha & $\omega$ \\
\hline (4) & $r$ & 16\% & $r$ & 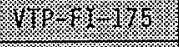 & $\sim$ & 1) & \\
\hline (6) & 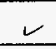 & Y. & 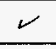 & 1) & $\checkmark$ & $112=0 \%$ & \\
\hline (1) & $\checkmark$ & 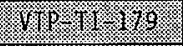 & & (5) & 2 & (1) & \\
\hline (Y) & & & & . & & & \\
\hline
\end{tabular}

5.1.11 VERIFY the Green "ILOFF" indicating Tight (located on the door of "CONTROL CABINET" VTP-CP-105) is ILLUMINATED:

5.1.12 VERIFY the digital readouts on the following DPTs are illuminated,

\begin{tabular}{|c|c|c|c|}
\hline 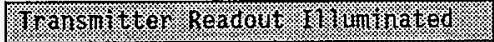 & $(8)$ & 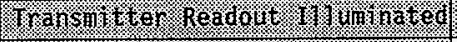 & (x) \\
\hline 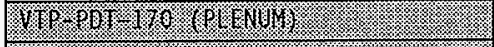 & 2 & (2) & $\leftarrow$ \\
\hline 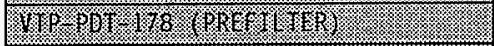 & L & W/ & $L$ \\
\hline Y) & $\checkmark$ & 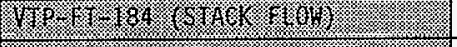 & \\
\hline 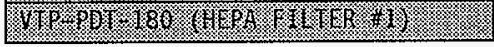 & & & \\
\hline
\end{tabular}

5.1.13 Test Director VERIFY section 5.1 is complete.

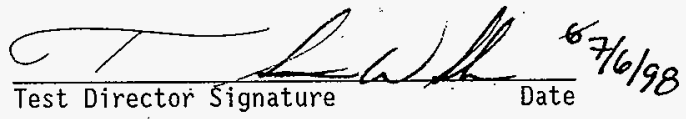

5.1.14 A/I Inspector VERIFY section 5.1 is complete.

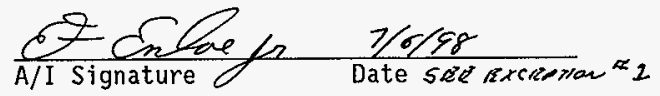




\subsection{PRESSURE DECAY TEST}

5.2 .1

5.2 .2

5.2 .3

5.2 .4

5.2 .5

5.2 .6

5.2 .7

5.2 .8

5.2 .9

5.2 .10

5.2 .11

NOTE -

5.2 .12

5.2 .13

5.2 .14
PERFORM valve Tine-up per Attachment 5, "ATP Initial Valve Lineup"

REMOVE blind flange from VTP-V -160 .

ENSURE "SEAL POT" VTP-SP-001 is empty by opening the "SEAL POT DRAIN VALVE" VTP-V-160.

- If not empty, allow to empty through VTP-V-160.

CLOSE "SEAL POT DRAIN VALVE" VTP-V-160.

REPLACE blind flange on VTP-V-160.

INSTALL preumatic pressure testing manifold (with gauge, pressure relief valve, isolation valve, and pressure regulator) into "lst HEPA TEST PORT" VTP-FTP-002.

INSTALL pressure gauge into "2nd HEPA TEST PORT" VTP-FTP-004.

CONNECT pressure test air source to testing manifold. PRESSURIZE housing/duct assembly to $+19.5 \pm 0.5$ INWC. ISOLATE the air supply from the filter housing. MAINTAIN pressure unti] temperature remains constant within $\pm 1^{\circ} \mathrm{F}$ as indicated by "lst HEPA INLET TEMPERATURE" VTP-TI-179 for a minimum of 10 minutes.

Next step starts checking positive pressure decay.

RECORD the initial time $\left(t_{i}\right)$, barometric pressure $\left(B P_{i}\right)$, housing pressure $\left(P_{i}\right)$, and temperature $\left(T_{i}\right)$ on the table provided in Attachment 9 .

- $\quad$ RECORD pressure and temperature readings once a minute for 15 minutes on Attachment 9 .

RECORD final time $\left(t_{f}\right)$, barometric pressure $\left(B P_{f}\right)$, housing pressure $\left(P_{f}\right)$ and temperature $\left(T_{f}\right)$ on the table AND TRANSFER required information to Attachment 10.

PERFORM the leak rate calculations per Attachment 10. 


\subsection{PRESSURE DECAY TEST (Cont.)}

5.2.15 IF $Q<L_{s}$ then RECORD "PASS" on Attachment 10 and proceed to step 5.2.17.

- Otherwise, RECORD "RETEST" on Attachment 10.

5.2.16 IF a retest is needed, then PERFORM the following:

5.2.16.1 DETERMINE the leak path(s) and REPAIR leaks as noted on the Exception Resolution.

5.2.16.2 REPEAT steps 5.2.9 through 5.2.15 using new data sheets.

5.2.17 DISCONNECT the air supply.

5.2.18 RELIEVE pressure slowly from housing/duct assembly through Testing Manifold assembiy.

5.2.19 CONNECT a vacuum source to the Pressure Testing Manifold Assembly.

5.2.20 DECREASE housing/duct internal pressure to Excepsw $-20 \pm .5-14.5( \pm 0.5)$ INWC as indicated by the pressure a. 17198 sus $7 / 7 / 98$ measuring device.

5.2 .21

ISOLATE the vacuum source from the filter housing.

5.2.22 MAINTAIN constant pressure until temperature remains constant within $\pm 1{ }^{\circ} \mathrm{F}$ as indicated by "1st HEPA INLET TEMPERATURE". VTP-TI-179 for a minimum of 10 minutes. 


\subsection{PRESSURE DECAY TEST (Cont.)}

NOTE - Next step starts checking negative pressure decay.

5.2.23 RECORD the initial time $\left(t_{i}\right)$, barometric pressure $\left(B P_{i}\right)$, housing pressure $\left(P_{i}\right)$, and temperature $\left(T_{i}\right)$ on the table in Attachment 9 .

- $\quad$ RECORD pressure and temperature readings once a minute for 15 minutes on Attachment 9.

5.2.24 RECORD final time $\left(t_{f}\right)$, barometric pressure $\left(B_{f}\right)$, housing pressure $\left(P_{f}\right)$ and temperature $\left(T_{f}\right)$ on table AND TRANSFER required information to Attachment 10 .

5.2.25 PERFORM the leak rate calculations per Attachment 10.

5.2.26 IF $Q<L_{s}$ then RECORD "PASS" on Attachment 10 and go to step 5.2.27.

- Otherwise, RECORD "RETEST" on Attachment 10.

5.2.26.1 IF a retest is needed, then PERFORM the following:

5.2.26.2 DETERMINE the leak path(s) and REPAIR leaks as noted on the Exception Resolution.

5.2.26.3 REPEAT steps 5.2.20 through 5.2.26 using new data sheets. 


\subsection{PRESSURE DECAY TEST (Cont.)}

5.2.27 SLOWLY EQUALIZE housing/duct pressure to atmospheric through the Testing Manifold Assembly.

5.2.28 DISCONNECT the test equipment.

5.2.29 REINSTALL the test port plugs.

5.2.30 OPEN High Isolation Valve Main Airstream VTP-V-135.

5.2.31 OPEN Low Isolation Valve Main Airstream VTP-V-136.

5.2.32 Test Djrector VERIFY section 5.2 is complete.

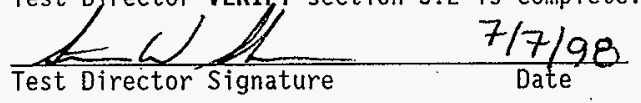

5.2.33 A/I Inspector VERIFY section 5.2 is complete.

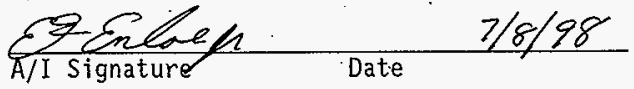

5.2.34 QC Inspector VERIFY section 5.2 is complete.

P) Gqumadof $\frac{7.8 .98}{\text { QC Signature }}$




\subsection{GLYCOL SYSTEM LEAK TEST}

5.3.1 ENSURE glycol heater piping isolation valves are open.

\begin{tabular}{|c|c|c|c|}
\hline Vylye romper & 010nen & Virte remplor & 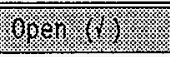 \\
\hline 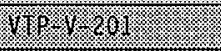 & $\checkmark$ & VIlp 1.263 & $\sim$ \\
\hline $287=1.262$ & $L$ & YY & 2 \\
\hline
\end{tabular}

5.3 .2

OPEN the fill cap on the expansion tank

5.3.3 CONNECT the air pressure supply manifold (with gauge, pressure relief valve, isolation valve and pressure regulator) to the expansion tank fill port

5.3.4 SLOWLY PRESSURIZE the heater reservoir and piping to $115.0(+/-2)$ INWC $(4.15+/-0.72$ PSI $)$.

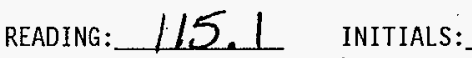

5.3.5 VISUALLY INSPECT leaks indicated by localized wetting of insulation. Perform this step for a minimum of 15 minutes.

5.3.6 RELEASE PRESSURE from giycol system.

5.3.7 REPAIR any leaks and add additional coolant to the expansion tank per Test Director direction.

5.3.8 SLOWLY PRESSURIZE the heater reservoir and piping to $115.0(+/-2)$ INWC.

5.3.9 ISOLATE the pressure source by closing the manifold isolation valve.

5.3 .10

RECORD the initial pressure and time below.

\section{PRESSURE}

Initial: $\quad 1 / 5.3$

5.3.11 WAIT 10 minutes

5.3 .12

RECORD the final pressure and time.

\section{PRESSURE}

Finat:

\section{6}

IIME

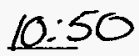




\subsection{GLYCOL SYSTEM LEAK CHECK (Cont.)}

5.3.12.1 VERIFY there was no pressure drop during the 10
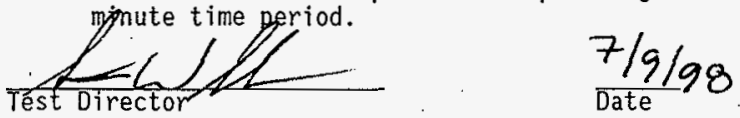

5.3.13 RELIEVE pressure from the system by slowly opening the manifold release valve.

5.3.14 DISCONNECT and REMOVE the pressure supply and manifold.

5.3 .15

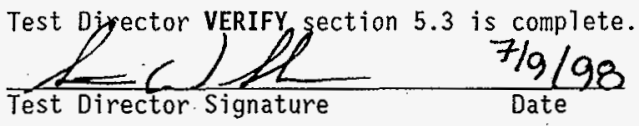

5.3 .16

A/I Inspector VERIFY section 5.3 is complete.

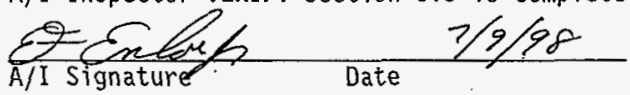

5.3.17 QC Inspector VERIFY section 5.3 is complete.

$\frac{P \text { Clumesdorf }}{\text { QC Signature o }}$




\subsection{EXHAUSTER FAN CHECK}

Note - Step 5.4.1 is optional, and may be replaced by a force on the seal pot per 2.4.9.

5.4.1 FILL VTP-SP-001 "SEAL POT" by performing the following:

5.4.1.1 REMOVE fill cover plug attached to VTP-V-162 "SEAL POT FILL PORT VALVE".

5.4.1.2 . OPEN VTP-V-162 "SEAL POT FILL PORT VALVE".

5.4.1.3 ADD water to the seal pot unti1 VTP-L1-185 "SEAL POT LEVEL" reads $60 \%+/-5 \%$ of volume.

Placed Force ON SEACPOT

5.4 .1 .4

5.4 .1 .5

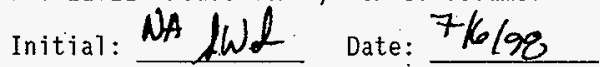

CLOSE VTP-V-162 "SEAL POT FILL PORT VALVE".

REPLACE the fill plug attached to VTP-V-162 "SEAL POT FILL·PORT VALVE".

5.4.2 POSITION the "EXHAUST FAN MOTOR DISCONNECT" VTP-DS-102

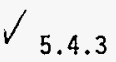
to ON.

5.4 .3

ENSURE "EXHAUST FAN MOTOR" VTP-M-001 does NOT start automatically.

ENSURE Green "ILOFF". light (located on door of "CONTROL CABINET" VTP-CP-105) is ILLUMINATED.

5.4 .5

ENSURE Red "ILRUN" 1 ight (located on door of "CONTROL CABINET" VTP-CP-105) is NOT ILLUMINATED.

$\vee_{5.4 .6}$

POSITION "FAN CONTROL" VTP-HS-103 to "ENABLE" (Tocated on door of "CONTROL CABINET" VTP-CP-105).

5.4 .7

ENSURE exhauster PLC control is in "Flow Control" operating mode.

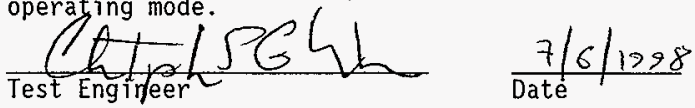

/5.4.8 PRESS "STOP PUSH BUTTON" VTP-PB-102 (located on door of "CONTROL CABINET" VTP-CP-105) to reset VFD.

$\sqrt{5.4 .9}$

PRESS "START PUSH BUTTON" VTP-PB-101 AND THEN QUICKLY PRESS "STOP PUSH BUTTON" VTP-PB-102 (i.e. bump the fan).

\begin{tabular}{|c|c|}
\hline 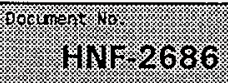 & 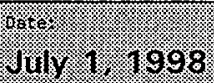 \\
\hline
\end{tabular}




\title{
TANK FARM ACCEPTANCE TEST PROCEDURE
}

\subsection{EXHAUSTER FAN CHECK (Cont.)}

\author{
$\int_{5.4 .10}$ \\ $r / 5 \cdot 4.12$
}

VERIFY the direction of rotation of the "EXHAUST FAN MOTOR" VTP-M-001 shaft is counter clockwise when viewed from the motor side of the fan housing.

IF "EXHAUST FAN MOTOR" VTP-M-001 rotation direction is correct, G0 TO step 5.4.13.

If direction of rotation of the "EXHAUST FAN MOTOR" VTP-M-001 is in the incorrect direction, THEN perform steps 5.4.11.1 through 5.4.11.5.

5.4.12.1 POSITION "EXHAUST FAN MOTOR DISCONNECT" VTP-DS-102 to OFF.

5.4.12.2 INSTALL Personal Locking Device on "EXHAUST FAN MOTOR DISCONNECT" VTP-DS-102.

5.4.12.3 CORRECT the "EXHAUST FAN" VTP-EF-001 rotation direction by CORRECTING the ieads at the fan pigtail.

5.4.12.4 REMOVE Personal Locking Device from "EXHAUST FAN MOTOR DISCONNECT" VTP-DS-102.

5.4.12.5 REPEAT steps 5.4.2 through 5.4.11.

5.4 .13

OPEN the High and Low valves on each three vaive manifold for the following DPTs:

\begin{tabular}{|c|c|c|c|c|}
\hline 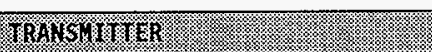 & 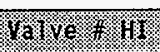 & (aper & 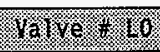 & 0020 \\
\hline 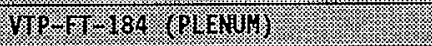 & $178+156$ & $\checkmark$ & 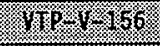 & $\checkmark$ \\
\hline 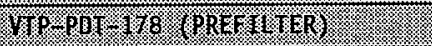 & $1 / 20.7 / 40$ & $\checkmark$ & 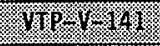 & $\checkmark$ \\
\hline 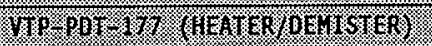 & $170.1-13 \%$ & $\checkmark$ & 1170 & $\checkmark$ \\
\hline To. & $17 \%=143$ & $\checkmark$ & $17901-144$ & $\checkmark$ \\
\hline 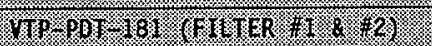 & $17 \%=146$ & $\overline{\sqrt{ }}$ & $197-147$ & $\checkmark$ \\
\hline 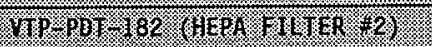 & $798 \cdot 1 / 49$ & $\checkmark$ & $17 \%=150$ & $\sqrt{ }$ \\
\hline
\end{tabular}

5.4 .14

POSITION the "EXHAUST FAN MOTOR DISCONNECT" VTP-DS-102 to $0 N$. 


\subsection{EXHAUSTER FAN CHECK (Cont.)}

5.4.15 ENSURE VTP-V-155, "HIGH ISOLATION VALVE STACK FLOW TRANSMITTER" and VTP-V-156, "LOW ISOLATION VALVE STACK FLOW TRANSMITTER" are CLOSED.

5.4.16 SET timer T4: tsetpoint to 600 seconds.

5.4.17 PRESS "STOP PUSH BUTTON" VTP-PB-102 to reset VFO.

5.4.18 PRESS "START PUSH BUTTON" VTP-PB-101 to turn on "EXHAUST FAN" VTP-EF-001.

5.4.19. VERIFY Green "ILOFF" Tight (located on door of "CONTROL CABINET" VTP-CP-105) is OFF.

5.4.20 VERIFY Red "ILRUN" light (Tocated on door of "CONTROL CABINET" VTP-CP-105) is ILLUMINATED.

5.4.21 ENSURE fan is operating normally with no unusual noise.

NOTE: Next step starts the "EXHAUST FAN" VTP-EF-001 vibration test. It may be necessary to start the fan several times to acquire all the required data.

5.4.22 MEASURE and RECORD the fan vibration data required in the table below with the fan at $60 \mathrm{~Hz}$.

5.4.23 VERIFY that the Bearing Vibration Levels on the fan shaft bearings meet the following criteria:

- Displacement $\leq 0.6$ MILS (PK-TO-PK) at one times the fan speed

$\mathrm{OR}$

- Velocity $\leq 0.11$ IN/SEC (PK) at one times the fan speed

LDL $7 / 6 / 98$

\begin{tabular}{|c|c|c|c|c|c|c|}
\hline (1) plane: & 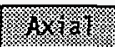 & (3) $(1)$ & tror 12 & no & 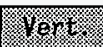 & 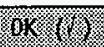 \\
\hline $\begin{array}{l}\text { Coupling gind shatt } \\
\text { Berring }\end{array}$ & .054 & & .104 & $\sim$ & .110 & $\longleftarrow$ \\
\hline 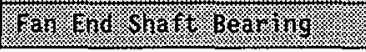 & .062 & 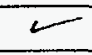 & .086 & 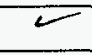 & .080 & 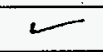 \\
\hline
\end{tabular}




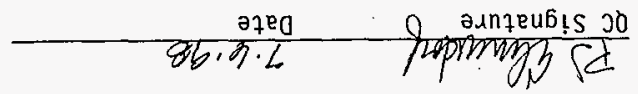

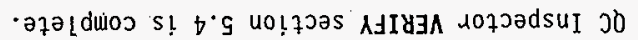

$2 \varepsilon \cdot \nabla^{*} \varsubsetneqq$

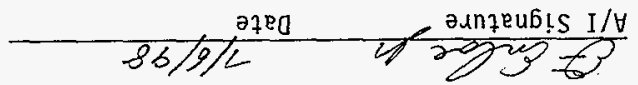

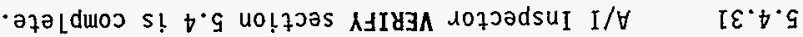

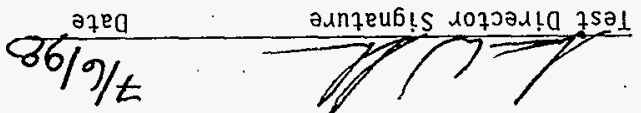

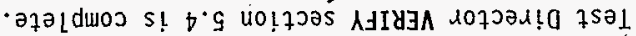

$0 \varepsilon \cdot \nabla \cdot q$

$99 I-\Lambda-d \perp \Lambda$

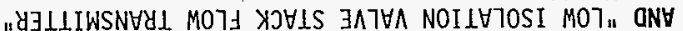

GSI $-\Lambda-d \perp \Lambda$

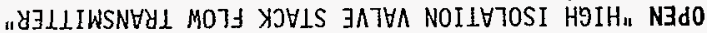

$62 \cdot \nabla \cdot 9$

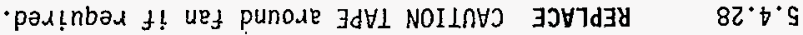

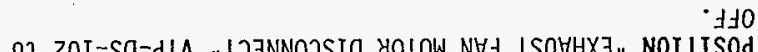

$\angle 2 \cdot \forall \cdot S$

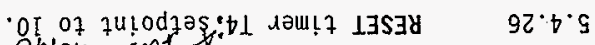

bb/n|t $1 \mathrm{~m} \mid$

- NMOOLnHS sey uef dazsneyx $\lambda \exists I$ IJA

$s 2 \cdot \bullet \cdot s$

-uej

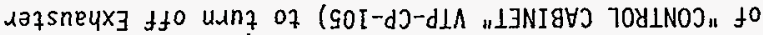

loop uo pazeวoL) 20I-gd-dIA „NOLIng HSOAd dOLS" SSJyd

$b 2 \cdot v \cdot g$

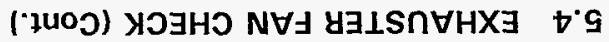




\subsection{HEAT TRACE CHECK}

Warning - Energized circuits and leads are contained inside the cabinets. Comply with HNF-PRO-088, "Electrical Work Safety" the energized electrical work permit in the work package.

5.5.1 REMOVE rheostat cover from "HEAT TRACE THERMOSTAT". VTP-TS-001 (Tocated on side of "CONTROL CABINET" VTP-CP-105).

NOTE: To perform this test outside temperature must be above $40^{\circ} \mathrm{F}$.

5.5.2 SET "HEAT TRACE THERMOSTAT" VTP-TS-001 at $40^{\circ} \mathrm{F}$.

5.5.3 ENSURE $O \dot{V}$ at terminals TB6HTC-1 and TB6HTC-2 (located in "HEAT TRACE CABINET" VTP-ENCL-104) using a DMM.

5.5.4 PLACE bag of ice water around "HEAT TRACE THERMOSTAT" VTP-TS-001 probe.

5.5 .5 WAIT $2-5$ minutes.

5.5.6 VERIFY $120 \mathrm{~V}$ at terminals TB6HTC-1 and TB6HTC -2 using a DMM.

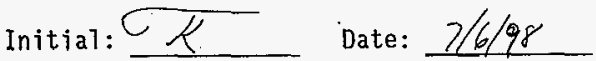

5.5.7 VERIFY "HEAT TRACE ON" amber Jight (located at door of "HEAT TRACE CABINET" VTP-ENCL-104) is ILLUMINATED.

5.5.8 REMOVE ice from the "HEAT TRACE THERMOSTAT" VTP-TS-001 probe.

5.5.9 VERIFY "HEAT TRACE ON" amber light is OFF after probe warms up (1-5 minutes).

5.5.10 VERIFY $0 \mathrm{~V}$ at terminals TB6HTC-1 and TB6HTC-2 using a DMM.

5.5.11 REPLACE rheostat cover on "HEAT TRACE THERMOSTAT" VTP-TS-001. 


\section{$9 \varepsilon$ ә6еd \\ 0 ^әу \\ 8892-בNH}

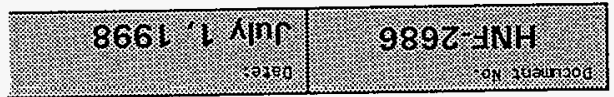

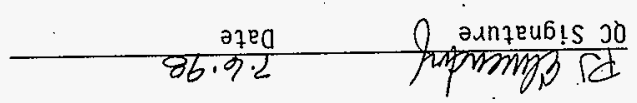

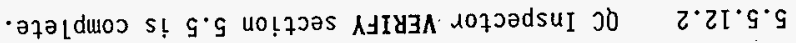

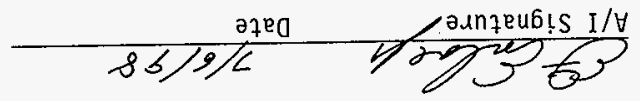

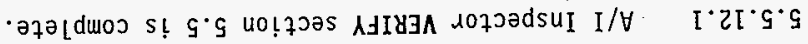

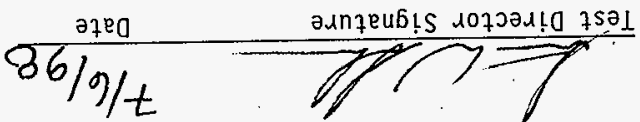

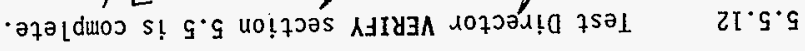

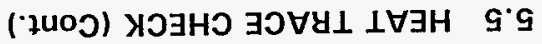




\subsection{FILTER \# 1 DP INTERLOCK/ALARM CHECK}

\begin{tabular}{|c|c|}
\hline NOTE - & $\begin{array}{l}\text { - Sections } 5.6-5.18 \text { are intended to test } \\
\text { specific interlock set points and operations. } \\
\text { Any alarm messages other than those described in } \\
\text { the current step of the procedure shall be } \\
\text { considered secondary alarms }\end{array}$ \\
\hline & Transmitter VTP-PDT-180 range is $0-10^{\prime \prime}$. \\
\hline NOTE- & $\begin{array}{l}\text { ENSURE that the covers of all Yokogawa and Drexelbrook } \\
\text { transmitters and thermocouples ARE REMOVED prior to } \\
\text { testing on those specific instruments and RETURNED } \\
\text { after completion of testing. }\end{array}$ \\
\hline 5.6 .1 & $\begin{array}{l}\text { CONNECT BT-200 to back terminats (plus and minus) of } \\
\text { "HEPA FILTER \#I DIFF PRESSURE" VTP-PDT-180. }\end{array}$ \\
\hline 5.6 .2 & ENSURE Valve lineup per Attachment 11. \\
\hline$\sqrt{5.6 .3}$ & $\begin{array}{l}\text { ENSURE "EXHAUST FAN MOTOR DISCONNECT" VTP-DS-102 is } \\
\text { ON. }\end{array}$ \\
\hline 5.6 .4 & $\begin{array}{l}\text { ENSURE "FAN CONTROL" VTP-HS-103 (located on door of } \\
\text { "CONTROL CABINET" VTP-CP-105) is in the ENABLE } \\
\text { position. }\end{array}$ \\
\hline 5.6 .5 & $\begin{array}{l}\text { ENSURE all alarms are cleared on VTP-MV-101 "MESSAGE } \\
\text { VIEW INTERACTIVE DISPLAY TERMINAL" (located on "ALARM } \\
\text { CABINET" VTP-ENCL-107 swing out panel). }\end{array}$ \\
\hline 5.6 .6 & PRESS "START PUSH BUTTON" VTP-PB-101. \\
\hline 5.6 .7 & $\begin{array}{l}\text { WAIT for the Exhauster fan to reach steady state } \\
\text { operation. }\end{array}$ \\
\hline$\sqrt{5.6 .8}$ & SET the BT-200 to test at $54.0 \%(53.0 \%-55.0 \%)$. \\
\hline$T R_{8}$ & 5.4 \\
\hline
\end{tabular}




\title{
5.6 FILTER \# 1 DP INTERLOCK/ALARM CHECK (Cont.)
}

5.6 .9

\author{
VERIFY the following: \\ $\checkmark$. "EXHAUST FAN" VTP-EF-001 has SHUTDOWN \\ $\checkmark$. Red "ILRUN" light is OFF \\ $\checkmark$. Green "ILOFF" 1 ight is ILLUMINATED
}

$\checkmark \quad$ Clear Rotating Beacon VTP-XA-101 (located on stack supporting framing) is ILLUMINATED

NOTE - Any secondary alarms that are still in alarm condition will also be indicated on VTP-MV-101. It may be necessary to wait until the display scrolls through a] arms.

$\checkmark$ "MESSAGE VIEW INTERACTIVE DISPLAY TERMINAL" VTP-MV-101 displays "FILTER I DP HI".

5.6.10 ACKNOWLEDGE the alarm by PRESSING the "l" button, then PRESSING the "r" button on the "MESSAGE VIEW INTERACTIVE DISPLAY TERMINAL" VTP-MV-101 twice.

NOTE - Any secondary alarms that are still in alarm condition will also be indicated on VTP-MV-101. It may be necessary to wait until the display scrolls through al arms.

5.6.11 ENSURE "MESSAgE VIEW INTERACTIVE DISPLAY TERMINAL" VTP-MV-101 displays "FILTER 1 DP HIHI".

5.6.12 RECORD the pressure indicated by "FILTER \#1 DIFF PRESSURE" VTP-PDI-180 (10cated on door of "CONTROL CABINET" VTP-CP-105).

Indicated Pressure:

5. 3 INWC

5.6.13 ACKNOWLEDGE the alarm by PRESSING the " 1 " button, then PRESSING the "+" button on the "MESSAGE VIEW INTERACTIVE DISPLAY TERMINAL" VTP-MV-101 twice.

- Wait for any secondary atarms and repeat this step until all alarms are cleared on VTP-MV-101. 


\subsection{FILTER \# 1 DP INTERLOCK/ALARM CHECK (Cont.)}

$\checkmark$ 5.6.14 VERIFY Clear Rotating Beacon VTP-XA-101 is OFF.

NOTE - Any secondary alarms that are still in alarm condition wijl also be indicated. It may be necessary to wait until the display scrolls through alarms.

$\checkmark$ 5.6.15 VERIFY "MESSAGE VIEW INTERACTIVE DISPLAY TERMINAL" VTP-MV-102 still displays "FILTER 1 DP HIHI".

$\sqrt{5.6 .16}$ CLEAR the BT-200 test setting.

5.6.17 VERIFY "FILTER \# 1 OP HI" \& "FILTER \#1 DP HIHI" have cleared.

5.6.18 CLEAR VTP-MV-101, and VERIFY VTP-MV-102 is clear.

5.6.19 ACKNOWLEDGE any secondary alarms on VTP-MV-101.

$\checkmark$ 5.6.20 ENTER a preset value of 1000 seconds for timer T4:2 (Address T4:2.PRE)

$\checkmark$ 5.6.21 PRESS "START PUSH BUTTON" VTP-PB-101.

5.6.22 WAIT for the Exhauster fan to reach steady state operation.

$\sqrt{5.6 .23}$ SET the BT-200 to test $1.0 \%(0.8 \%-1.1 \%)$.

NOTE - This is equivalent to approximateiy 0.1 INWC. 


\subsection{FILTER \#1 DP INTERLOCK/ALARM CHECK (Cont.)}

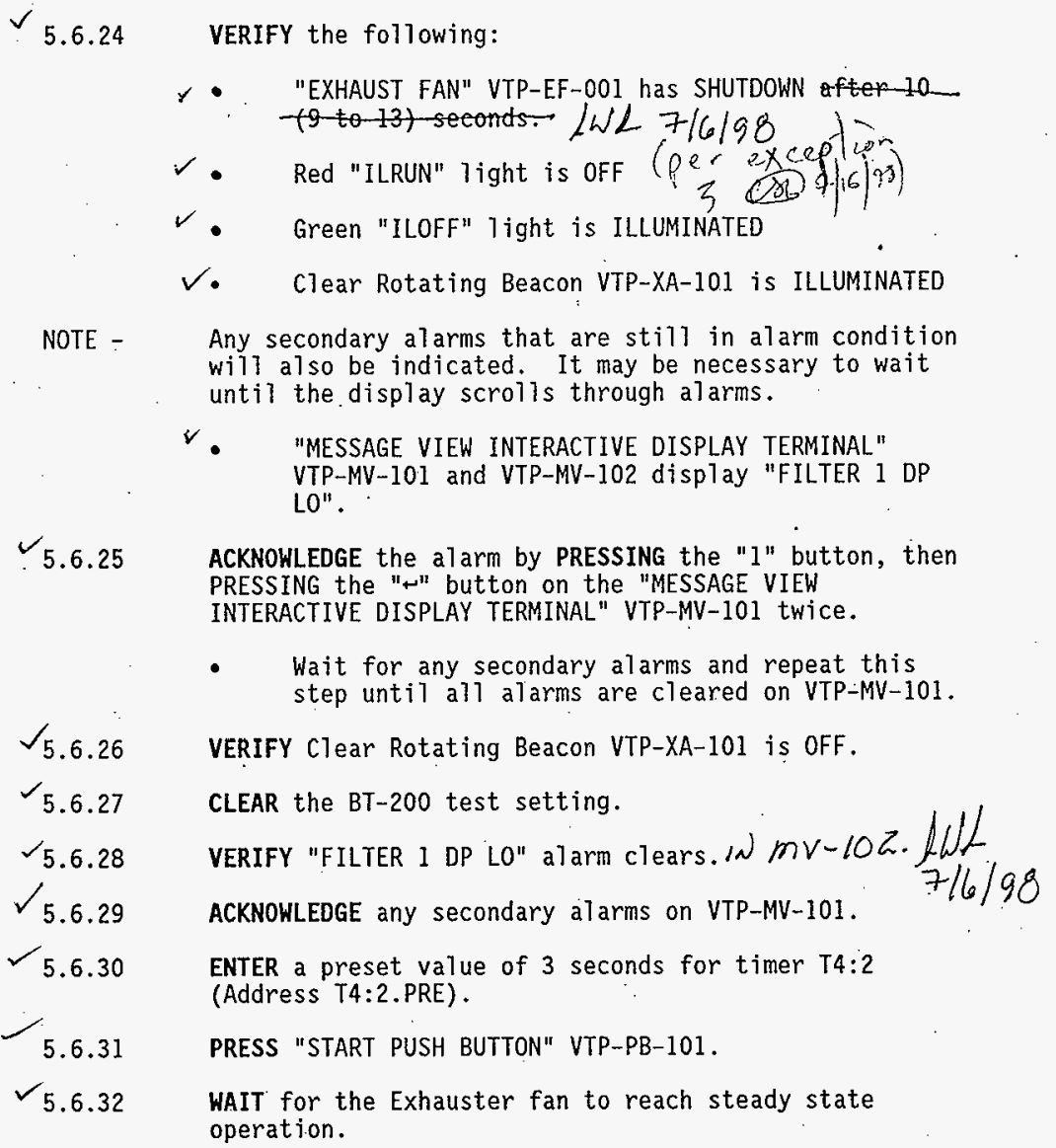




\subsection{FILTER \#1 DP INTERLOCK/ALARM CHECK (Cont.)}

$\checkmark$ 5.6.33 RECORD the pressure indicated by "HEPA FILTER \#1

DIFF PRESSURE" VTP-PDT- 180.

Indicated Pressure: $\quad 0.74 \quad$ INWC

Note - Alarm in VTP-MV-102 will clear as soon as the alarm condtion no longer exists. ROC looks for an increase in flow. Soon after the exhauster has shutdown, there will no longer be a ROC message in VTP-MV-102.

5.6.34 SET the BT-200 to test at 0.5 INWC less than the value recorded in the previous step from VTP-PDI-180, and VERIFY "MESSAGE VIEW INTERACTIVE DISPLAY TERMINAL" VTP-MV-102 indicates "FILTER I DP ROC" within 3 to 6 seconds.

5.6.35 RECORD the following:

\begin{tabular}{|c|c|c|}
\hline 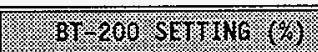 & (1) $101-180 .(\mathrm{Wh})$ & $2018180.91400)$ \\
\hline 2.4 & 0.24 & 0.23 \\
\hline
\end{tabular}

$\checkmark$ V.6.36 VERIFY the following:

$\checkmark$. $\quad$ EXHAUST FAN" VTP-EF-001 has SHUTDOWN

- Red "ILRUN" Tight is OFF

- Green "ILOFF" jight is ILLUMINATED

$\checkmark \quad$ Clear Rotating Beacon VTP-XA-101 is ILLUMINATED

NOTE - Any secondary alarms that are still in alarm condition will al so be indicated. It may be necessary to wait until the display scrolls through alarms.

- "MESSAgE VIEW INTERACTIVE display terminaL" VTP-MV-101 displays "FILTER 1 DP ROC".

$\checkmark$ 5.6.37 ACKNOWLEDGE the alarm by PRESSING the "I" button, then PRESSING the " + " button on the "MESSAGE VIEW INTERACTIVE DISPLAY TERMINAL" VTP-MV-101 twice.

- Wait for any secondary alarms and repeat this step until all alarms are cleared on VTP-MV-101.

$\checkmark_{5.6 .38}$ VERIFY Clear Rotating Beacon VTP-XA-101 is OFF. 


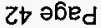 0 ^อу 889Z-JNH}

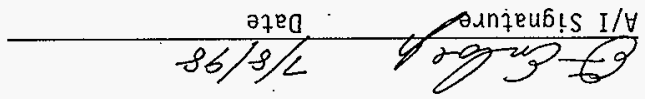

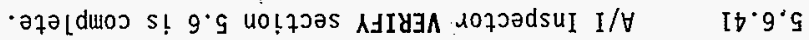

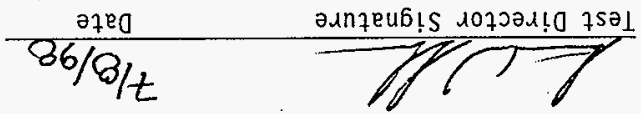

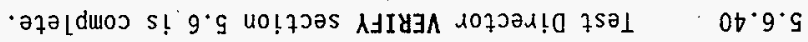

$08[-10 \mathrm{~d}-\mathrm{d} 1 \mathrm{~A}$

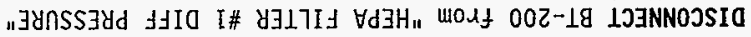

$6 \varepsilon \cdot 9 \cdot 9$

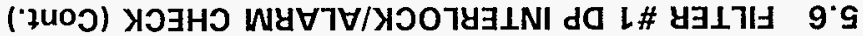




\subsection{FILTER \#2 DP INTERLOCK/ALARM CHECK}

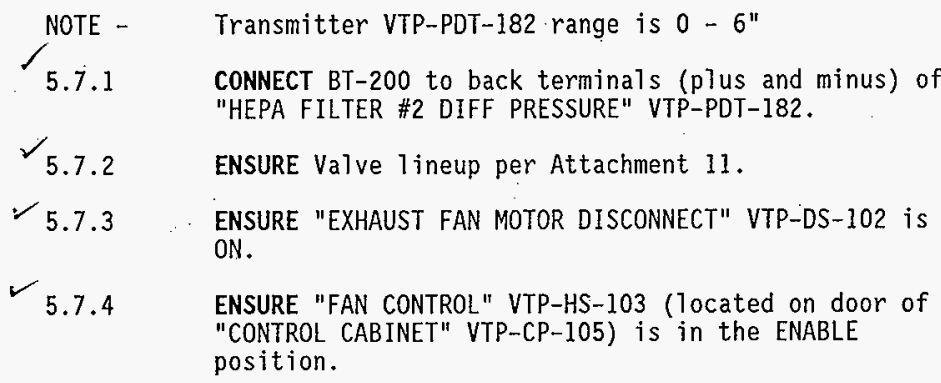

5.7.5 ENSURE alj alarms are cleared on VTP-MV-101 "MESSAGE VIEW INTERACTIVE DISPLAY TERMINAL" (located on "ALARM CABINET" VTP-ENCL-107 swing out pane?).
5.7.6 PRESS "START PUSH BUTTON" VTP-PB-101.
5.7.7 WAIT for the Exhauster fan to reach steady state operation.
$\checkmark 5.7 .8$ SET the BT-200 to test at $061.7 \%(061.5$ to $061.9 \%)$.
NOTE - This is equivalent to approximately 3.7 INWC.
5.7.9 VERIFY the following:
$\checkmark \quad$ "EXHAUST FAN" VTP-EF-001 has SHUTDOWN.
$\checkmark$ Red "ILRUN" light is OFF
$\checkmark$ Green "ILOFF" light is ILLUMINATED
Clear Rotating Beacon VTP-XA-101 is ILLUMINATED
NOTE - Any secondary alarms that are still in alarm condition wi1l also be indicated on VTP-MV-101. It may be necessary to scroll through the alarms by pressing the "w" button.
$\checkmark \quad$ "MESSAGE VIEW INTERACTIVE DISPLAY TERMINAL" VTP-MV-101 DISPLAYS "FILTER 2 .DP HI".




\title{
5.7 FILTER \#2 DP INTERLOCK/ALARM CHECK (Cont.)
}

\author{
$\sqrt{5.7 .10}$ \\ ACKNOWLEDGE the alarm by PRESSING the "1" \\ button, then PRESSING the " + " button on the \\ "MESSAGE VIEW INTERACTIVE DISPLAY TERMINAL" \\ VTP-MV-101 twice. \\ NOTE - Any secondary alarms that are still in alarm condition \\ will also be indicated on VTP-MV-101. It may be \\ necessary to wait until the display scrolls through \\ alarms. \\ $\checkmark_{5,7.11}$ \\ VERIFY "MESSAGE VIEW INTERACTIVE DISPLAY TERMINAL" \\ VTP-MV-102 displays "FILTER 2 DP HIHI". \\ 5.7.12 RECORD the pressure indicated by "FILTER \#2 DIFF \\ PRESSURE" VTP-PDI-182. \\ READING: $\quad 3.69$ INWC \\ 5.7.13 ACKNOWLEDGE the alarm by PRESSING the "1" button, then \\ PRESSING the "ه" button on the "MESSAGE VIEW \\ INTERACTIVE DISPLAY TERMINAL" VTP-MV-101 twice. \\ - Wait for any secondary alarms and repeat this \\ step until all alarms are cleared. \\ 5.7.14 VERIFY Clear Rotating Beacon VTP-XA-101 is OFF. \\ NOTE - Any secondary alarms that are still in alarm condition \\ will also be indicated. \\ 5.7.15 ENSURE "MESSAGE VIEW INTERACTIVE DISPLAY TERMINAL" \\ VTP-MV-102 STILL DISPLAYS "FILTER 2 DP HIHI". \\ 5.7.16 CLEAR the BT-200 test setting. \\ $\checkmark$ 5.7.17 ACKNOWLEDGE any secondary alarms on VTP-MV-101. \\ $\checkmark$ 5.7.18 ENTER a preset value of 1000 seconds for timer. T4:3 \\ (Address T4:3.PRE) \\ 5.7.19 PRESS "START PUSH BUTTON" VTP-PB-101.
}

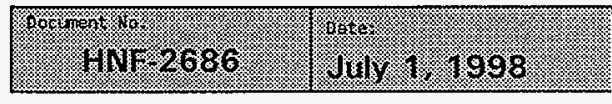




\subsection{FILTER \#2 DP INTERLOCK/ALARM CHECK (Cont.)}

5.7.20 WAIT for the Exhauster fan to reach steady state operation.

5.7.21 SET the BT-200 to test at $001.6 \%(001.4-001.8 \%)$.

NOTE - This is equivalent to approximately 0.1 INWC.

5.7.22 VERIFY the following:

". "EXHAUST FAN" VTP-EF-001 has SHUTDOWN after 10. (7.13)-seconds $7 / 6 / 98 \mathrm{lW} / 2$

- Red "ILRUN" light is OFF

$\checkmark \quad$ Green "ILOFF" 7ight is ILLUMINATED

r. Clear Rotating Beacon VTP-XA-101 is ILLUMINATED

NOTE - Any secondary alarms that are still in alarm condition . will also be indicated.

" "MESSAGE VIEW INTERACTIVE DISPLAY TERMINAL" VTP-MV-101 AND VTP-MV-102 DISPLAY "FILTER 2 DP LO".

5.7.23 ACKNOWLEDGE the a Tarm by PRESSING the "1" button, then PRESSING the "↔" button on the "MESSAGE VIEW

INTERACTIVE DISPLAY TERMINAL" VTP-MV-101 twice.

- Wait for any secondary alarms and repeat this step until all alarms are cleared.

$\checkmark$ 5.7.24 VERIFY Clear Rotating Beacon VTP-XA-101 is OFF.

NOTE - Any secondary alarms that are still in alarm condition will also be indicated.

VERIFY "MESSAGE VIEW INTERACTIVE DISPLAY-TERMTNAL" $7 / 6 / 98$
VIR-MV-102-Sti77 displaYS- "IFILTER? DPLO"

5.7.26 CLEAR the BT-200 test setting.

5.7 .27 VERIFY that "FHTER-2 OP-tQ"-alarm-clears. $7 / 6 / 98 / \mathrm{LL} / 1$

5.7.28 ACKNOWLEDGE any secondary alarms on VTP-MV-101.

$$
\begin{aligned}
& \text { (1) changed per Exceptron } 3 \rightarrow W \text { on } 710190 \\
& \text { AFP - OO3 } \Rightarrow \text { HN }=2637 \text {. int } 7469
\end{aligned}
$$




\subsection{FILTER \#2 DP INTERLOCK/ALARM CHECK (Cont.)}

\begin{tabular}{|c|c|}
\hline 5.7 .29 & $\begin{array}{l}\text { ENTER a preset value of } 3 \text { seconds for timer } T 4: 3 \\
\text { (Address } T 4: 3 \text {.PRE) }\end{array}$ \\
\hline 5.7 .30 & PRESS "START PUSH BUTTON" VTP-PB-101. \\
\hline 5.7 .31 & $\begin{array}{l}\text { WAIT for the Exhauster fan to reach steady state } \\
\text { operation. }\end{array}$ \\
\hline \multirow[t]{2}{*}{$\checkmark 5.7 .32$} & $\begin{array}{l}\text { RECORD the pressure indicated by "HEPA FILTER \#2 DIFF } \\
\text { PRESSURE" VTP-PDT-182. }\end{array}$ \\
\hline & Indicated Pressure: $\quad 0.83$ INWC \\
\hline Note - & $\begin{array}{l}\text { Alarm in VTP-MV-102 will clear as soon as the alarm } \\
\text { condtion no longer exists. ROC looks for an increase } \\
\text { in flow. Soon after the exhauster has shutdown; there } \\
\text { will no longer be a ROC message in VTP-MV-102. }\end{array}$ \\
\hline 5.7 .33 & $\begin{array}{l}\text { SET the BT-200 to test at } 0.5(0.5-0.55) \text { INWC less } \\
\text { than the value recorded in the previous step from VTP- } \\
\text { PDI-182, and VERIFY "MESSAGE VIEW INTERACTIVE DISPLAY } \\
\text { TERMINAL" VTP-MV-102 indicates "FILTER } 2 \text { DP ROC" } \\
\text { within } 3 \text { to } 6 \text { seconds. }\end{array}$ \\
\hline$\sqrt{5}$ & RECORD the following: \\
\hline
\end{tabular}

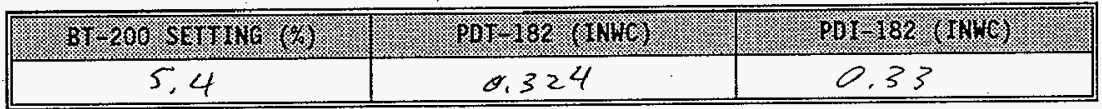

5.7.35 VERIFY the following:

$\checkmark$ "EXHAUST FAN" VTP-EF-001 has SHUTDOWN' after 3-5 seconds.

$\checkmark$ Red "ILRUN" Tight is OFF

$\checkmark$ Green "ILOFF" 1 ight is ILLUMINATED

r. Clear Rotating Beacon VTP-XA-101 is ILLUMINATED

NOTE - Any secondary alarms that are still in alarm condition will also be indicated.

$\checkmark$ "MESSAGE VIEW INTERACTIVE DISPLAY TERMinal" VTP-MV-101 displays "FILTER 2 DP ROC". 


\section{$\angle \forall$ ə6ed \\ 0 ^əу \\ $8892-\exists N H$}

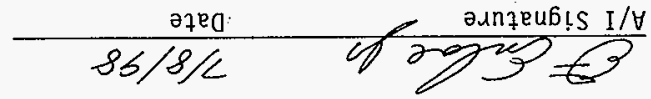

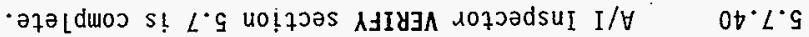

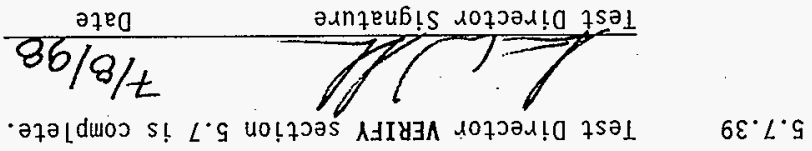

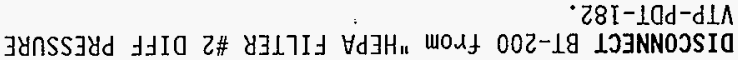

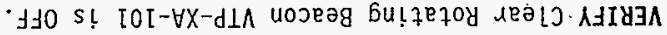

$8 \varepsilon^{\cdot} L^{\circ} \mathrm{G}$

$\angle \mathcal{E} \cdot L \cdot \mathrm{s} \wedge$

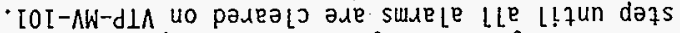

s!47 feadad pue susele kiepuoras fue lof 7 !eM

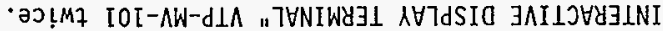

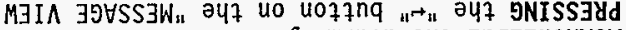

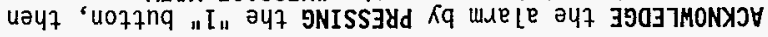

$9 \varepsilon \cdot L^{\circ} \mathrm{G}$

(')นоว) ㄱว 


\section{TANK FARM ACOEPTANCE TEST PROCEDURE}

\subsection{FILTER \#1 \& \#2 DP INTERLOCK/ALARM CHECK}

\begin{tabular}{|c|c|}
\hline NOTE - & Transmitter VTP-PDT-18I range is $0-6^{\prime \prime}$. \\
\hline 5.8 .1 & $\begin{array}{l}\text { CONNECT BT-200 to back terminals (plus and minus) of } \\
\text { "FILTER TRAIN DIFF PRESSURE" VTP-PDT-181. }\end{array}$ \\
\hline 5.8 .2 & ENSURE Valve lineup per Attachment 11. \\
\hline 5.8 .3 & $\begin{array}{l}\text { ENSURE "EXHAUST FAN MOTOR DISCONNECT" VTP-DS-102 is } \\
\text { ON. }\end{array}$ \\
\hline V 5.8 .4 & $\begin{array}{l}\text { ENSURE "FAN CONTROL" VTP-HS-103 (located on door of } \\
\text { "CONTROL CABINET" VTP-CP-105) is in the ENABLE } \\
\text { position. }\end{array}$ \\
\hline$\sqrt{5.8 .5}$ & $\begin{array}{l}\text { ENSURE all a Tarms are cleared on VTP-MV-101 "MESSAGE } \\
\text { VIEW INTERACTIVE DISPLAY TERMINAL" ( } 1 \text { ocated on "ALARM } \\
\text { CABINET" VTP-ENCL-107 swing out pane1). }\end{array}$ \\
\hline 5.8 .6 & PRESS "START PUSH BUTTON" VTP-PB-101. \\
\hline$\checkmark 5.8$ & $\begin{array}{l}\text { WAIT for the Exhauster fan to reach steady state } \\
\text { operation. }\end{array}$ \\
\hline$\sqrt{5.8 .8}$ & SET the BT-200 to test at $090.0 \%(89.5-90.5 \%)$. \\
\hline NOTE - & This is equivalent to approximately 5.4 INWC. \\
\hline$\checkmark_{5.8 .9}$ & VERIFY the following: \\
\hline & - "EXHAUST FAN" VTP-EF-OOl has SHUTDOWN \\
\hline & - Red "ILRUN" light is OFF \\
\hline & - Green "ILOFF" 1 ight is ILLUMINATED \\
\hline & - Clear Rotating Beacon VTP-XA-101 is ILLUMINATED \\
\hline NOTE - & $\begin{array}{l}\text { Any secondary alarms that are still in alarm condition } \\
\text { will also be indicated. }\end{array}$ \\
\hline & $\begin{array}{l}-\quad \text { "MESSAGE VIEW INTERACTIVE DISPLAY TERMINAL" } \\
\text { VTP-MV-10I DISPLAYS "FILTERS } 1 \& 2 \text { DP.HIHI". }\end{array}$ \\
\hline 5.8 .10 & $\begin{array}{l}\text { RECORD the pressure indicated by "FILTER TRAIN } \\
1 / 2 \text { PRESSURE" VTP-PDI-181. }\end{array}$ \\
\hline & READING: 5.3 .8 INWC \\
\hline
\end{tabular}

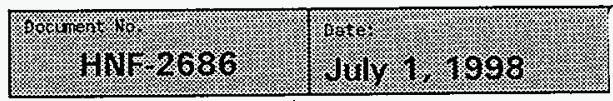

HNF-2688

Rev 0

Page 48 


\subsection{FILTER \# 1 \& \#2 DP INTERLOCK/ALARM CHECK (Cont.)}

$\sqrt{5.8 .11}$

5.8 .12

NOTE -

5.8 .13

5.8 .14

5.8 .15

5.8 .16

$\sim 5.8 .17$

5.8 .18

5.8 .19

NOTE -

5.8 .20

NOTE -
ACKNOWLEDGE the alarm by PRESSING the " 1 " button, then PRESSING the "ه" button on the "MESSAGE VIEW INTERACTIVE DISPLAY TERMINAL" VTP-MV-101 twice.

- Wait for any secondary alarms and repeat this step until all alarms are cleared.

VERIFY Clear Rotating Beacon VTP-XA-101 is OFF.

Any secondary alarms that are still in alarm condition will also be indicated.

VERIFY "MESSAGE VIEW INTERACTIVE DISPLAY TERMINAL" VTP-MV-102 stíl dispTays "FILTERS I \& 2 DP HIHI".

CLEAR the BT-200 test setting.

VERIFY "FILTERS 1 \& 2 DP HIHI" message has cleared from VTP-MV-102.

ACKNOWLEDGE any secondary alarms on VTP-MV-101.

PRESS "START PUSH BUTTON" VTP-PB-I01.

WAIT for the Exhauster fan to reach steady state operation.

SET the BT-200 to test at $001.6 \%(001.4-001.8 \%)$.

This is equivalent to approximatery 0.1 INWC.

VERIFY the following:

$\checkmark$

- "EXHAUST FAN" VTP-EF-001 has SHUTDOWN after-10seconds $718198 \mathrm{LW}) \Rightarrow$ Exceprion 3

$\checkmark$ Red "ILRUN" light is OFF

$\checkmark$ Green "ILOFF" light is ILLUMINATED

$\checkmark$ - Clear Rotating Beacon VTP-XA-101 is ILLUMINATED

Any secondary alarms that are still in alarm condition will also be indicated.

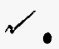

"MESSAGE VIEW INTERACTIVE DISPLAY TERMINAL" VTP-MV-101 displays "FILTERS 1 \& 2 DP LO".

\section{HNF-2688}

Rev 0

Page 49 


\subsection{FILTER \# 1 \& \#2 DP INTERLOCK/ALARM CHECK (Cont.)}

$\checkmark 5.81$

$\sqrt{5.8 .22}$

5.8.23

5.8 .24

$\sqrt{5.8 .25}$

$/ 5.8 .26$

5.8 .27

.8 .28
ACKNOWLEDGE the alarm by PRESSING the " 1 " button, then PRESSING the "w" button on the "MESSAGE VIEH INTERACTIVE DISPLAY TERMINAL" VTP-MV-101 twice.

- Wait for any secondary alarms and repeat this step until all alarms are cleared.

VERIFY Clear Rotating Beacon VTP-XA-101 is OFF.

CLEAR the BT-200 test setting.

VERIFY VTP-MV-102 is no longer dsplays "FILTERS 1/2 DP LO".

ACKNOWLEDGE any secondary alarms on VTP-MV-101.

DISCONNECT BT-200 from "FILTER TRAIN DIFFERENTIAL PRESSURE" VTP-PDT-181.

Test Director VERIFY section $\mathbf{5 . 8}$ is complete.
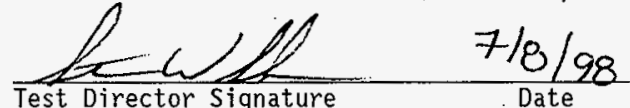

Date

A/I Inspector VERIFY section 5.8 is complete.

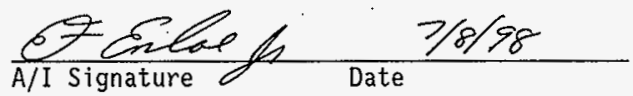




\subsection{STACK FLOW INTERLOCK/ALARM CHECK}

\begin{tabular}{|c|c|}
\hline NOTE - & ransmitter VTP-FT-184 range is $0-4^{\prime \prime}$. \\
\hline 5.9 .1 & $\begin{array}{l}\text { CONNECT BT-200 to back terminals (plus and minus) of } \\
\text { "STACK FLOW" VTP-FT-184. }\end{array}$ \\
\hline$\checkmark 5.9 .2$ & ENSURE Valve Tineup per Attachment 11. \\
\hline 5.9 .3 & $\begin{array}{l}\text { ENSURE "EXHAUST FAN MOTOR DISCONNECT" VTP-DS-102 is } \\
\text { ON. }\end{array}$ \\
\hline$\checkmark 5.9 .4$ & $\begin{array}{l}\text { ENSURE "FAN CONTROL" VTP-HS-103 (located on door of } \\
\text { "CONTROL CABINET" VTP-CP-105) is in the ENABLE } \\
\text { position. }\end{array}$ \\
\hline$\checkmark 5.9 .5$ & $\begin{array}{l}\text { ENSURE alT alarms are cleared on VTP-MV-101 "MESSAGE } \\
\text { VIEW INTERACTIVE DISPLAY TERMINAL" (located on "ALARM } \\
\text { CABINET" VTP-ENCL-107 swing out panel). }\end{array}$ \\
\hline$\checkmark 5.9 .6$ & PRESS "START PUSH BUTTON" VTP-PB-101. \\
\hline 5.9 .7 & $\begin{array}{l}\text { WAIT for the Exhauster fan to reach steady state } \\
\text { operation. }\end{array}$ \\
\hline \multirow[t]{2}{*}{$\checkmark_{5.9 .8}$} & $\begin{array}{l}\text { RECORD value indicated by "STACK FLOW" indicator } \\
\text { VTP-FI-184. }\end{array}$ \\
\hline & READING: $\quad 1006$ SCFM \\
\hline$\checkmark 5.9 .9$ & $\begin{array}{l}\text { PLACE the fan in manual mode by setting the } \\
\text { auto/manual bit } N 20: 41 / 6 \text { to } 0 \text {. }\end{array}$ \\
\hline$\checkmark_{5.9 .10}$ & $\begin{array}{l}\text { SET the BT-200 to test at } 84.5 \% \text {, or a value that } \\
\text { increases "STACK FLOW" VTP-FI-184 to between } \\
1100 \text { and } 1105 \text { CFM. } \\
(88.5 \%)\end{array}$ \\
\hline
\end{tabular}




\subsection{STACK FLOW INTERLOCK/ALARM CHECK (Cont.)}

5.9 .11

5.9 .12
PERFORM the following:

. VERIFY Clear Rotating Beacon VTP-XA-101 is ILLUMINATED

$\checkmark$ RECORD value indicated on "STACK FLOW" VTP-FI-184.

READING: $\quad 110 !$

$\checkmark$ VERIFY "MESSAGE VIEW -INTERACTIVE DISPLAY

TERMINAL" VTP-MV-101 AND VTP-MV-102 DISPLAYS "STACK FLOW HI"

VERIFY the fan has shut down after a 10 to 20 second delay.

ACKNOWLEDGE the alarm by PRESSING the "1" button, then PRESSING the " + " button on the "MESSAGE VIEW INTERACTIVE DISPLAY TERMINAL" VTP-MV-101 twice.

- Wait for any secondary alarms and repeat this step until a11 alarms are cleared on VTP-MV-101

\section{$\checkmark_{5.9 .13}$ \\ $\checkmark 5.9 .14$}

$\checkmark .9 .15$

$\checkmark 5.9 .16$

$\checkmark 5.9 .17$

5.9 .18

$\checkmark 5.9 .19$

$\checkmark 5.9 .20$

$\sqrt{5.9 .21}$
VERIFY Clear Rotating Beacon VTP-XA-101 is OFF.

VERIFY "MESSAGE VIEW INTERACTIVE DISPLAY TERMINAL" VTP-MV-102 maintains a 7 arm message.

CLEAR the BT-200.

VERIFY that the "STACK FLOW HIGH" message has cleared from VTP-MV-102.

ACKNOWLEDGE any secondary a7arms on VTP-MV-101.

PRESS "START PUSH BUTTON" VTP-PB-101.

WAIT for the Exhauster fan to reach steady state operation.

PLACE the fan in manual mode by setting the auto/manual bit $\mathrm{N} 20: 41 / 6$ to 0 .

SET the BT-200 to test at $17.5 \%$ or a value required to drop the stack flow bewteen 469 and 464 SCFM as indicated on the stack flow meter VTP-FI-184. 


\subsection{STACK FLOW INTERLOCK/ALARM CHECK (Cont.)}

5.9.22 RECORD the value indicated on "STACK FLOW" VTP-FI-I84. READING: 468 SCFM

$\checkmark$ V.9.23 VERIFY the Clear Rotating Beacon VTP-XA-101

ILLUMINATES after 10 to 15 seconds.

$\sqrt{5.9 .24}$ VERIFY the fan stops after 30 to 35 seconds.

$\checkmark$ 5.9.25 VERIFY the following:

$\checkmark$ - Ciear rotating beacon VTP-XA-101 is ILLUMINATED

V. Red. "ILRUN" light is OFF

$\checkmark$. Green "ILOFF" 1 ight is ILLUMINATED

$\checkmark \quad$ "MESSAGE VIEW INTERACTIVE DISPLAY TERMINAL" VTP-MV-101 DISPLAYS "STACK. FLOW LO".

5.9 .26

ACKNOWLEDGE the alarm by PRESSING the " $I$ " button, then PRESSING the "w" button on the "MESSAGE VIEW INTERACTIVE DISPLAY TERMINAL" VTP-MV-101 twice.

- Wait for any secondary alarms and repeat this step unti.t all alarms are cleared on VTP-MV-101. 


\subsection{STACK FLOW INTERLOCK/ALARM CHECK (Cont.)}

$\checkmark 5.9 .27$ VERIFY Clear Rotating Beacon VTP-XA-101 is OFF.
$\checkmark 5.9 .28$ CLEAR the BT-200.
5.9 .29 DISCONNECT BT-200 from "STACK FLOW" VTP-FT-184.
5.9 .30 Test Director VERIFY section 5.9 is complete.


5.10 SEAL POT INTERLOCK/ALARM CHECK (Cont.)

$\int 5.10 .8 .5$

LIFT the red lead from the Drexelbrook transmitter's signal positive terminal.

$\checkmark_{5.10 .8 .6}$

ATTACH a short (approximately 3") piece of 12 to 18 gauge wire at the signal positive terminal of the Drexelbrook transmitter.

$\checkmark 5.10 .8 .7$

CONNECT to the wire just attached with the black alligator clip of the-black test lead of the Calibration system. gray $7 / \%$ / g

$\checkmark$ 5.10.8.8 CONNECT the red alligator clip of the brack test lead to the red lead removed from the transmitter in Step 5.10.8.5.

PLUG gray test lead into the calibration system on the right side of the unit above the meter in accordance with the colors painted on the plug connector.

$\checkmark$ 5.10.8.10 PLUG black test lead into the calibration system on the right side of the unit above the knob in accordance with the colored dots painted on the plug connecter.

\subsubsection{LAND ground lead from the black test lead onto} the grounding terminal provided on the calibration system.
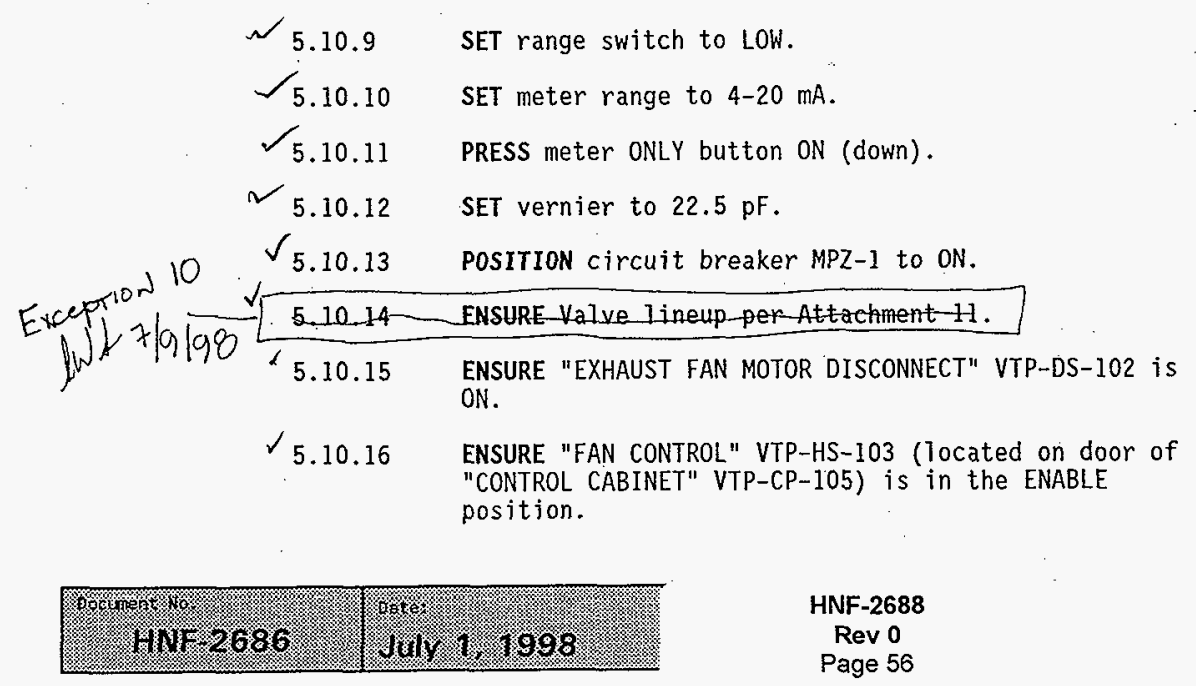

HNF-2688

Rev 0

Page 56 


\subsection{SEAL POT INTERLOCK/ALARM CHECK (Cont.)}

5.10 .17

ENSURE all alarms are cleared on VTP-MV-101 "MESSAGE VIEW INTERACTIVE DISPLAY TERMINAL" (Tocated on "ALARM CABINET" VTP-ENCL-107 swing out pane1).

$\sqrt{5} .10 .18$

$\checkmark 5.10 .19$

$\checkmark \quad 5.10 .20$

5.10 .21
PRESS "START PUSH BUTTON" VTP-PB-101.

WAIT for the Exhauster fan to reach steady state operation.

SET vernier to $16 \mathrm{pF}(8.3$ to $8.8 \mathrm{~mA})$ or less than $30 \%$ of the seal pot level.

RECORD values indicated below:

\begin{tabular}{|c|c|}
\hline 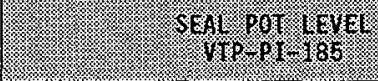 & 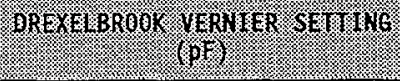 \\
\hline 29 & 15 \\
\hline
\end{tabular}

5.10.22 VERIFY the following: $\checkmark \cdot \quad$ "MESSAGE VIEW INTERACTIVE DISPLAY TERMINAL"
VTP-MV-101 AND VTP-MV-102 DISPLAY "SEAL POT LEVEL LO"

$\checkmark \quad T$ The "EXHAUST FAN" VTP-EF-001 has shutdown

$\checkmark$ Red "ILRUN" light is OFF

$\checkmark$ Green "ILOFF" Tight is ILLUMINATED

$\checkmark$ Clear Rotating Beacon VTP-XA-101 is ILLUMINATED

$\checkmark$ Fan motor does NOT energize when the "START PUSH BUTTON" VTP-PB-101 is pressed.

5.10.23 ACKNOWLEDGE the alarm by PRESSING the " 1 " button, then PRESSING the "\$" button on the "MESSAGE VIEW INTERACTIVE DISPLAY TERMINAL" VTP-MV-101 twice.

$\checkmark$ Wait for any secondary alarms and repeat this step until all alarms are cleared on VTP-MV-101.

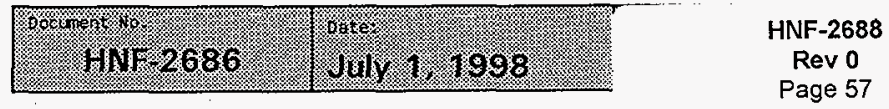




\subsection{SEAL POT INTERLOCK/ALARM CHECK (Cont.)}

$\sqrt{5.10 .24}$ VERIFY Clear Rotating Beacon VTP-XA-101 is OFF.

5.10 .25 VERIFY "MESSAGE VIEW INTERACTIVE DISPLAY TERMINAL" VTP-MV-102 maintains alarm message.

$\sqrt{5.10 .26}$ SET vernier to $22.5 \mathrm{pF}$.

$\checkmark$ PRESS "START PUSH BUTTON" VTP-PB-101.

$\checkmark$ W.10.28 WAIT for the Exhauster fan to reach steady state operation.

$\checkmark$ 5.10.29 SET vernier to $29 \mathrm{pF}$ or a value between $70-73 \%$ of the seal pot level.

5.10.30 RECORD the values indicated below:

\begin{tabular}{|c|c|}
\hline 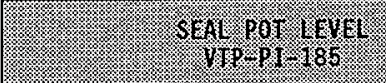 & 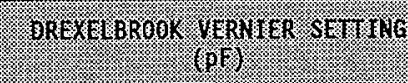 \\
\hline 72 & 29 \\
\hline
\end{tabular}

$\checkmark$ 5.10.31 VERIFY peristaltic pump VTP-P-004 is pumping water by removing insulation and observing hose.

5.10 .32 SET vernier to $32 \mathrm{pF}$ or a value greater than $80 \%$ of the seal pot level.

5.10.33 RECORD the values indicated below:

\begin{tabular}{|c|c|}
\hline 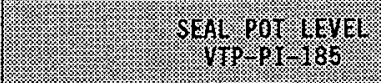 & 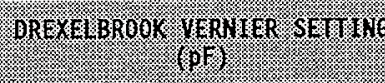 \\
\hline 81 & 32 \\
\hline
\end{tabular}




\subsection{SEAL POT INTERLOCK/ALARM CHECK (Cont.)}

5.10.34 VERIFY the following:

$\checkmark$. Clear rotating beacon VTP-XA-101 is ILLUMINATED

$\checkmark$ Red "ILRUN" light is OFF

$\checkmark$ - Peristaltic Pump is pumping water

$\checkmark \quad$ Fan motor does NOT energize when the "START PUSH BUTTON" VTP-PB-101 is pressed

$\checkmark$ - Green "ILOFF". Jight is ILLUMINATED

$\checkmark$.EXHAUST FAN" VTP-EF-001 has shutdown.

$\sqrt{5.10 .35}$ VERIFY that the "MESSAGE VIEW INTERACTIVE DISPLAY TERMINAL" VTP-MV-101 AND VTP-MV-102 DISPLAY "SEAL POT LEVEL HI".

$\checkmark 5.10 .36$ ACKNOWLEDGE the alarm by PRESSING the " $\mathrm{l}$ " button, then PRESSING the " $\sim$ " button on the "MESSAGE VIEW INTERACTIVE DISPLAY TERMINAL" VTP-MV-101 twice unti1 a]l alarms are cleared.

$\checkmark 5.10 .37$ VERIFY Clear Rotating Beacon VTP-XA-101 is OFF.

$\checkmark \mathbf{5} 10.38$ VERIFY "MESSAGE VIEW INTERACTIVE DISPLAY TERMINAL"

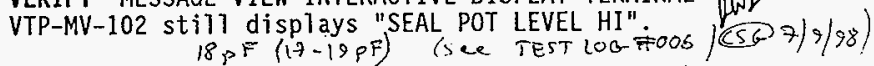

5.10 .39 SET vernier to 22.5 - PF ( $35 \%$ to $40 \%$ on VTP-LI-185).

$\checkmark 5.10 .40$ VERIFY "MESSAGE VIEW INTERACTIVE DISPLAY TERMINAL" VTP-MV-102 message has cleared.

$\checkmark 5.10 .41 \quad$ VERIFY Seal Pot Pump has stopped pumping water. 


\subsection{SEAL POT INTERLOCK/ALARM CHECK (Cont.)}

5.10.42 TURN "SEAL POT PUMP CONTROL" VTP-HS-101 to "HAND" position.

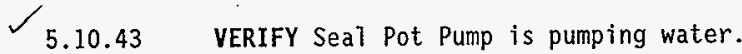

$\checkmark$. 10.44

RELEASE "SEAL POT PUMP CONTROL" VTP-HS-101 from "HAND" position.

$\checkmark$ 5.10.45 VERIFY Seal Pot Pump has stopped pumping water.

5.10 .46 POSITION circuit breaker MPZ-1 to OFF.

$\checkmark 5.10 .47$ DISCONNECT Drexelbrook C-Box.

-5.10.48 RECONNECT probe leads to "Seal Pot Level Transmitter" VTP-LT-185.

-5.10.49 POSITION circuit breaker MPZ-1 to ON.

5.10.50 VERIFY control cabinet POR-007-VTP-CP-105 digita? indicators are illuminated.

$\checkmark$ 5.10.51 RESTORE seal pot forces removed in Step 5.10 .2 (I:3.1, binary code: 0010100111000000 ).

5.10.52 Test Director VERIFY section 5.10 is complete.

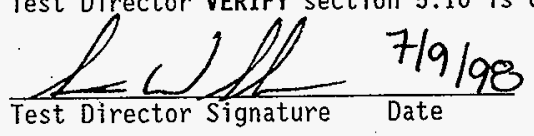

5.10.53 A/I Inspector VERIFY section 5.10 is complete.

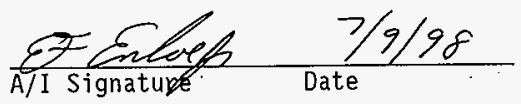




\section{TANK FARM ACGEPTANCE TEST PROCEDURE}

\subsection{GLYCOL INTERLOCK/ALARM CHECK}
5.11 .1
ENSURE the following glycol
system isolation valves are open:

\begin{tabular}{|c|c|c|c|}
\hline 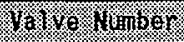 & open $(1)$ & 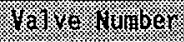 & open $(1)$ \\
\hline (4) & $r$ & 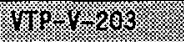 & 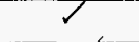 \\
\hline WP & 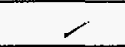 & 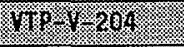 & $\checkmark$ \\
\hline
\end{tabular}

$\checkmark$ 5.11.2 ENSURE Circuit Breaker MPZ - 1 is OFF.

5.11.3 CONNECT Drexelbrook C-Box meter calibration unit leads in series with VTP-LT-205 as follows:

5.11.3.1 REMOVE Drexelbrook level probe transmitter cover.

5.11.3.2 REMOVE de-term the leads attached at SHD and CW on the probe side of the level transmitter. ult $x$ 18198

5.11.3.3 LAND the red lead from the Calibration System's black wire test lead to the SHD terminal of the level transmitter's probe side.

5.11.3.4 LAND the blue lead from the Calibrations System's black two ${ }^{3}$ wire test lead to the $\mathrm{CW}$ terminal of the level transmitter's probe side.

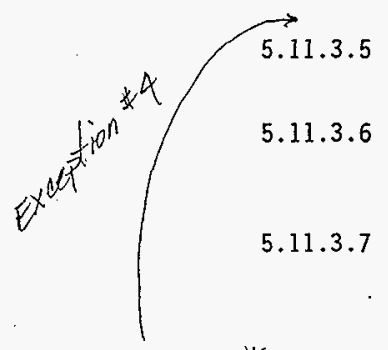

LIFT the red lead (FB2-20) from the Drexelbrook transmitter's signal positive terminal.

ATTACH a short (approximately $3 "$ ) piece of 12 to 18 gauge wire at the signal positive terminal of the Drexelbrook transmitter.

CONNECT to the wire just attached with the black alligator clip of the black test lead of the calibration system. gray Ex.4 9/9/98

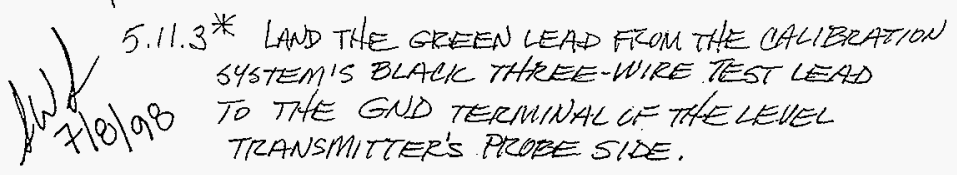

\begin{tabular}{|c|c|}
\hline \%p & (161) \\
\hline
\end{tabular}




\subsection{GLYCOL INTERLOCK/ALARM CHECK (Cont.)}

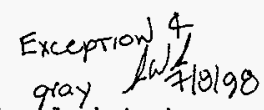

5.11.3.8 CONNECT the red alligator clip of the flack test lead to the red lead removed from the transmitter in Step 5.11.3.5.

5.11.3.9 PLUG gray test lead into the calibration system on the right side of the unit above the meter in accordance with the colors painted on the plug connector.

$$
\text { left Excopions } 7 \text { olgo }
$$

5.11.3.10 PLUG black/test lead into the calibration system on the right side of the unit above the knob in accordance with the colored dots painted on the plug connecter.

5.11.3.11 LAND ground lead from the black test lead onto the grounding terminal provided on the calibration system.

5.11.4 SET range switch to NORMAL.

5.11.5 SET meter range to $4-20 \mathrm{~mA}$.

5.11.6 PRESS meter ONLY button ON (down).

5.11.7 POSITION Circuit Breaker MPZ-1 to ON.

5.11.8 SET Vernier Dial to $71 \mathrm{pf}$.

NOTE - This is equal to greater than $60-65 \%$ volume (13.6 mA).

5.11.9 POSITION "GLYCOL PUMP" Control Switch VTP-HS-102 to ON.

5.11.10 VERIFY/RECORD the following:

- Vajue on "GLYCOL LEVEL" VTP-LI-205

READING: $60 \%$

- GTycol Circulation Pump is operating by

listening to and/or feeling the pump

- Giycol System has no visible leaks.

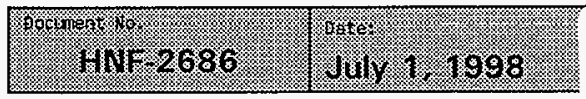




\subsection{GLYCOL INTERLOCK/ALARM CHECK (Cont.)}

\section{WARNING}

Energized circuits and leads are contained inside the cabinets. Comply with HNF-PRO-088, "Electrical Work Safety" the energized electrical work permit in the work package.

$\checkmark$ 5.11.11 ENSURE VTP-DS-201 "GLYCOL HEATER DISCONNECT" is OFF.

$\checkmark 5.11 .12$ REMOVE the thermostat cover on "GLYCOL HEATER"

$\checkmark$ 5.11.13 ENSURE the Heater Thermostat is set to $180^{\circ} \mathrm{F}$.

$\checkmark$ 5.11.14 REPLACE the thermostat cover on VTP-HTR-001.

$\checkmark 5.11 .15$ OPEN door on "GLYCOL HEATER DISCONNECT" VTP-DS-201 cabinet.

$\checkmark$ 5.11.16 POSITION the "GLYCOL HEATER DISCONNECT" VTP-DS-201 to ON.

$\checkmark$ ENSURE MPZ-3 is ON.

$\checkmark 5.11 .18$ VERIFY the Glycol Heater has started by using the DMM at the "GLYCOL HEATER CONTACTOR" VTP-CON-206 (iocated at "GLYCOL HEATER DISCONNECT" VTP-DS-201) and performing the following:

5.11.18.1 RECORD voltage between Terminal $T 1$ and Terminal T2.

READING: $\quad 489$

5.11.18.2 RECORD voltage between Terminal $\mathrm{Tl}$ and Terminal T3.

READING: 487

5:11.18.3 RECORD voltage between Terminal T2 and Terminal T3. READING: 489 
5.11 GLYCOL INTERLOCK/ALARM CHECK (Cont.)

$$
\begin{aligned}
& \text { 5.11.19 REDUCE the impedance to } 61 \mathrm{pF} \text {, or a value equal to } \\
& \text { 48-50\% Volume on the "GLYCOL TANK LEVEL" VTP-LT-205. } \\
& \checkmark \text { 5.11.20 VERIFY the following: } \\
& \checkmark \text { Clear rotating beacon VTP-XA-101 is. ILLUMINATED } \\
& \text {. Glycol Heater has shutdown by observing that the } \\
& \text { "GLYCOL HEATER CONTACTOR" VTP-CON-206 is OPEN } \\
& \text { \% "GLYCOL CIRCULATION PUMP" VTP-P-00I has shutdown } \\
& \text { by listening to and/or feeling the pump } \\
& \checkmark \text {.MESSAGE VIEW INTERACTIVE DISPLAY TERMINAL" } \\
& \text { VTP-MV-101 AND VTP-MV-102 DISPLAY "GLYCOL LEVEL } \\
& \text { LO" . }
\end{aligned}
$$

5.11.21 RECORD the Tiquid 7evel indication on "GLYCOL LEVEL" indicator VTP-LI-205.

READING: 49

$\checkmark$ 5.11.22 ACKNOWLEDGE the alarm by PRESSING the "1" button, then PRESSING the " + " button on the "MESSAGE VIEW INTERACTIVE DISPLAY TERMINAL" VTP-MV-101 twice.

- Wait for any secondary alarms and repeat this step until ai7 alarms are cleared on VTP-MV-101.

5.11.23 VERIFY Clear Rotating Beacon. VTP-XA-101 is OFF.

5.11.24 VERIFY "MESSAGE VIEW INTERACTIVE DISPLAY TERMINAL" VTP-MV-102 maintains a arm message.

$\checkmark$ 5.11.25 POSITION Circuit Breaker MPZ-1 to OFF.

$\checkmark 5.11 .26$ DISCONNECT the DrexelBrook Calibrator from the "GLYCOL TANK LEVEL" transmitter VTP-LT-205.

ExcepTION $5^{2} 5.11 .27$ RECONNECT probe leads to transmitter VTP-LT-205. 718/1998 $\overrightarrow{v_{5}}$ position MBz-1 to ON.

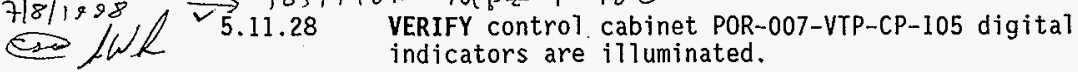




$$
\begin{gathered}
\text { G9 əбеd } \\
0 \text { ^әу } \\
8892- \pm N H
\end{gathered}
$$

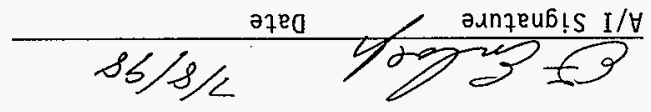

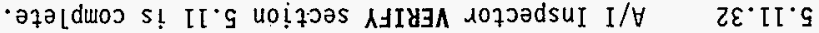

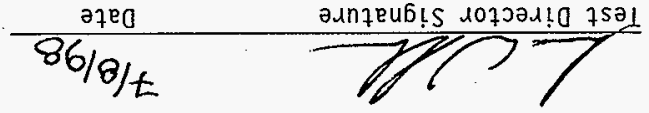

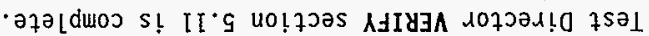

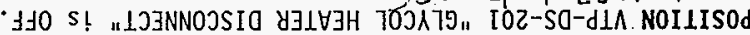
$-1 j 0$ a t 1-zdW nolbisod

$\exists \pm 0$ of 20I-SH-dIN "dWIN $703 k 79$ "NOIIISOd

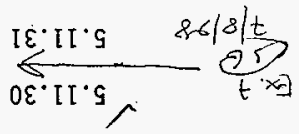

$6 Z \cdot 11 \cdot \mathrm{g}$

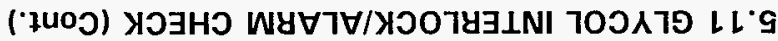




\subsection{THERMOCOUPLE INTERLOCK/ALARM CHECK}

\section{WARNING}

Energized circuits and leads are contained inside the cabinets.

Comply with HNF-PRO-088, "Electrical Work Safety" and the energized electrical work permit in the work package.

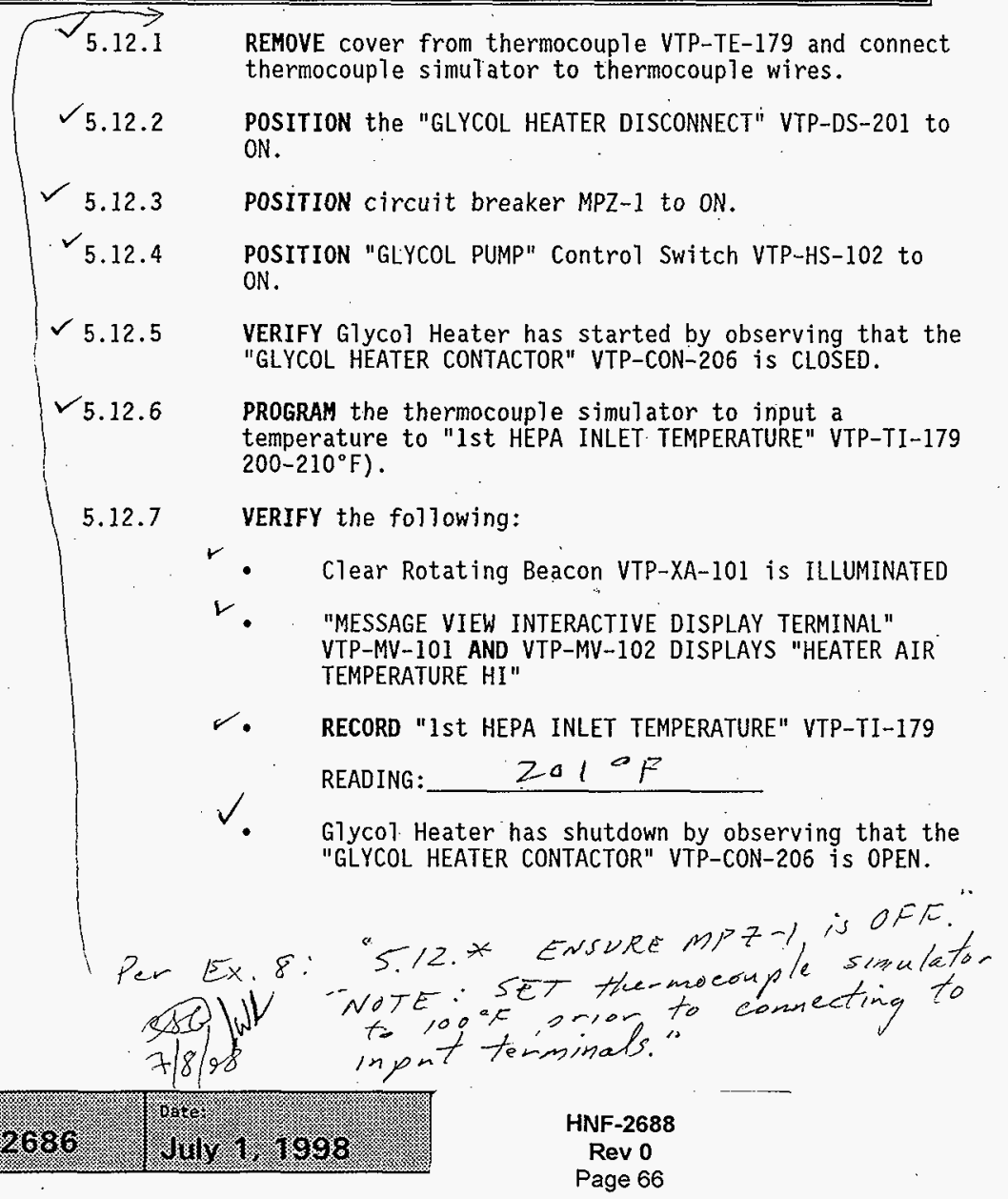




\subsection{THERMOCOUPLE INTERLOCK/ALARM CHECK(Cont.)}

5.12.8 ACKNOWLEDGE the alarm by PRESSING the "1" button, then PRESSING the "w" button on the "MESSAGE VIEW. INTERACTIVE DISPLAY TERMINAL" VTP-MV-101 twice.

- Wait for any secondary alarms and repeat this step until all alarms are cleared on VTP-MV-101.

$\searrow_{5.12 .9}$

VERIFY Clear Rotating Beacon VTP-XA-101 is OFF.

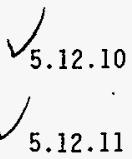

5.12.11 PROGRAM the thermocouple simulator to input a temperature to "1st HEPA INLET TEMPERATURE" VTP-TI-179 $<40^{\circ} \mathrm{F}$.

5.12 .12

VERIFY the following

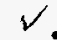

VERIFY "MESSAGE VIEW INTERACTIVE DISPLAY TERMINAL" VTP-MV-102 maintains alarm message.

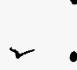

Clear Rotating Beacon VTP-XA-101 is ILLUMINATED

RECORD "1st HEPA INLET TEMPERATURE" VTP-TI-179 READING: $\quad 39^{\circ} \mathrm{E}$

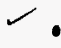

"MESSAGE VIEW INTERACTIVE DISPLAY TERMINAL" VTP-MV-101 AND VTP-MV-102 DISPLAY "HEATER TEMPERATURE- 10". $7 / 8 / 98$ LaL

5.12.13 ACKNOWLEDGE the alarm by PRESSING the "l" button, then PRESSING the "a" button on "the "MESSAGE VIEW INTERACTIVE DISPLAY TERMINAL" VTP-MV-101 twice.

- Wait for any secondary alarms and repeat this step until all alarms are cleared.

$\checkmark / 5.12 .14$

5.12 .16

5.12 .17
VERIFY Clear Rotating Beacon VTP-XA-IOI is OFF. VERIFY "MESSAGE VIEW INTERACTIVE DISPLAY TERMINAL" VTP-MV-102 DISPLAYS a Tarm message.

REMOVE thermocouple wires from thermocouple simulator AND RECONNECT to thermocouple terminals.

VERIFY display is indicating. 


\subsection{THERMOCOUPLEINTERLOCK/ALARM CHECK(Cont.)}

$\sqrt{5}_{5.12 .18}$ POSITION the "GLYCOL HEATER DISCONNECT" VTP-DS-201 to OFF.

5.12.19 Test Director VERIFY section 5.12 is complete.

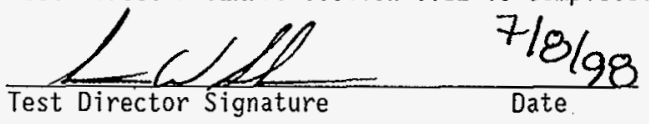

5.12.20 A/I Inspector VERIFY section 5.12 is complete.

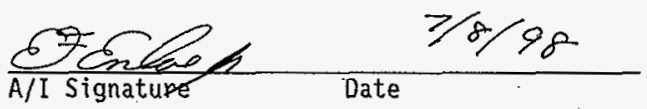




\title{
5.13 PLENUM PRESSURE DP INTERLOCK/ALARM CHECK
}

\author{
NOTE - Transmitter VTP-PDT-170 range is -5 to +5 INWC. \\ 5.13.1 CONNECT BT-200 to back terminals (plus and minus) of \\ "PLENUM DIFF PRESSURE" VTP-PDT-170. \\ $\checkmark$ 5.13.2 ENSURE Valve lineup per Attachment 11 . \\ 5.13.3 ENSURE "EXHAUST FAN MOTOR DISCONNECT" VTP-DS-102 is \\ ON. \\ $\sqrt{5.13 .4}$ ENSURE "FAN CONTROL" VTP-HS-103 (located on door of \\ "CONTROL CABINET" VTP-CP-105) is in the ENABLE \\ position. \\ 5.13.5 ENSURE all alarms are cleared. on VTP-MV-101 "MESSAGE \\ VIEW INTERACTIVE DISPLAY TERMINAL" (located on "ALARM \\ CABINET" VTP-ENCL-107 swing out pane1). \\ 5.13.6 PRESS "START PUSH BUTTON" VTP-PB-101. \\ $\checkmark 5.13 .7$ WAIT for the Exhauster fan to reach steady state \\ operation.

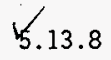 \\ SET the BT-200 to test at $14.9 \%(13-17 \%)$, or a value \\ greater than -3.5 INWC vacuum. \\ レ.13.9 \\ VERIFY the following: \\ $\checkmark \quad$ "EXHAUST FAN" VTP-EF-001 has SHUTDOWN \\ $\checkmark$ Red "ILRUN" light is OFF \\ - Green "ILOFF" light is ILlUMINATED \\ $\sim$ \\ Clear Rotating Beacon VTP-XA-101 is ILLUMINATED \\ NOTE - Any secondary alarms that are still in alarm condition \\ witl also be indicated. \\ "MESSAGE VIEW INTERACTIVE DISPLAY TERMINAL" \\ VTP-MV-101 displays "PLENUM VACUUM 1 HI".
}




\subsection{PLENUM PRESSURE DP INTERLOCK/ALARM CHECK (Cont.)}

5.13.10 RECORD the following indications:

\begin{tabular}{|c|c|c|}
\hline BT 200 SEITING & VTP $($ PDTHC) & YTP PI I 170 \\
\hline 14.9 & -3.51 & -3.5 \\
\hline
\end{tabular}

5.13.11 ACKNOWLEOGE the alarm by PRESSING the "1" button, then PRESSING the " $"$ " button on the "MESSAGE VIEW INTERACTIVE DISPLAY TERMINAL" VTP-MV-10I twice.

- Wait for any secondary alarms and repeat this step until all alarms are cleared.

$\checkmark$ 5.13.12 VERIFY.Clear Rotating Beacon VTP-XA-101 is OFF.

NOTE - Any secondary alarms that are still in alarm condition will also be indicated.

$\checkmark 5.13 .13$ ENSURE "MESSAGE VIEW INTERACTIVE DISPLAY TERMINAL" VTP-MV-102 sti11 displays "PLENUM VACUUM $1 \mathrm{HI"}$.

5.13.14 CLEAR the BT-200 test setting.

$\checkmark$ VERIFY the "PLENUM VACUUM $1 \mathrm{HI}$ " message has cleared from VTP-MV-102.

$\checkmark 5.13 .16$ ACKNOWLEDGE any secondary alarms.

5.13 .17 PRESS "START PUSH BUTTON" VTP-PB-101.

$\checkmark$.13.18 WAIT for the Exhauster fan to reach steady state operation.

5.13 .19 $100 \%(100-102 \%)$. Exce ption 6 SET the BT-200 to test at $49 \%(48-50 \%)$. This is equivalent to approximately -0.1 INWC. $+5.0$ 


\section{TANK FARM ACCEPTANCE TEST PROCEDURE}

\subsection{PLENUM PRESSURE DP INTERLOCK/ALARM CHECK (Cont.)}

5.13.20 VERIFY the following:

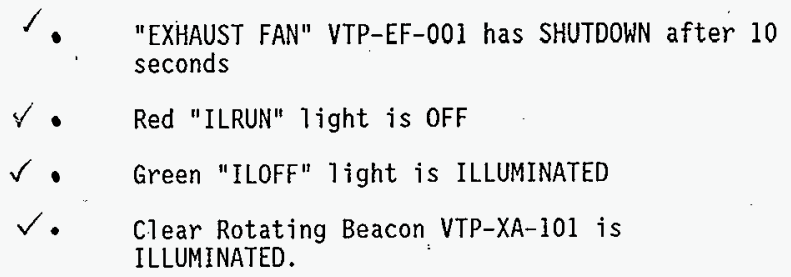

NOTE - Any secondary alarms that are still in alarm condition will also be indicated.

- "MESSAGE VIEW INTERACTIVE DISPLAY TERMINAL" VTP-MV-101 AND VTP-MV-102 DISPLAYS "PLENUM + PRESSURE $\mu_{1}$ II". $\mid f_{7}^{4} / 8 / 98$

5.13.21 RECORD the following indications:

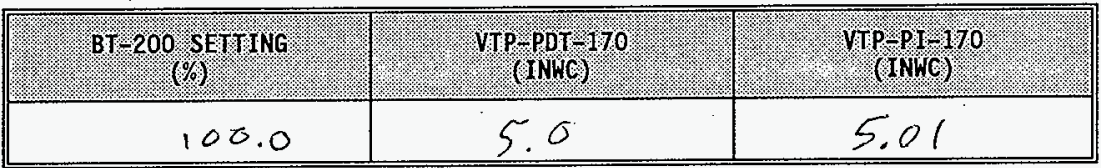

$\checkmark 5.13 .22$ ACKNOWLEDGE the alarm by PRESSING the "1" button, then PRESSING the "ه" button on the "MESSAGE VIEW INTERACTIVE DISPLAY TERMINAL" VTP-MV-101 twice.

- Wait for any secondary alarms and repeat this step until all alarms are cleared.

5.13.23 VERIFY Clear Rotating Beacon VTP-XA-101 is OFF.

NOTE - Any secondary alarms that are still in alarm condition will also be indicated.

$\checkmark 5.13 .24$ VERIFY "MESSAGE VIEW INTERACTIVE DISPLAY TERMINAL" VTP-MV-102 sti11 DISPLAYS "PLENUM-1 PRESSURE ${ }_{\Lambda} H I "$.

5.13.25 CLEAR the BT-200 test setting. $7 / 8 / 78$ 17/8/98 


\subsection{PLENUM PRESSURE DP INTERLOCK/ALARM CHECK (Cont.)}

$\checkmark_{5.13 .26}$ DISCONNECT BT-200 from "1st PLENUM PRESSURE"
VTP-PDT-170.

5.13.27 Test Director VERIFY that section 5.13 is complete.

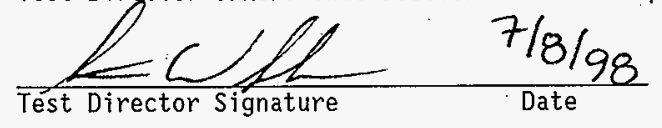

5.13.28 A/I Inspector VERIFY section 5.13 is complete.

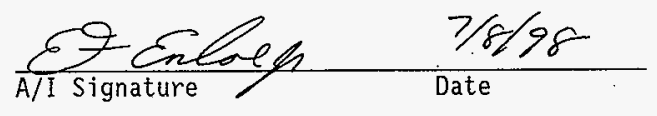




\title{
TANK FARM ACCEPTANCE TEST PROCEDURE
}

\subsection{GLYCOL HEATER TEST}

\author{
$\checkmark$ 5.14.1 ENSURE Valve 1ineup per Attachment 11. \\ $\checkmark$ 5.14.2 ENSURE "EXHAUST FAN MOTOR DISCONNECT" VTP-DS-102 is \\ ON. \\ $\sqrt{5.14 .3}$ ENSURE "FAN CONTROL" VTP-HS-103 (located on door of \\ "CONTROL CABINET" VTP-CP-105) is in the ENABLE \\ position.
}

5.14.4 ENSURE all alarms are cleared on VTP-MV-101 "MESSAGE VIEW INTERACTIVE DISPLAY TERMINAL" (located on "ALARM CABINET" VTP-ENCL-107 swing out pane1).

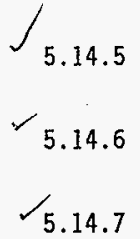

PRESS "START PUSH BUTTON" VTP-PB-101 to start "EXHAUST FAN" VTP-EF-001.

POSITION the "GLYCOL HEATER DISCONNECT" VTP-DS-201 to ON.

POSITION "GLYCOL PUMP" Control Switch VTP-HS-102 to ON AND RECORD initial values for time, inlet temperature, and outlet temperature below.

\begin{tabular}{|c|c|c|}
\hline 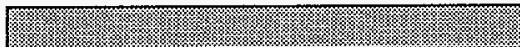 & $m=$ & 101010 \\
\hline Ttree and bate: & 7181980941 & $7 / 8 / 980948$ \\
\hline Thlet temperative ( & 85 & 84 \\
\hline Gitiet tenperature (IF), WTP-TI Th9 & 89 & 104 \\
\hline
\end{tabular}

$\checkmark 5.14 .8$

5.14 .9

5.14 .10

$-5.14 .11$

5.14 .12

5.14 .13
CONTINUE exhauster operation until the airflow temperature indicated by "lst HEPA INLET TEMPERATURE" VTP-TI-179 is $20^{\circ} \mathrm{F}$ above "INLET TEMPERATURE" VTP-TI-176.

RECORD final values for time, inlet temperature, and outlet temperature.

POSITION HS-102 to OFF.

POSITION DS-201 to OFF.

PUSH "STOP" button.

OPEN VTP-DS-102. 


$$
\begin{gathered}
t \angle \text { ə6ed } \\
0 \text { ^әу } \\
8897-\unlhd N H
\end{gathered}
$$

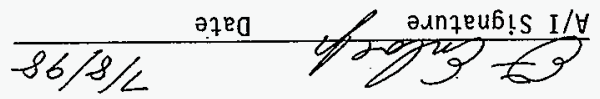

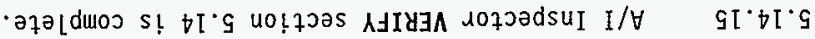

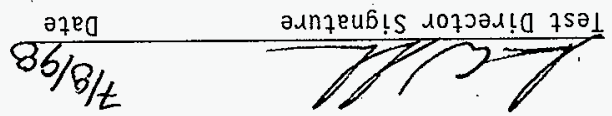

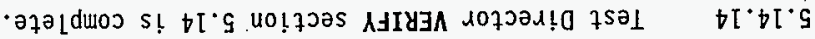

('7นoว) $1 S \exists \perp$ y $\exists \perp \forall \exists H 700 \lambda 10$ เL'9 


\subsection{FAN INLET VACUUM INTERLOCKIALARM CHECK- PRESSURE CONTROL}

Note - Transmitter VTP-PDT-170 range is 0 to -20 INWC.

Note - $\quad$ Some adjustment of VTP-V-135 may be required at start up to prevent high/low stack flow set points from being exceeded. Such adjustments do not qualify as a Test Exception.

$\sqrt{5.15 .1}$

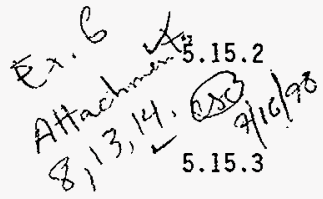

$\checkmark 5.15,4$

5.15 .5

5.15 .6

5.15 .7

5.15 .8

5.15 .9

5.15 .10

5.15 .11

5.15 .12
ENSURE that the pressure differential transmitter sensing plenum vacuum has been disconnected and the transmitter sensing fan inlet vacuum has been connected.

ENSURE that the PLC 500 has been configured for Pressure Control, with set points as identified in Attachment 13.

CONNECT BT-200 to back terminals (plus and minus) of "PLENUM DIFF PRESSURE" VTP-PDT-170.

ENSURE Valve lineup per Attachment 11.

CLOSE VTP-V-135 to approximately $75 \%$ closed.

ENSURE "EXHAUST FAN MOTOR DISCONNECT" VTP-DS-102 is ON.

ENSURE "FAN CONTROL" VTP-HS-103 (Tocated on door of "CONTROL CABINET" VTP-CP-105) is in the ENABLE posjtion.

ENSURE all alarms are cleared on VTP-MV-101 "MESSAGE VIEW INTERACTIVE DISPLAY TERMINAL" (located on "ALARM CABINET" VTP-ENCL-107 swing out panel).

PRESS "START PUSH BUTTON" VTP-PB-101.

WAIT for the Exhauster fan to reach steady state operation.

PLACE PID in Manual Mode $($ N20:41/6=0)

SET the BT-200 to test at $63.8 \%(63.5-64 \%)$. This is equivalent to 12.75 INWC vacuum. 


\subsection{FAN INLET VACUUM INTERLOCK/ALARM CHECK- PRESSURE CONTROL (Cont.)}

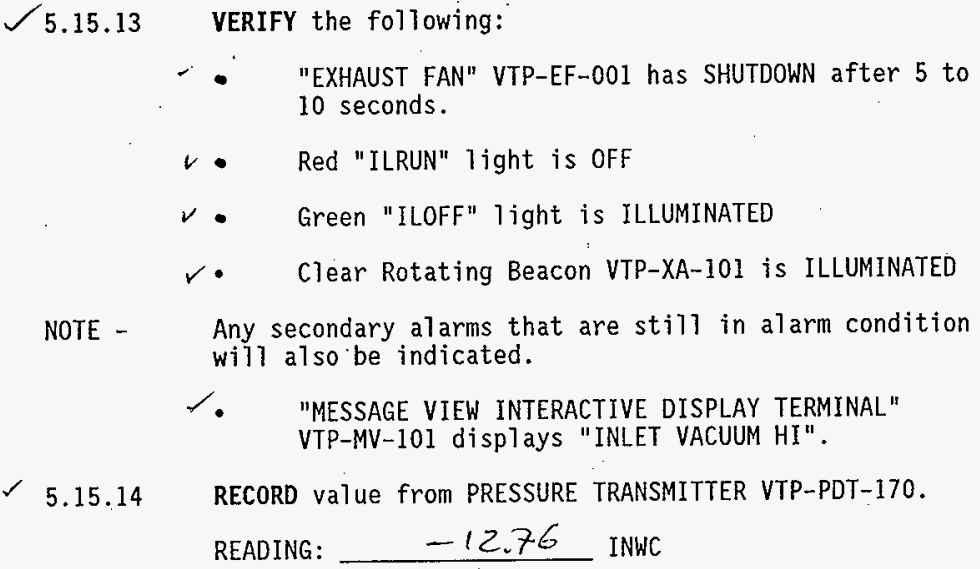
$\checkmark 5.15 .15$ ACKNOWLEDGE the alarm by PRESSING the " 1 " button, then
PRESSING the "+" button on the "MESSAGE VIEW INTERACTIVE. DISPLAY TERMINAL" VTP-MV-101 twice.

- Wait for any secondary alarms and repeat this step until all alarms are cleared.

5.15.16 VERIFY Clear Rotating Beacon VTP-XA-101 is OFF.

NOTE - Any secondary alarms that are still in alarm condition will also be indicated.

$\checkmark$ E.15.17 ENSURE "MESSAGE VIEW INTERACTIVE DISPLAY TERMINAL" VTP-MV-102 sti17 displays "INLET VACUUM HI".

$\checkmark$ 5.15.18 CLEAR the BT-200 test setting.

$\checkmark$ VERIFY the "INLET VACUUM HI" message has cleared from VTP-MV-102.

$\sqrt{5.15 .20}$ ACKNOWLEDGE any secondary alarms.

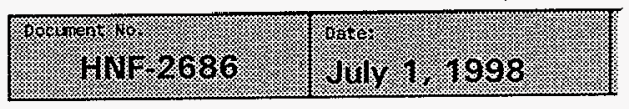




\title{
5.15 FAN INLET VACUUM INTERLOCK/ALARM CHECK- PRESSURE CONTROL (Cont.)
}

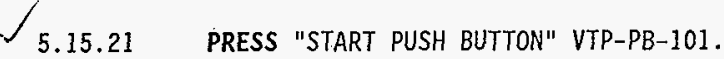 \\ 5.15.22 WAIT for the Exhauster fan to reach steady state \\ operation. \\ 5.15.23 PLACE PID in Manual Mode (N20:41/6=0) \\ $\checkmark 5.15 .24$ SET the BT-200 to test at $29.9 \%(29.5-30.5 \%)$. This is \\ equivalent to approximately. 6 INWC. \\ 5.15.25 RECORD value from PRESSURE TRANSMITTER VTP-PDT-170. \\ READING: \\ -5.98 INWC \\ 5.15.26 VERIFY the following: \\ $\checkmark$. Clear Rotating Beacon VTP-XA-101 is \\ ILLUMINATED (after 5 to 7 seconds). \\ NOTE - Any secondary alarms that are still in alarm condition \\ will also be indicated. \\ *. "MESSAGE VIEW INTERACTIVE DISPLAY TERMINAL" \\ VTP-MV-101 AND VTP-MV-102 DISPLAYS. "INLET VACUUM \\ LO". \\ 5.15.27 CLEAR the BT-200 test setting. \\ 5.15.28 ACKNOWLEDGE uncleared alarms by PRESSING the "1" \\ button, then PRESSING the "ه" button on the "MESSAGE \\ VIEW INTERACTIVE DISPLAY TERMINAL" VTP-MV-101 twice. \\ - Wait for any secondary alarms and repeat this \\ step until all alarms are acknowledged. \\ 5.15.29 VERIFY Clear Rotating Beacon VTP-XA-101 is OFF. \\ 5.15 .30 DISCONNECT BT-200 from "1st PLENUM PRESSURE" \\ VTP-PDT-170.
}




\subsection{FAN INLET VACUUM INTERLOCK/ALARM CHECK- . PRESSURE CONTROL (Cont.)}

5.15.31 Test Director VERIFY that section 5.15 is complete.

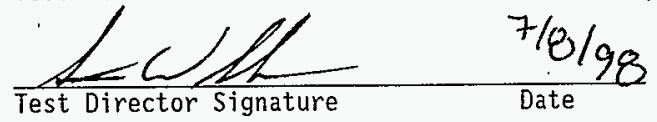

5.15.32 A/I Inspector VERIFY section 5.15 is complete.

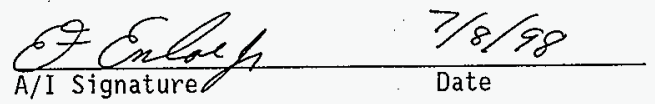




\section{TANK FARIV ACOEPTANCE TEST PROCEDURE}

\subsection{STACK FLOW INTERLOCK/ALARM CHECK-PRESSURE CONTROL}

Note - Transmitter VTP-FT-184 range is $0-4^{\prime \prime}$.

Note - $\quad$ Some adjustment of VTP-V-135 may be required at start up to prevent high/low stack flow set points from being exceeded. Such adjustments do not qualify as a Test Exception.

$J_{5.16 .1}$ ENSURE that the pressure differential transmitter sensing plenum vacuum has been disconnected and the transmitter sensing fan inlet vacuum has been connected.

$J_{5.16 .2}$

ENSURE that the PLC 500 has been configured for Pressure Control, with set points as identified in Attachment 13 .

$\checkmark$ CONNECT BT-200 to back terminals (plus and minus) of "STACK FLOW" VTP-FT-184.

5.16.4 ENSURE Valve lineup per Attachment 11.

5.16.5 CLOSE VTP-V-135 to approximately $75 \%$ closed.

$\checkmark 5.16 .6$

ENSURE "EXHAUST FAN MOTOR DISCONNECT" VTP-DS-102 is ON.

$\checkmark$ 5.16.7 ENSURE "FAN CONTROL" VTP-HS-103 (located on door of "CONTROL CABINET" VTP-CP-105) is in the ENABLE position.

5.16.8 ENSURE all alarms are cleared on VTP-MV-101 "MESSAGE. VIEW INTERACTIVE DISPLAY TERMINAL" (located on "ALARM CABINET" VTP-ENCL-107 swing out panel).

5.16.9 PRESS "START PUSH BUTTON" VTP-PB-101.

5.16.10 WAIT for the Exhauster fan to reach steady state operation.

5.16.11 RECORD value indicated by "STACK FLOW" indicator VTP-FI-184.

READING:

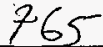
SCFM 


\subsection{STACK FLOW INTERLOCK/ALARM CHECK-PRESSURE CONTROL (Cont.)}

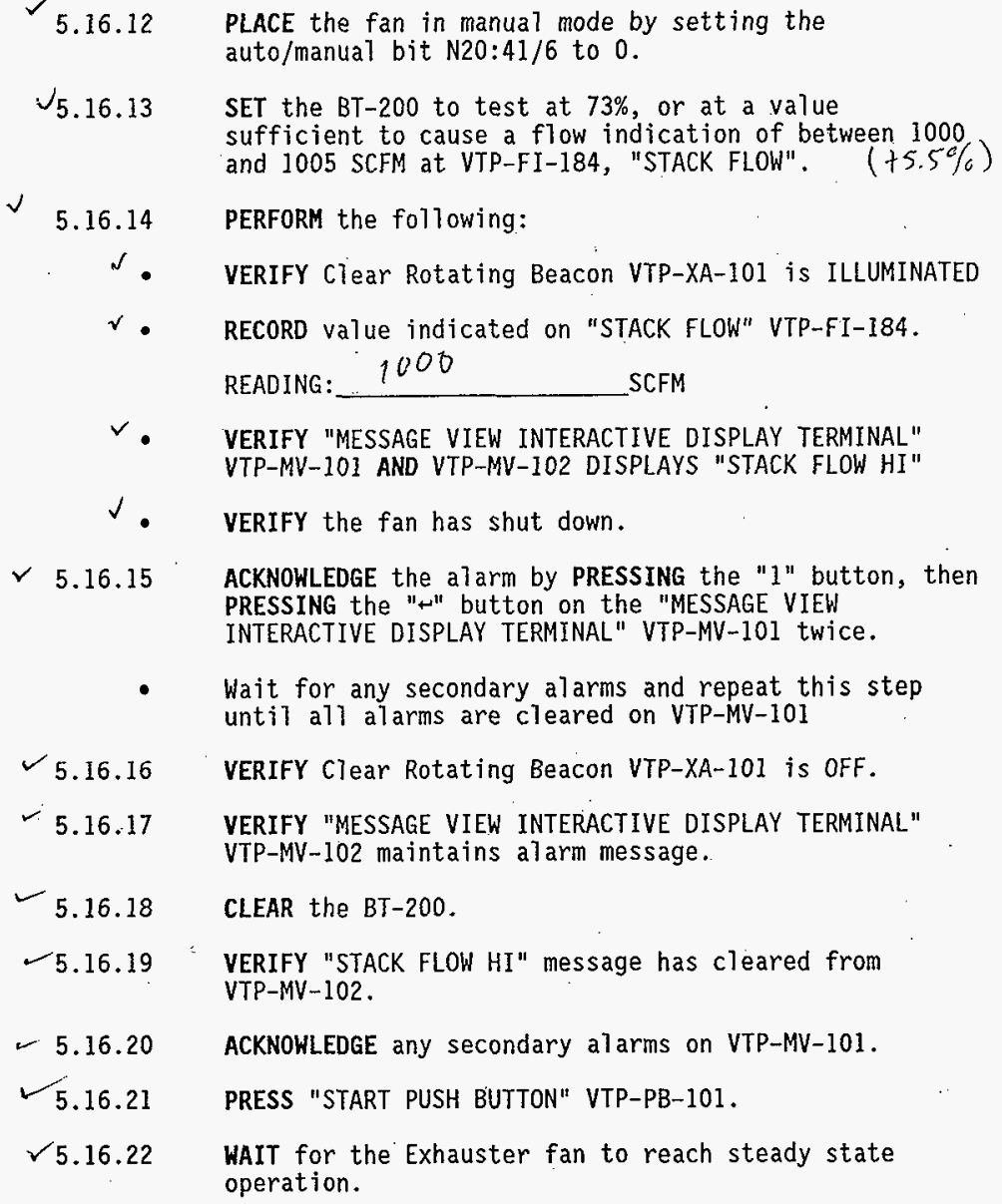




\subsection{STACK FLOW INTERLOCK/ALARM CHECK-PRESSURE CONTROL (Cont.)}

\begin{tabular}{|c|c|}
\hline$V_{5.16 .23}$ & $\begin{array}{l}\text { PLACE the fan in manual mode by setting the } \\
\text { auto/manual bit } \mathrm{N} 20: 41 / 6 \text { to } 0 \text {. }\end{array}$ \\
\hline$V \cdot 5.16 .24$ & $\begin{array}{l}\text { SET the BT-200 to test at } 32.5 \% \text { or a value required to } \\
\text { drop the stack flow between } 675 \text { and } 670 \text { SCFM as } \\
\text { indicated on the stack flow meter VTP-FI-184. }\end{array}$ \\
\hline$\sqrt{ } 5.16 .2$ & $\begin{array}{l}\text { RECORD the value indicated on "STACK FLOW" VTP-FI-184. } \\
\text { READING: } \quad 673 \quad \text { SCFM }\end{array}$ \\
\hline
\end{tabular}

$\checkmark 5.16 .26$ VERIFY the following:
$\checkmark$. Clear rotating beacon VTP-XA-101 is ILLUMINATED after 10 to 15 seconds.

$\checkmark \quad$ "MESSAGE VIEW INTERACTIVE DISPLAY TERMINAL" VTP-MV-101 DISPLAYS "STACK FLOW LO".

$\checkmark$ 5.16.27 CLEAR the BT-200.

5.16 .28

- 5.16.29 VERIFY Clear Rotating Beacon VTP-XA-101 is OFF.

5.16.30 DISCONNECT BT-200 from "STACK FLOW" VTP-FT-184.

5.16.31 Test Director VERIFY section 5.16 is complete.

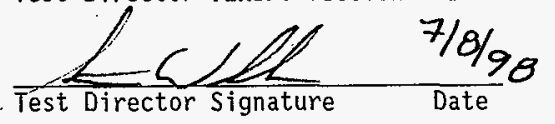

5.16.32 A/I Inspector VERIFY section 5.16 is complete.

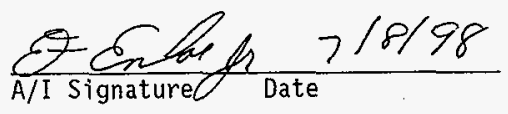




\subsection{HIGH INLET VACUUM INTERLOCK CHECK-HIGH VACUUM}

Note - Transmitter VTP-PDT-170 range is 0 to -20 INWC.

Note - Some adjustment of VTP-V-135 may be required at start up to prevent high/low stack flow set points from being exceeded. Such adjustments do not qual ify as a Test Exception.

5.17.1 ENSURE that the pressure differential transmitter sensing plenum vacuum has been disconnected and the transmitter sensing fan inlet vacuum has been connected.

5.17.2 ENSURE that the PLC 500 has been configured for High Vacuum Operation, with set points as identified in Attachment 14.

$\checkmark$ 5.17.3 CONNECT BT-200 to back terminals (plus and minus) of "PLENUM DIFF PRESSURE" VTP-PDT-170.

5.17.4 ENSURE Valve lineup per Attachment 11.

5.17 .5 CLOSE VTP-V-135 to approximately $75 \%$ closed.

5.17.6 ENSURE "EXHAUST FAN MOTOR DISCONNECT" VTP-DS-102 is ON.

5.17.7 ENSURE "FAN CONTROL" VTP-HS-103 (located on door of "CONTROL CABINET" VTP-CP-105) is in the ENABLE position.

5.17.8 ENSURE all alarms are cleared on VTP-MV-101 "MESSAGE VIEW INTERACTIVE DISPLAY TERMINAL" (located on "ALARM CABINET" VTP-ENCL-107 swing out pane1).

5.17.9 PRESS "START PUSH BUTTON" VTP-PB-101.

5.17.10 WAIT for the Exhauster fan to reach steady state operation.

5.17 .11

SET the BT-200 to test at $97.6 \%(97.5-98.0 \%)$, or a value required to increase the inlet vacuum to 19.5 INWC as indicated on VTP-PDT-170. 


\section{TANK FARI ACCEPTANCE TEST PROCEDURE}

\subsection{HIGH VACUUM INTERLOCK CHECK-HIGH VACUUM (Cont.)}

$\checkmark 5.17 .12 \quad$ VERIFY the following:
$\checkmark \quad$ "EXHAUST FAN" VTP-EF-001 has SHUTDOWN
$\checkmark$ after 5-7 seconds.
$\checkmark$ Red "ILRUN" light is OFF
$\checkmark$ Green "ILOFF" light is ILLUMINATED

NOTE - Any secondary alarms that are still in alarm condition will also be indicated.

$\checkmark$ "MESSAGE VIEW INTERACTIVE DISPLAY TERMINAL" VTP-MV-10I displays "INLET VACUUM HI".

5.17.13 RECORD VaTue from PRESSURE TRANSMITTER VTP-PDT-170. READING: $-19,52$ INWC

5.17.14 ACKNOWLEDGE the alarm by PRESSING the "1" button, then PRESSING the "म" button on the "MESSAGE VIEW INTERACTIVE DISPLAY TERMINAL" VTP-MV-101 twice.

- Wait for any secondary alarms and repeat this step until all alarms are cleared.

5.17.15 VERIFY Clear Rotating Beacon VTP-XA-101 is OFF.

NOTE - Any secondary alarms that are still in alarm condition will also be indicated.

5.17.16 ENSURE "MESSAGE VIEW INTERACTIVE DISPLAY TERMINAL" VTP-MV-102 sti11 displays "INLET VACUUM HI".

5.17.17 CLEAR the BT-200 test setting.

5.17 .18 VERIFY "INLET VACUUM HI" has cleared from VTP-MV-102.

$\checkmark 5.17 .19$ ACKNOWLEDGE any secondary alarms.

5.17 .20

DISCONNECT BT-200 from "1st PLENUM PRESSURE" - VTP-PDT -170. 
5.17 HIGH VACUUM INTERLOCK CHECK-HIGH VACUUM (Cont.)

5.17.21 Test Director VERIFY that section 5.17 is complete.

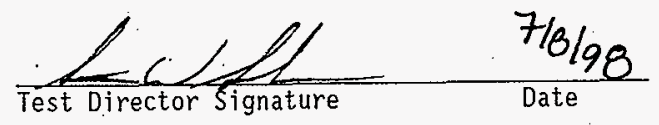

5.17.22 A/I Inspector VERIFY section 5.17 is complete.

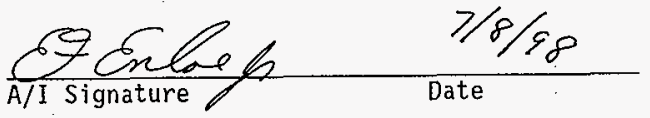


(2) S'St) WJJS c00[-000I

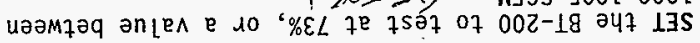
WJTS 218 : $\cdot \succcurlyeq 8[-I j-d \perp \Lambda$

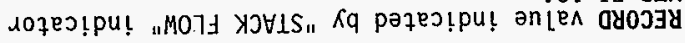
- vo!fesado

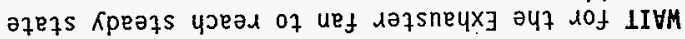

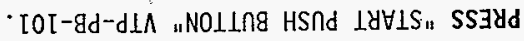

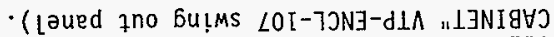

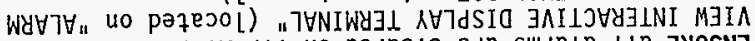

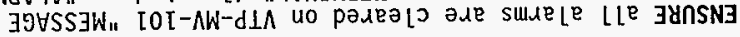

$\cdot 40 ! 7 !$ sod

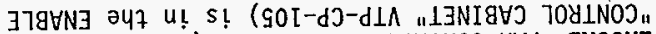

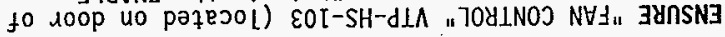

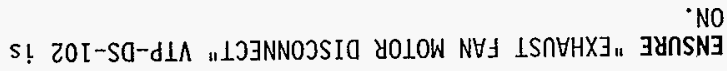

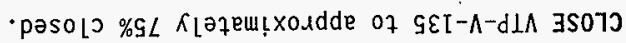

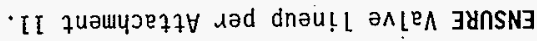
$\cdot \curvearrowleft 8[-1]-d \perp \Lambda$ ॥MO to (snuṭu pue snld) s[euțuəf yวeq of 00z-18 LJanNoJ

$\rightarrow[$ quәшцวет7H

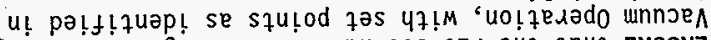

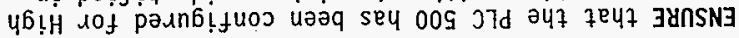
- uo 7 daว 7 z $75 a 1$

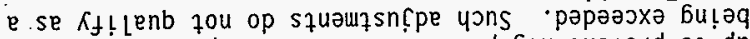

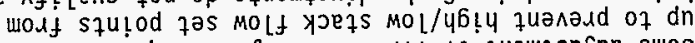

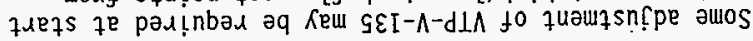

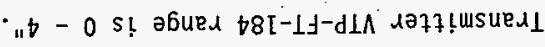

$\left[I^{\circ} 8 I^{\circ} 9 \wedge\right.$

$0 I^{\cdot} 8 I^{\circ} \mathrm{g}$

$$
\begin{aligned}
& 6.8 I^{\circ} 9 \\
& 8.8 I^{\circ} 9
\end{aligned}
$$

$L^{\circ} 8 I^{\circ} 9$

$9^{\circ} 8 I^{\circ} \mathrm{G}$

$G \cdot 8 I^{\circ} \mathrm{g}-1$

$t^{\circ} 8 I^{\circ} 9$

$\varepsilon^{\circ} 8 I^{\prime} 9$

$2 \cdot 8 L^{\circ} 9$

I.8I'

- $270 N$

- $270 N$

Wกกง 


\section{TANR FARM ACCEPTANCE TEST PROCEDURE}

\subsection{STACK FLOW ALARM CHECK-HIGH VACUUM (Cont.)}

$\checkmark 5.18 .12$ PERFORM the following:

$\checkmark$ VERIFY clear Rotating Beacon YTP-XA-10] is ILLUMINATED

$\checkmark$ RECORD value indicated on "STACK FLOW" VTP-FI-184.

READING: 1005

$\checkmark$ VERIFY "MESSAGE VIEW INTERACTIVE DISPLAY TERMINAL"

VTP-MV-101 AND VTP-MV-102 DISPLAYS "STACK FLOW HI"

5.18.13 ACKNOWLEDGE the alarm by PRESSING the "l" button, then

PRESSING the "- " button on the "MESSAGE VIEW

INTERACTIVE DISPLAY TERMINAL" VTP-MV-101 twice.

- Wait for any secondary alarms and repeat this step until all alarms are cleared on VTP-MV-101

$\checkmark$ 5.18.14 VERIFY Clear Rotating Beacon VTP-XA-101 is OFF.

$\checkmark$ 5.18.15 VERIFY "MESSAGE VIEW INTERACTIVE DISPLAY TERMINAL" VTP-MV-102 maintains a Tarm message.

5.18.16. CLEAR the BT-200.

$\checkmark 5.18 .17$ ACKNOWLEDGE any secondary alarms on VTP-MV-101.

5.18.18 DISCONNECT BT-200 from "STACK FLOW" VTP-FT-184.

5.18.19 Test Director VERIFY section 5.18 is complete.

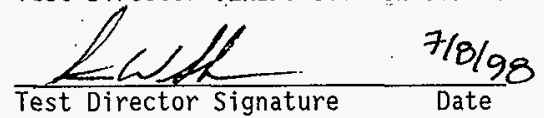

5.18.20 A/I Inspector VERIFY section 5.18 is complete.

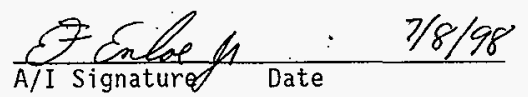




\subsection{FUNCTIONAL TEST - FLOW CONTROL (1000 CFM)}

5.19.1 CONNECT exhauster to the portable inlet filter station, flex hoses and throttle valve per Figure 1.7

NOTERemove inlet filter lid sinsent Pre-files per Excepron olz. Figure 1 is a schematic showing a test setup to min
connecting the portable exhauster to a waste tank.

5.19 .2

ENSURE exhauster programming is set-up for "flow control" with operating, alarm, and interlock set points as identified in Attachment 8.

5.19.3 PERFORM valve line-up per Attachment 11 .

5.19.4 ENSURE EW-1 is OPEN.

5.19.5 PERFORM electrical al ignment per Attachment 12.

5.19.6 POSITION the "EXHAUST FAN MOTOR DISCONNECT" VTP-DS-102 to $\mathrm{ON}$.

5.19.7 PRESS "START PUSH BUTTON" VTP-PB-101 to start "EXHAUST FAN" VTP-EF-001.

5.19.8 ROSEYFTON the "GLYCOL HEATER DISCONNECT" VTP-DS-201, to is 71698 ON.

5.19.9 ENsuse JWL $7 / 15 / 90$

Ensuler $7 / 215 / 90$ ON.

5.19.10 RECORD the values as identified in the table below.

\begin{tabular}{|c|c|c|}
\hline Date: $7 / 15 / 98$ & 1045 & Initials: \\
\hline $19010170 \mathrm{R}$ & VAII E & REAOU6 \\
\hline 110.1 .184$. & 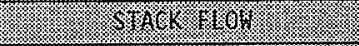 & 1000 \\
\hline $17 / 10.140 .001$ & 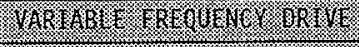 & 45.5 \\
\hline 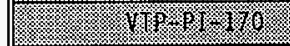 & 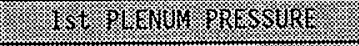 & -0.94 \\
\hline 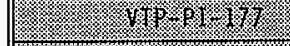 & 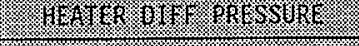 & 0.54 \\
\hline 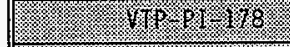 & 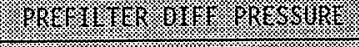 & 0.20 \\
\hline . & 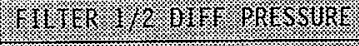 & $3: 04$ \\
\hline 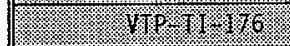 & 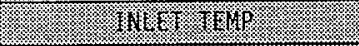 & 89 \\
\hline 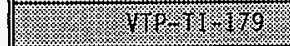 & 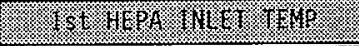 & 105 \\
\hline
\end{tabular}


88 ә6е d

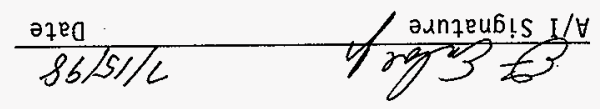

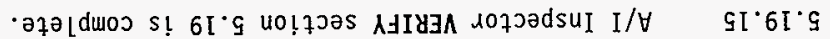

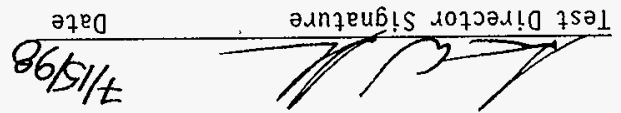

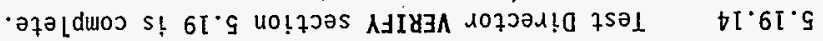

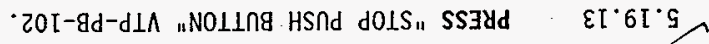

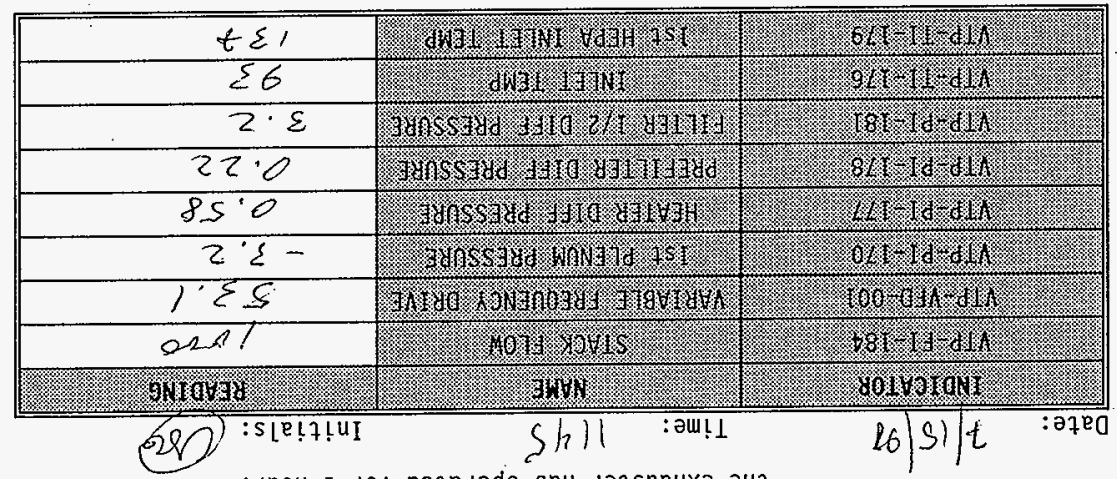

- inoy I dof pazedado sey lazsneyxa әу

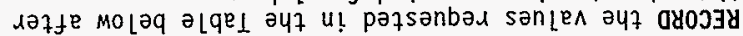

$2\left[\cdot 6 I^{\prime} \cdot \mathrm{s}\right.$

כMNI g.0 $-1+0 \cdot \varepsilon$ jo

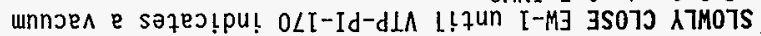

II $\cdot 6[\cdot 9$

("7uos)

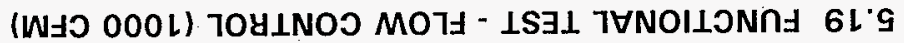




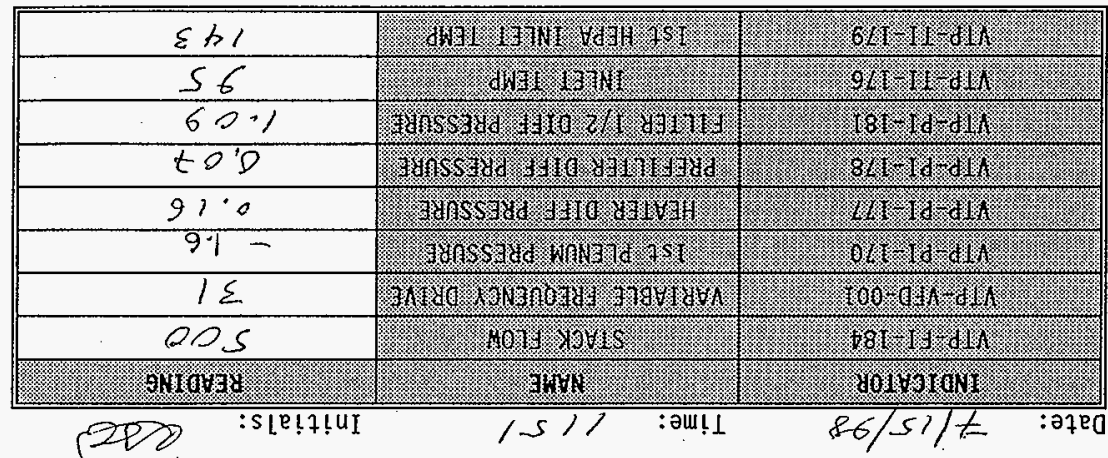

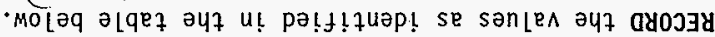

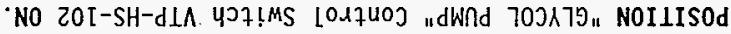

•NO IOZ-SO-dLA "LJJNNOJSIO YJIHJH 70JRT9" NOIIISOd

$[1 \cdot 02 \cdot 9$

$\cdot[00-73-d] \Lambda$ "NHJ

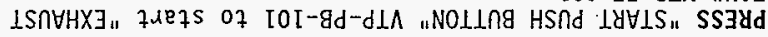

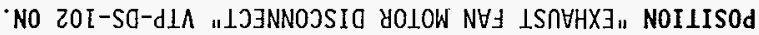

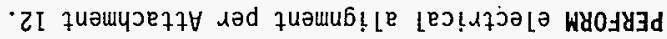
-NJdO S! [-MJ JynSN] $0\left[\cdot 0 z^{\prime} \mathrm{s} /\right.$ $6 \cdot 02 \cdot 9$

$8 \cdot 02 \cdot 2 /$

$L \cdot 02 \cdot s$,

$9 \cdot 02 \cdot 9$

$g \cdot 0 z \cdot 9 \mu$

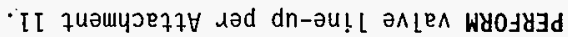

$\forall \cdot 02 \cdot 9$

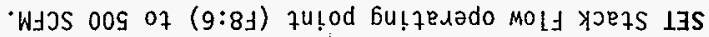

$\varepsilon^{\circ} 0 z^{\cdot} 9$

-8 quәшцวеq7甘 u! pa!f!quap! se squ!od

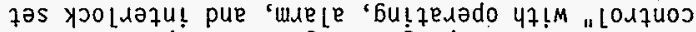
MOLf" lof dn-zas s! Guṭuretbold lapsneyxa zynsN

$z \cdot 0 Z \cdot 9$

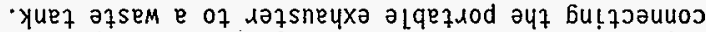

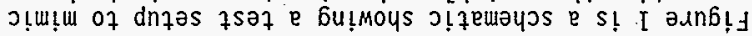

$-310 N$

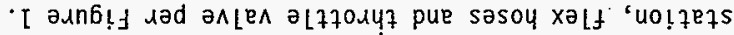

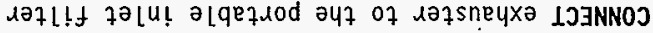

$[\cdot 02 \cdot 9$

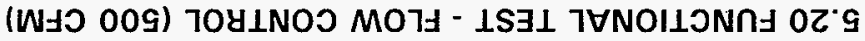


06 ə6ิed

0 ^әу

$889 Z-\unlhd \mathrm{NH}$
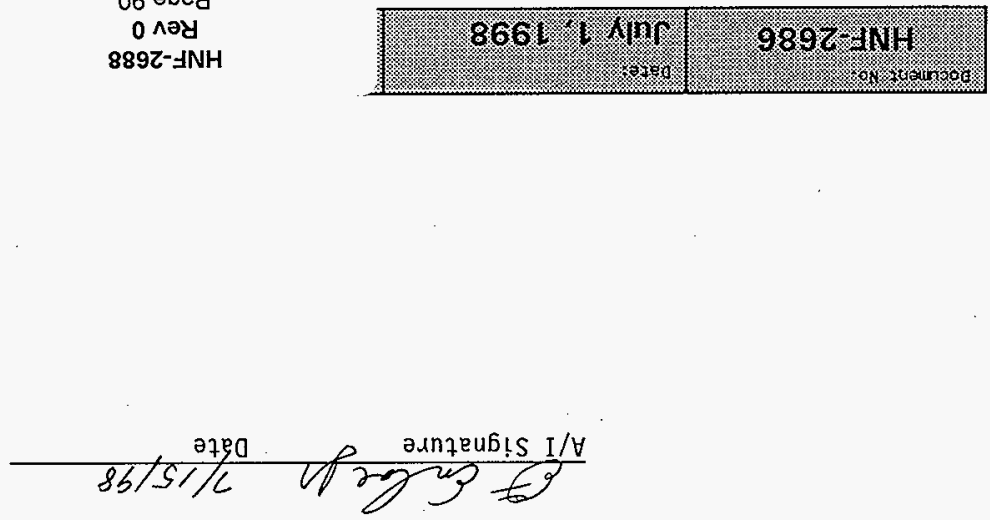

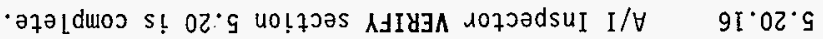

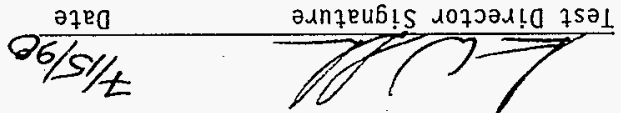

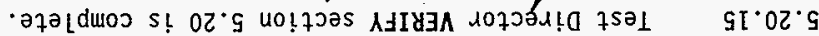

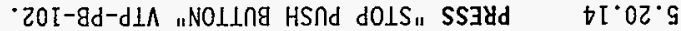

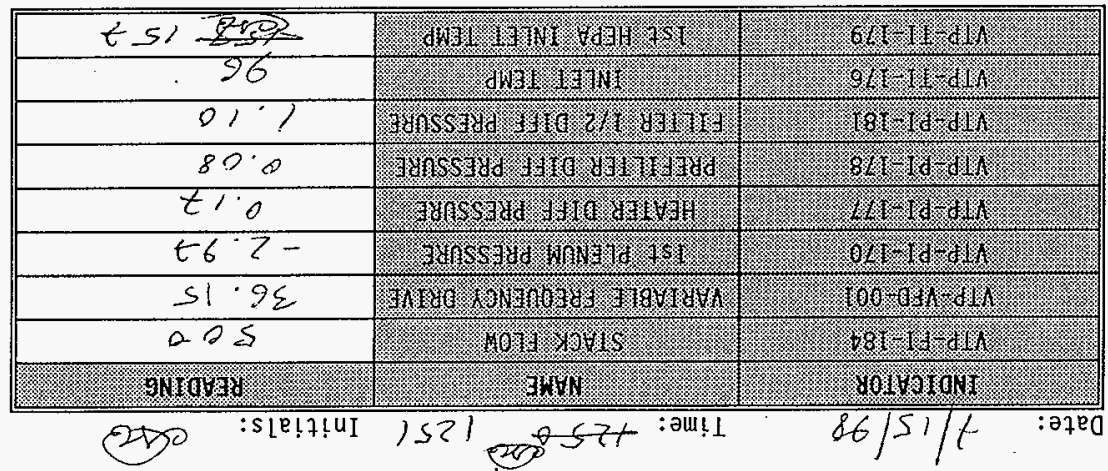

unoy I lof pazejado sey dazsneyxa әyz

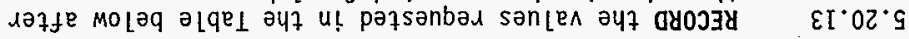

- JMNI $g^{\circ} 0-1+0^{\circ} \varepsilon f 0$

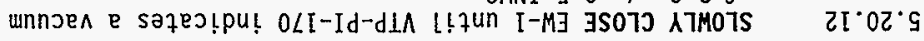

(7)oว)

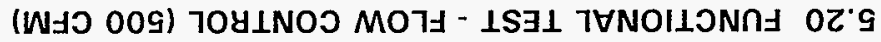




\subsection{FUNCTIONAL TEST - PRESSURE CONTROL}

Note - $\quad$ Some adjustment of VTP-V-135 may be required at start up to prevent high/low stack flow set points from being exceeded. Such adjustments do not qualify as a Test Exception.

5.21.1. CONNECT exhauster to the portable inlet filter station, flex hoses and throttle valve per Figure 1 .

Note- Figure 1 is a schematic showing a test setup to mimic connecting the portable exhauster to a waste tank.

5:21.2 ENSURE that exhauster has been reconfigured with VTPPDT-I70 sensing fang inlet vacuum.

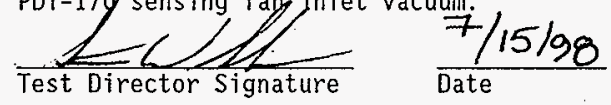

5.21.3 ENSURE exhauster programming is set-up for "pressure control" with set, alarm, and interlock points as identifjed in Attachment 13.

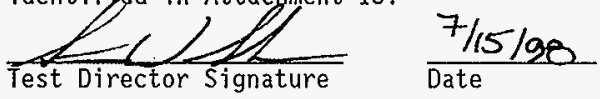

5.21.4 PERFORM valve line-up per Attachment 11.

$\checkmark 5.21 .5$ CLOSE VTP-V-135 to approximately $75 \%$ closed.

$\checkmark$ C.21.6 CLOSE VTP-V-158 "FAN ISOLATION VALVE"

5.21.7 PERFORH electrical alignment per Attachment 12.

5.21.8 ENSURE the "EXHAUST FAN MOTOR DISCONNECT" VTP-DS-102 to $O N$.

5.21 .9 OPEN EW-1.

$\checkmark$ 5.21.10 PRESS "START PUSH BUTTON" VTP-PB-10I to start "EXHAUST FAN" VTP-EF-001.

Note- Valves must be positioned very slowly with the fan operational to prevent a ROC shutdown of the exhauster. If fan shutdown does occur, the Test Director may direct the restart of the fan, and clearing of alarms and does not. constitute an exception to the ATP

5 . 2 2 $\neq 15190$

5.21.11 SLOWLY OPEN VTP-V-13,5 unt 11 VTP-VI-184 "STACK FLOW" indicates $925(+/-25)$ SCFM. 


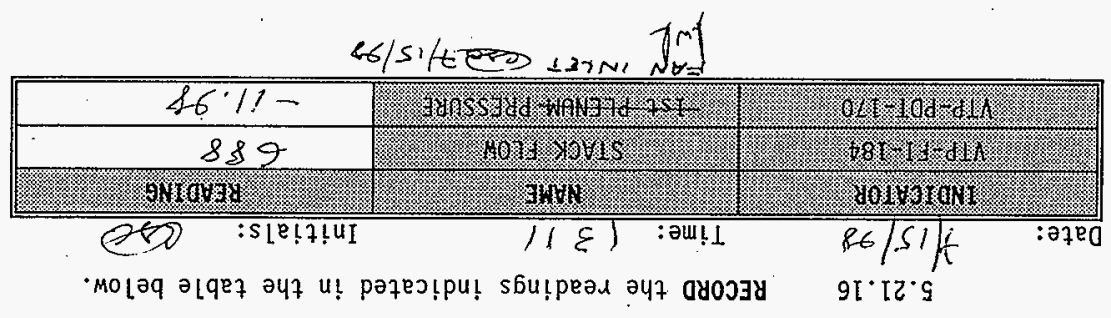

'WJIS $(92-1+) 00 L$ of pəonpəd uәəq sey

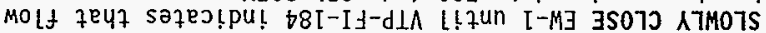

$G[\cdot[Z \cdot G$

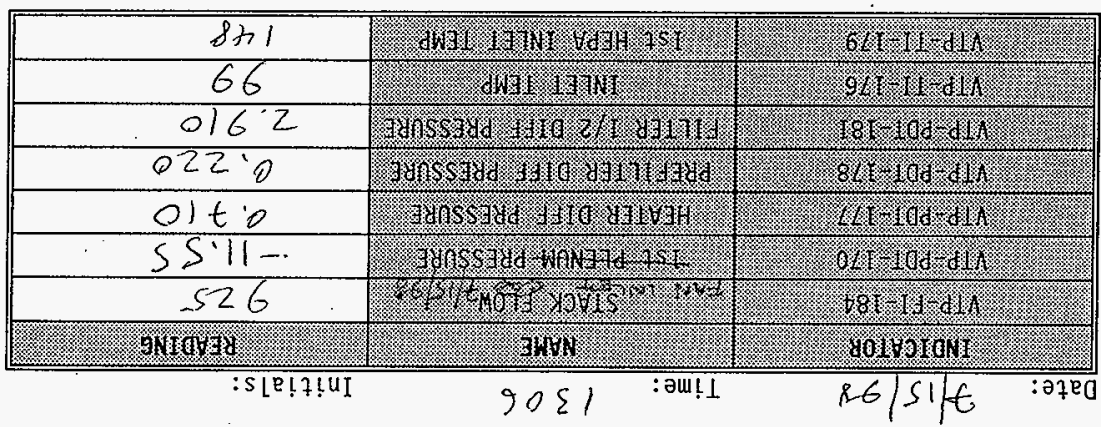

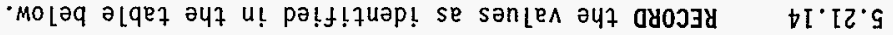

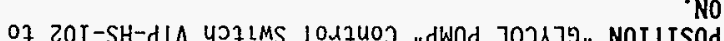

$\varepsilon I^{\circ}\left[I^{\prime} \cdot 9\right.$,

-NO

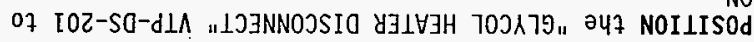

$2 I \cdot\left[Z \cdot \Omega^{\circ}\right.$

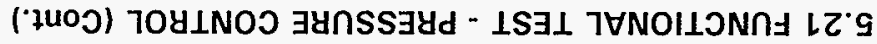




\section{TANK FARM ACCEPTANCE TEST PROCEDURE}

\subsection{FUNCTIONAL TEST - PRESSURE CONTROL (Cont.)}

5.21.17 RECORD the values requested in the Table below after

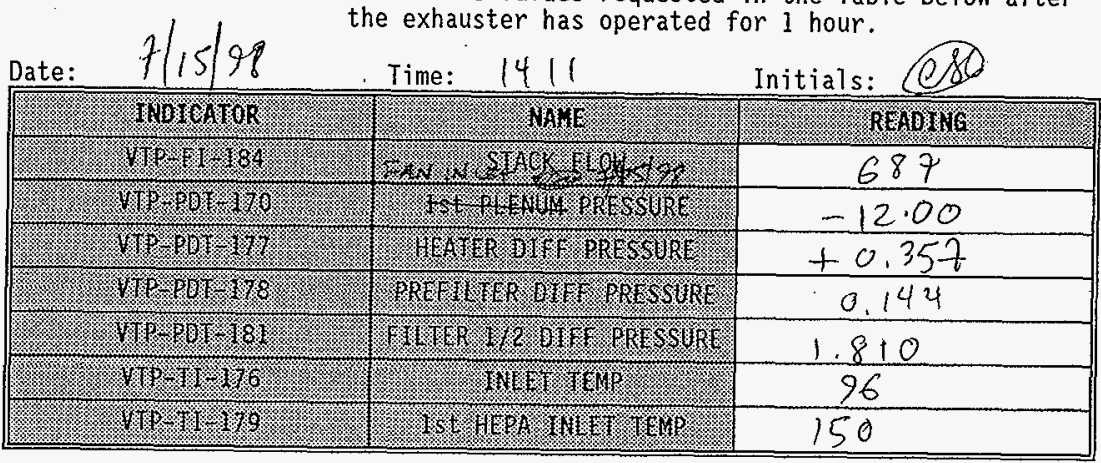

$\sqrt{ } 5.21 .18 \quad$ PRESS "STOP PUSH BUTTON" VTP-PB-102.

5.21.19 VERIFY section 5.21 is complete.
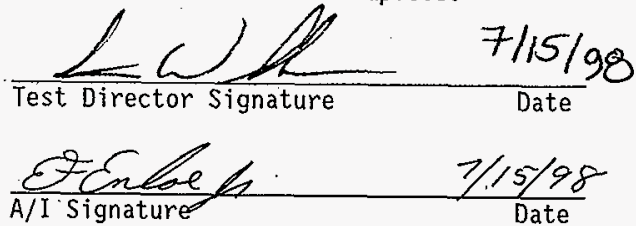

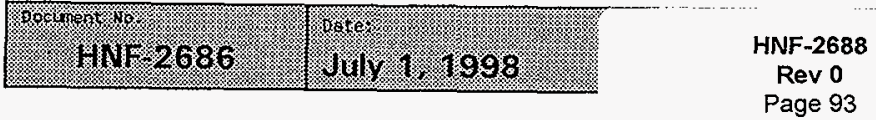




\subsection{FUNCTIONAL TEST - HIGH VACUUM}

5.22.1 CONNECT exhauster to the portable inlet filter station, flex hoses and throttle valve per Figure 1 .

NOTE- Figure 1 is a schematic showing a test setup to mimic connecting the portable exhauster to a waste tank.

5.22.2 ENSURE that exhauster has been configured with VTPPDT-170 sensing fan inlet vacuum.

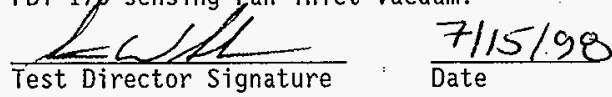

5.22.3 ENSURE exhauster programming is set-up for high vacuum operation, with operating, alarm, and interlock set points as identified in Attachment 14 .

5.22.4 PERFORM valve line-up per Attachment 5.

5.22.5 DISCONNECT PDT-170 sensing 7 ine from the fan inlet transition, and CAP transition.

5.22.6 CLOSE VTP-V-158, "FAN ISOLATION VALVE"

5.22.7 PERFORM electrical alignment per Attachment 4.

5.22.8 REMOVE HEME and HEPA, and pre-filters per the direction of the Test Director.

5.22.9 INSTALL 7-1" test plugs in plenum drain 1 ines, and REPLACE HEPA and pre-filters and all covers.

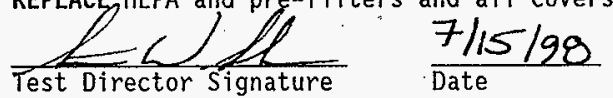

NOTE- Perform pressure/vacuum decay test to ensure exhauster plenum has been isolated from the seal pot.

5.22.10 REMOVE blind flange from VTP-V-160. 


\subsection{FUNCTIONAL TEST - HIGH VACUUM (cont.)}

5.22.11 ENSURE "SEAL POT" VTP-SP-001 is empty by opening the "SEAL. POT DRAIN VALVE" VTP-V-160.

- IF not empty, allow to empty through VTP-V-160.

5.22.12 INSTALL pneumatic pressure testing manifold (with gauge, pressure relief valve, isolation valve, pressure gauge, and pressure regulator) into "1st HEPA TEST PORT" VTP-FTP-002.

TEST LOG $\# 7$ : Add STEP

5.22 .13

5.22 .14

5.22 .15

5.22 .16

DS-101, MPZ MAN $B R K-101, \angle$ MPZ-1 are

NOTE -

ON." LWL 7/15/98
5.22 .17

5.22 .18

5.22 .19
CONNECT pressure test air source to testing manifold.

PRESSURIZE housing/duct assembly to $+19.5 \pm 0.5$ INWC.

ISOLATE the air supply from the filter housing.

MAINTAIN pressure until temperature remains constant within $+1{ }^{\circ} \mathrm{F}$ as indicated by "1st HEPA INLET

TEMPERATURE" VTP-TI-179 for a minimum of 10 minutes.

Next step starts checking positive pressure decay.

RECORD the initial time $\left(t_{i}\right)$, barometric pressure $\left(B P_{i}\right)$, housing pressure $\left(P_{i}\right)$, and temperature $\left(T_{i}\right)$ on the table provided in Attachment 9.

- RECORD pressure and temperature readings once a minute for 15 minutes on Attachment 9 .

RECORD final time $\left(t_{f}\right)$, barometric pressure $\left(B P_{f}\right)$, housing pressure $\left(P_{f}\right)$ and temperature $\left(T_{f}\right)$ on the table AND TRANSFER required information to Attachment 10.

PERFORM the leak rate calculations per Attachment 10 . 


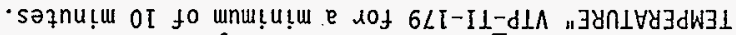

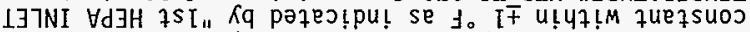
sutemad aunz̧edadura L!qun ainssaid queqsuos NIVINI甘W

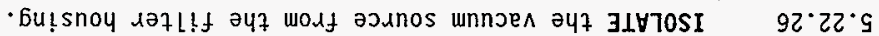

$$
\cdot \partial ว ! \wedge ә p \text { butınseau }
$$

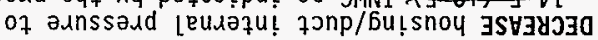

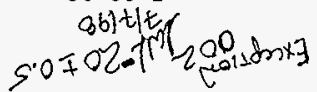

$$
\cdot \kappa \text { lquass plof tueW }
$$

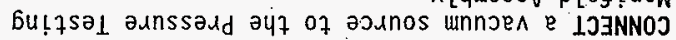

$$
\downarrow z \cdot 2 z \cdot 9
$$

- $\kappa$ Lquasse $\mathrm{plof!ueW} \mathrm{bu!7sa!} \mathrm{y6nody7}$

$\kappa$ Lquasse fanp/bu!snoy woif $\kappa[M O L S$ aunssaid $\exists \wedge \exists I 7 \exists y$

$$
\varepsilon \tau^{*} 2 Z^{\prime} \mathrm{s}
$$

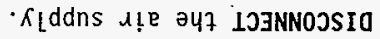

$22 * 22 \cdot 9$

$$
\text { -sqazys eqep }
$$

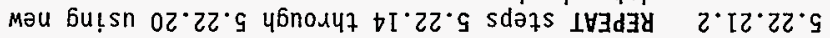

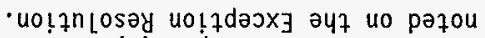

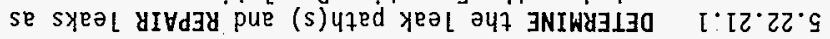

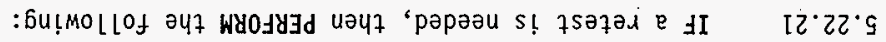

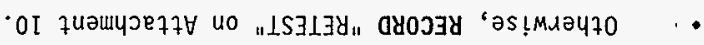

$\cdot 22 \cdot 2 z^{\prime} \mathrm{g}$ dazs of pazoud

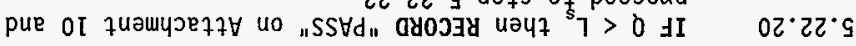

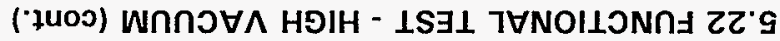




\subsection{FUNCTIONAL TEST - HIGH VACUUM (Cont.)}

NOTE - Next step starts checking negative pressure decay.

5.22.28 RECORD the initial time $\left(t_{i}\right)$, barometric pressure $\left(B P_{i}\right)$, housing pressure $\left(P_{i}\right)$, and temperature $\left(T_{i}\right)$ on the table in Attachment 9 .

- RECORD pressure and temperature readings once a minute for 15 minutes on Attachment 9.

5.22.29 RECORD final time $\left(t_{f}\right)$, barometric pressure $\left(B_{f}\right)$, housing pressure $\left(P_{f}\right)$ and temperature $\left(T_{f}\right)$ on table AND TRANSFER required information to Attachment 10 .

5.22.30 PERFORM the leak rate calculations per Attachment 10.

5.22.31 IF $Q<L$ then RECORD "PASS" on Attachment 10 and go to step 5.22.32.

- Otherwise, RECORD "RETEST" on Attachment 10.

5.22.31.1 IF a retest is needed, then PERFORM the following:

5.22.31.2 DETERMINE the leak path(s) and REPAIR leaks as noted on the Exception Resolution.

5.22.31.3 REPEAT steps 5.22.25 through 5.22.31 using new data sheets. 


\subsection{FUNCTIONAL TEST - HIGH VACUUM (Cont.)}

5.22.32 SLOWLY EQUALIZE housing/duct pressure to atmospheric through the Testing Manifold Assembly.

5.22.33 DISCONNECT the test equipment.

5.22.34 REINSTALL the test port plugs.

5.22.35 OPEN High Isolation Valve Main Airstream VTP-V-135.

5.22.36 OPEN LOW Isolation Valve Main Airstream VTP-V-136.

5.22.37 RECONNECT VTP-PT-170 sensing Tine removed in Step 5.22 .5

5.22.38 Test Director VERIFY pressure decay testing is

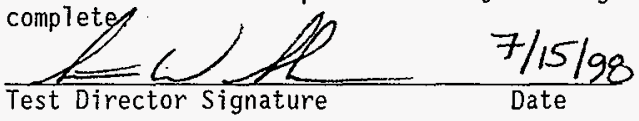

5.22.39 A/I Inspector VERIFY pressure decay testing is complete.

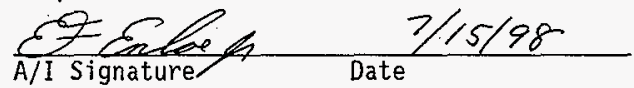

Note- During High Vacuum Testing of the exhauster, it may be necessary to throttle VTP-V-135 and VTP-V-136 to balance the system (unstable flow condition). The Test Director may authorize positioning of these valves as required at any time during this test.

5.22.40 PERFORM valve line-up per Attachment 11.

5.22.41 POSITION damper EW-I approximately $75 \%$ closed.

5.22.42 ENSURE VTP-V-158 "FAN ISOLATION VALVE" is fu11y closed.

5.22.43 PERFORM Electrical Line-up per Attachment 12.

5.22.44 ENSURE a11 alarms are cleared on VTP-MV-10I "MESSAGE VIEW INTERACTIVE DISPLAY TERMINAL" (1 ocated on "ALARM CABINET" VTP-ENCL-107 swing out pane1).

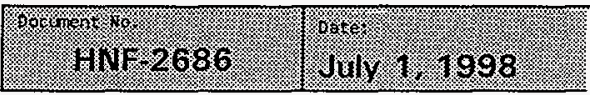




\subsection{FUNCTIONAL TEST - HIGH VACUUM (Cont.)}

5.22.45 PRESS "START PUSH BUTTON" VTP-PB-101 to start "EXHAUST FAN" VTP-EF-001.

Note- $\quad$ EW-1 must be operated very slowly to prevent an ROC shutdown of the exhauster. If fan shutdown does occur, the Test Director may direct the restart of the fan, and does not constitute an exception to the ATP.

Note - Some adjustment of VTP-V-135 and EW-1 may be required at start up to prevent high/low stack flow set points from being exceeded. Such adjustments do not qualify as a Test Exception. Objective is to have VTP-V-135 full open, and make flow adjustments at EW-1.

5.22.46 RECORD fan inlet yacuum (INDICATOR FOR VTP-PDT-170) +A.A2 14.05

5.22.47 POSITION the "GLYCOL HEATER DISCONNECT" VTP-DS-201 to ON.

5.22.48 POSITION "GLYCOL PUMP" Control Switch VTP-HS-102 to ON AND RECCORD initial values for time, inlet temperature, and ist HEPA Inlet temperature below.

"INLET TEMPERATURE" VTP-TI-176

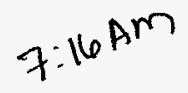

READING:

"Ist HEPA INLET TEMPERATURE" VTP-TI-179

READING: 95

Note - Low Stack Flow alarm may cause fan shutdown during performance of the next step. If this should occur, Test Director may authorize restart of the fan after EW- 1 has been repositioned. Testing at flows prescribed in Step 5.22 .49 below stack flow alarm point is not required, and a Test Exception is not required.

NOTE- Exhauster may not be able to achieve the higher flow rates identified in the table below. Enter the maximum flow rate and associated vacuum as identified by the Test Director. Enter NA for test points above the maximum ability of the exhauster. 


\section{TANK FARM ACCEPTANCE TEST PROCEDURE}

\subsection{FUNCTIONAL TEST - HIGH VACUUM (Cont.)}

Note- If EW-1 lacks sufficient control to perform the next step, the Test Director may authorize adjustments to flow using VTP-V-135. Use of VTP-V-135 to make the adjustments below does not constitute a Test Exception.

5.22.49 SLOWLY CLOSE EW-1 to reduce "STACK FLOW" VTP-FI-184 in 100 SCFM (+/- 15 SCFM) increments. Record VTP-PDT-170 vacuum levels and FI-184 flow rates at each change until table below is completely filled out, or maximum vacuum capacity of the fan is obtained. Enter NA if not applicable. THEN PROCEED.

\begin{tabular}{|c|c|c|c|c|c|}
\hline $\begin{array}{l}\text { TRRGE } \\
\text { Fons SCRH }\end{array}$ & 900 & 800 & 700 & 600 & 500 \\
\hline 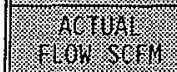 & 900 & 804 & 704 & 606 & 505 \\
\hline 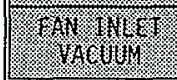 & 12.5 & 13.06 & 13.55 & 13.95 & 14.25 \\
\hline
\end{tabular}

5.22.50 SLOWLY OPEN VTP-V-135 OR EW-1 UNTIL

- VTP-FI-184 exceeds 800 SCFM

$\mathrm{OR}$

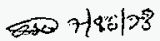

- VTP-PDT-170 exceeds-14 INWC.

5.22.51 PERFORM the following after exhauster has operated for 1 hour:

5.22.51.1 RECORD "STACK FLOW" VTP-FI-184

READING: 790 CFM

5.22.51.2 RECORD VTP-QPT- PDT L L $7 / 16 / 90$

READING: 12.50 INWC

5.22.51.3 RECORD "INLET TEMPERATURE" VTP-TI-176

READING:__._

\begin{tabular}{|c|c|}
\hline mII 2886 & Jily 1.1998 \\
\hline
\end{tabular}

HNF-2688

Rev 0

Page 100 
5.22 FUNCTIONAL TEST - HIGH VACUUM (Cont.)

5.22.51.4 RECORD "1st HEPA INLET TEMPERATURE" VTP-TI-179 READING: 145

5.22.52 PRESS "STOP PUSH BUTTON" VTP-PB-102.

5.22.53 ALIGN exhauster vaives per Attachment 15, ATP Final Valve Lineup.

5.22.54 REMOVE HEPA and pre-filters per the direction of the Test Director.

5.22.55 REMOVE 7-1" test plugs in plenum drain lines, and REPLACE HEPA, HEME and pre-filters, and their covers.

Test Director Signature

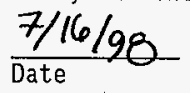

5.22.56 Test Director VERIFY section 5.22 is complete.

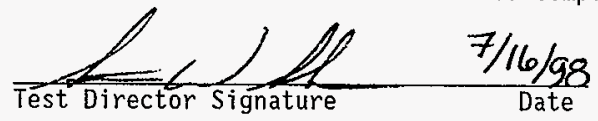

5.22.57 A/I Inspector VERIFY section 5.22 is complete.

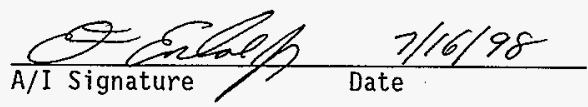




\section{ZOL a6ed \\ 0 ^อบ \\ 8892-JNH}

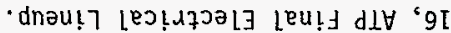

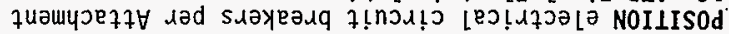

$9 \cdot \varepsilon 2 \cdot 9$

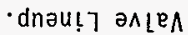

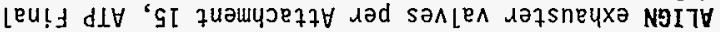

$\mathrm{g}^{\cdot} \varepsilon Z^{*} \mathrm{~g}$

- $09[-\Lambda-d \perp \Lambda$ uo abuela pu! 1q. jog7dje

$b^{\cdot} \varepsilon Z^{*} \mathrm{G}$

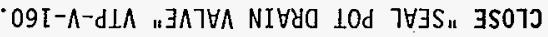

$\varepsilon \cdot \varepsilon Z^{\cdot} \mathrm{s}$

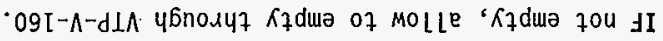

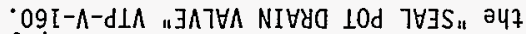

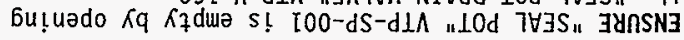

$Z \cdot \varepsilon Z^{\cdot} \underline{9}$

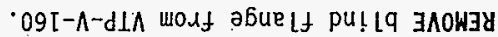

$\left[\cdot \varepsilon Z^{\cdot} \mathfrak{g}\right.$

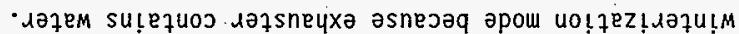

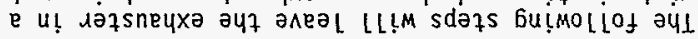

$-310 N$

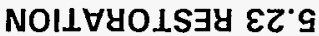




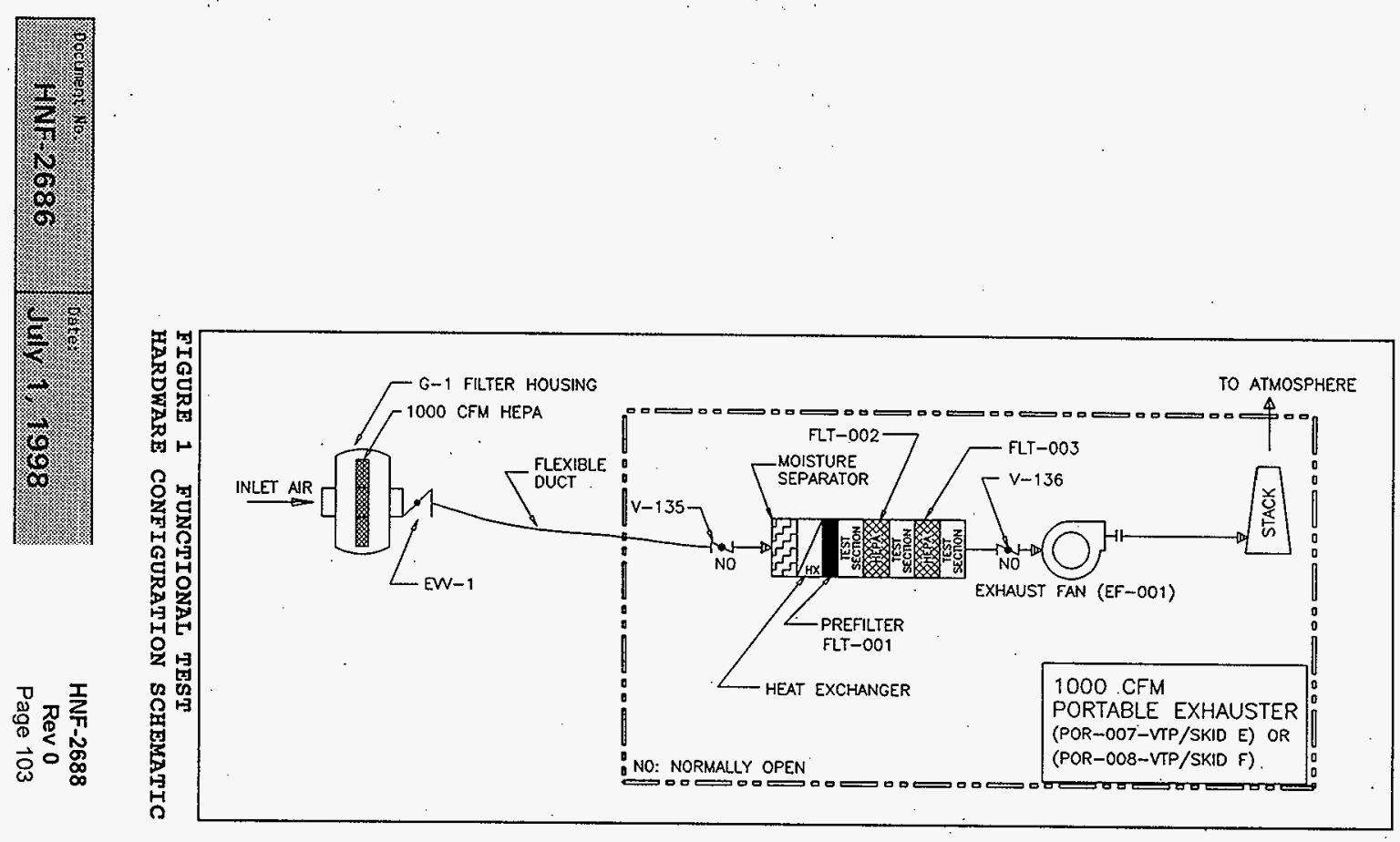


TANK FARM ACCEPTANCE TEST PROCEDURE

ATTACHMENT 1 - ATP TEST LOG

(This page may be reproduced as necessary)

PAGE 1 of 4

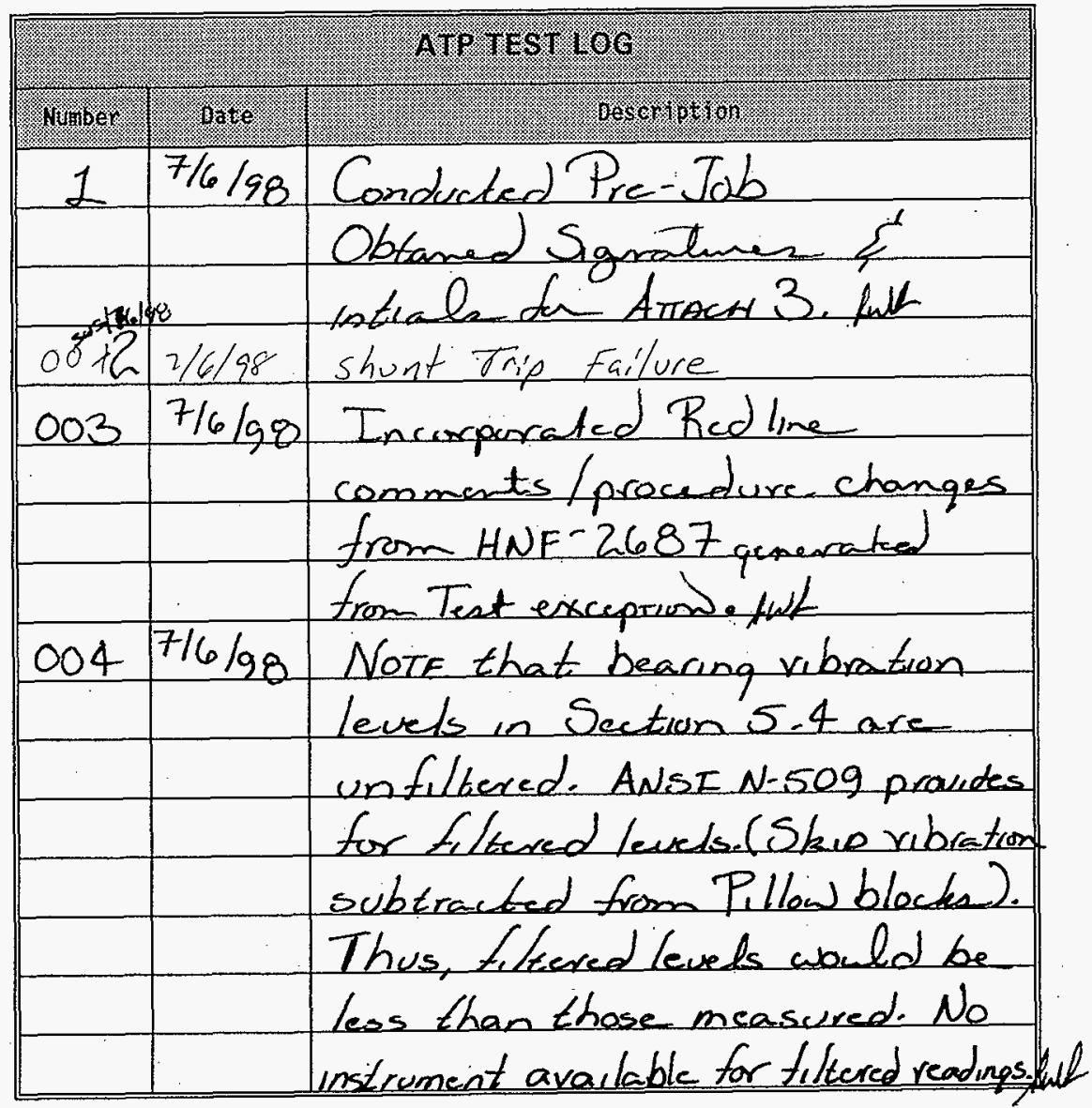

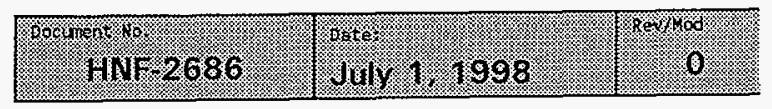

HNF-2688

Rev 0

Page 104 
TANK FARM ACCEPTANCE TEST PROCEDURE

ATTACHMENT 1 - ATP TEST LOG

(This page may be reproduced as necessary)

PAGE 2 of 4

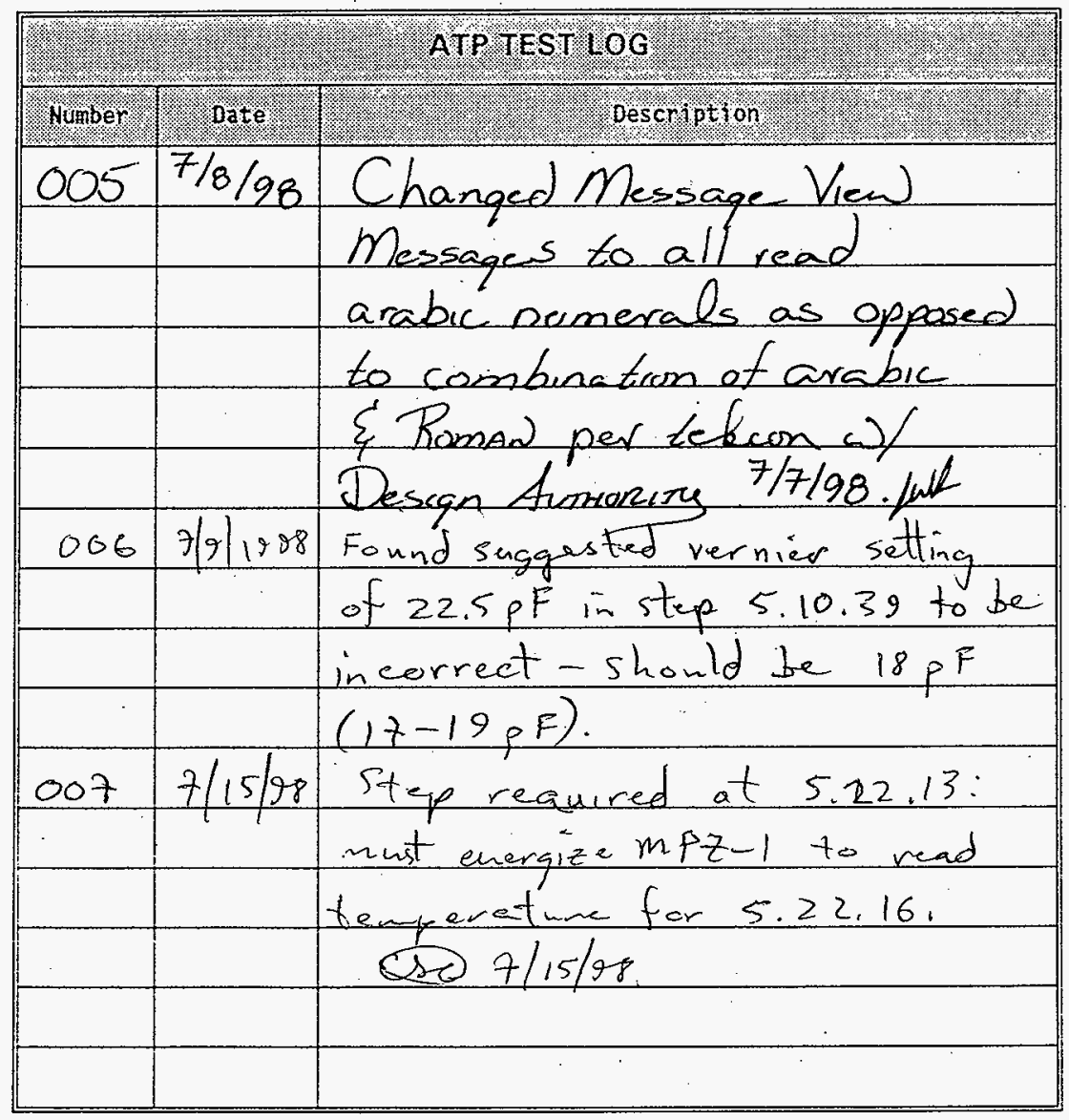

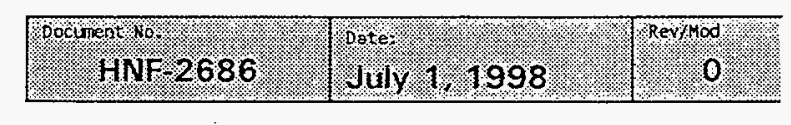

HNF-2688

Rev 0

Page 105 
TANK FARM ACCEPT ANCE TEST PROCEDURE

ATTACHMENT 1 - ATP TEST LOG

(This page may be reproduced as necessary)

PAGE 3 of 4

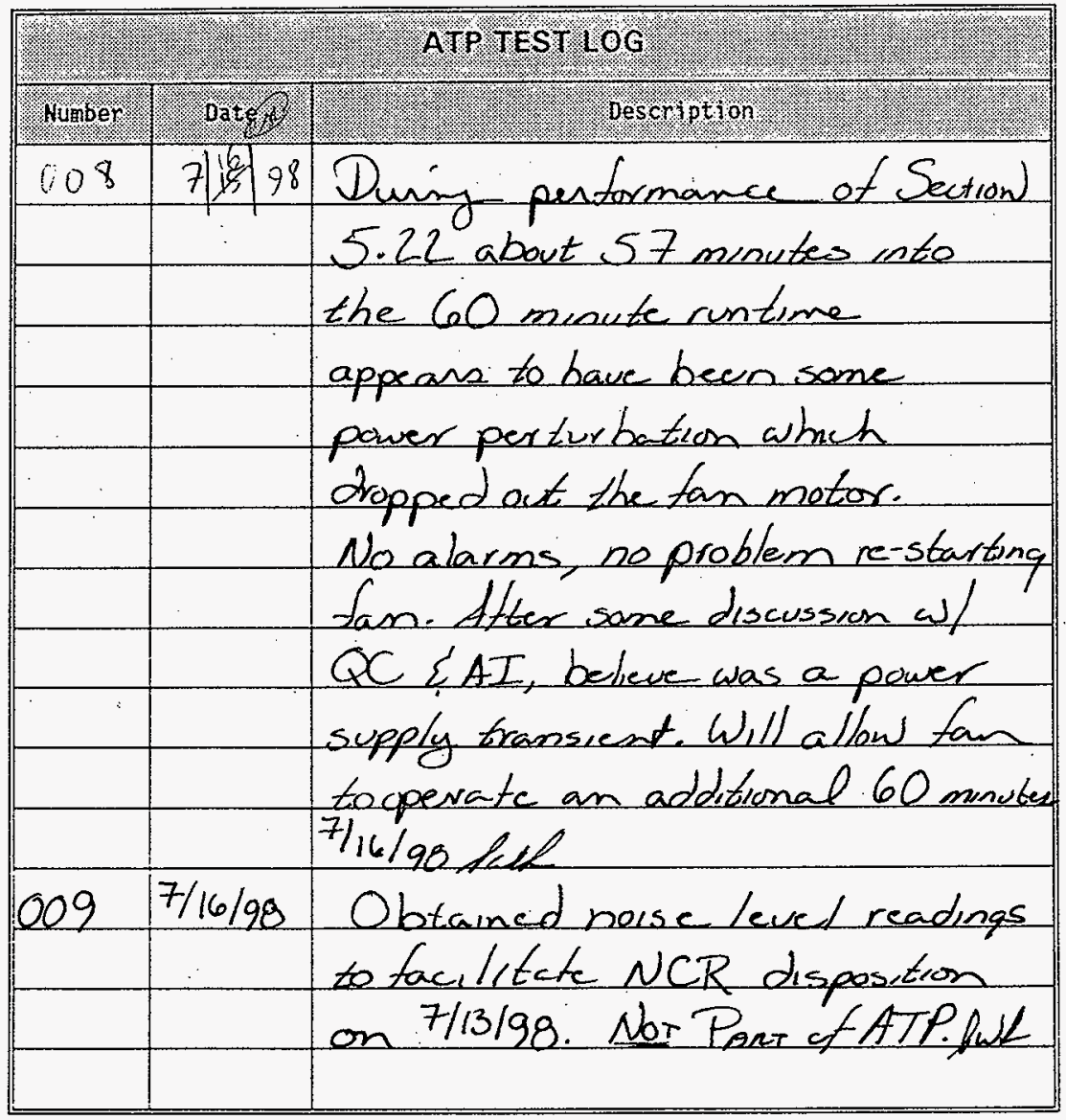

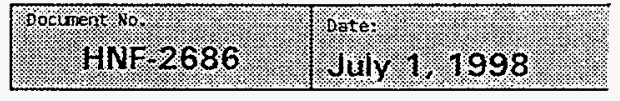

HNF-2688

Rev 0 
TANK FARM ACCEPTANCE TEST PROCEDURE

ATTACHMENT 1 - ATP TEST LOG

(This page may be reproduced as necessary)

PAGE 4 of 4

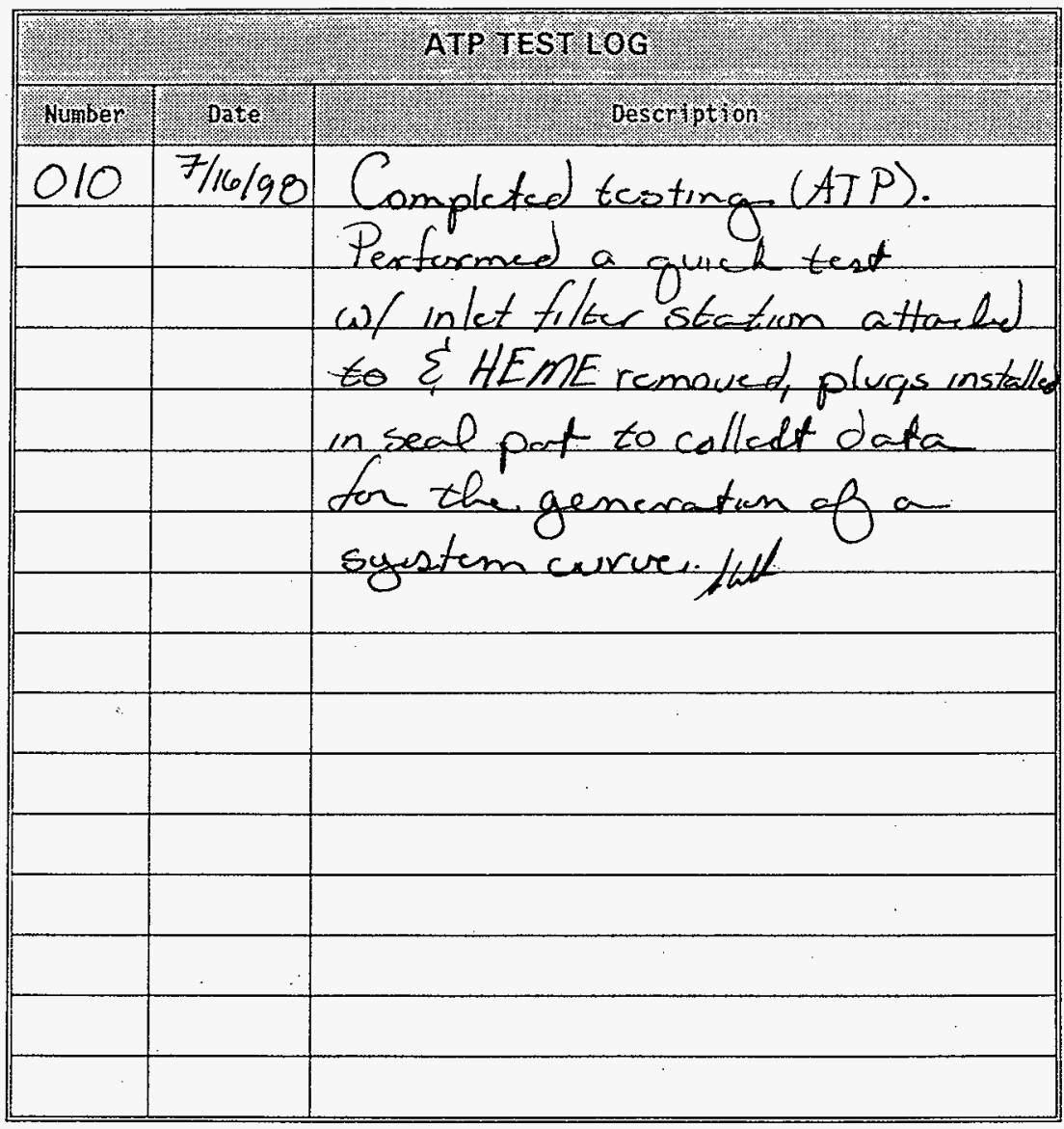

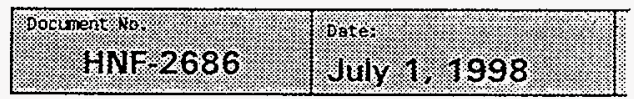

HNF-2688

Rev 0

Page 107 
TANK FARM ACCEPTANCE TEST:PROCEDURE

ATTACHMENT 2 - ATP TEST EXCEPTION REPORT

(This page may be reproduced as necessary)

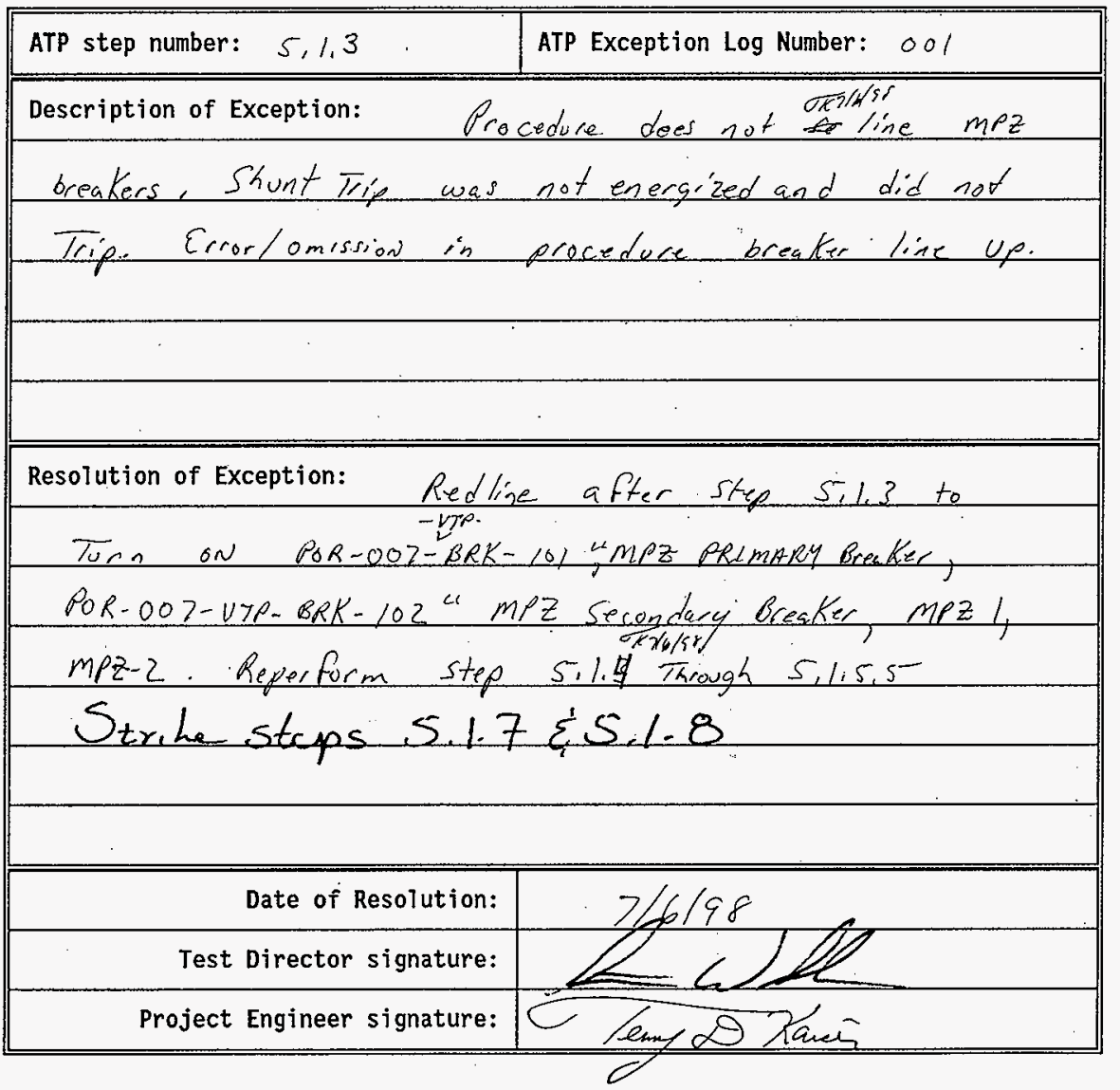

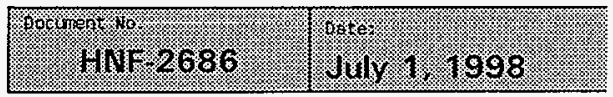

HNF-2688

Rev 0

Page 108 


\section{ATTACHMENT 2 - ATP TEST EXCEPTION REPORT}

(This page may be reproduced as necessary)

\begin{tabular}{|l|l|}
\hline ATP step number: 5.2 .20 \& 5.22 .25 & ATP Exception Log Number: 102 \\
\hline Description of Exception: Procedural deficiency. Steps only require a vacuum \\
\hline of 14.5 INWC, when 20 is required. \\
\hline \\
\hline \\
\hline \multicolumn{2}{|c|}{} \\
\hline Resoiution of Exception: Redline steps 5.2 .20 and 5.22 .25 to indicate a vacuum \\
\hline of $20.0 \pm$ 0.5 INWC is required. \\
\hline \multicolumn{2}{|c|}{} \\
\hline \\
\hline \\
\hline
\end{tabular}




\section{ATTACHMENT 2 - ATP TEST EXCEPTION REPORT}

(This page may be reproduced as necessary)

\begin{tabular}{|c|c|}
\hline ATP step number: 5.7 .27 & ATP Exception Log Number: 003 \\
\hline \multicolumn{2}{|c|}{ Description of Exception: After clearing BT-200 test setting, Filter 2 DP L0 } \\
\hline \multicolumn{2}{|c|}{ alarm did not clear. Further investigation shows that instrument was "set-up" } \\
\hline \multicolumn{2}{|c|}{ but not zero'd. No criteria for reset condition/value. Program presently } \\
\hline \multicolumn{2}{|l|}{ resets $\bullet 0.02$ INWC } \\
\hline & \\
\hline \multicolumn{2}{|c|}{ Resolution of Exception: Per Cog Engineer, Reset condition should be } \\
\hline \multicolumn{2}{|c|}{ "acknowledge MV-101 alarm". Change PLC logic to match. Re-run 5.7.18 through } \\
\hline \multicolumn{2}{|c|}{ 5.7.27. No 10 second delay logic. Modify procedure step 5.7.22. Also re-run } \\
\hline \multicolumn{2}{|c|}{ 5.6.20-5.6.28, modify procedure steps 5.6 .24 and 5.8.20 to eliminate 10 second } \\
\hline \multicolumn{2}{|l|}{ delay. } \\
\hline Date of Resolution: & $7 / 8 / 98$ \\
\hline Test Director signature: & \\
\hline Project Engineer signature: & w \\
\hline
\end{tabular}




\section{TANK FARM ACCEPTANCE TEST PROCEDURE}

\section{ATTACHMENT 2 - ATP TEST EXCEPTION REPORT}

(This page may be reproduced as necessary)

\begin{tabular}{|c|c|}
\hline ATP step number: $5.11 .3,5.10 .8$ & ATP Exception Log Number: 004 \\
\hline \multirow{2}{*}{\multicolumn{2}{|c|}{$\begin{array}{l}\text { Description of Exception: Calibration System's black 3-wire lead. Procedur } \\
\text { needs to provide for ground connection. 5.11.3.8 lead color identified }\end{array}$}} \\
\hline & \\
\hline \multicolumn{2}{|c|}{ incorrectiy. 5.11.3.10 incorrect side of transmitter called out. Make } \\
\hline similar chamges to & section $5.10 .8 . \propto 7 / 9 / 98$. \\
\hline \multicolumn{2}{|c|}{ Resolution of Exception: Redline procedure to accomodate procedural } \\
\hline \multicolumn{2}{|c|}{ deficiencies as required to hook-up calibration system correctly. } \\
\hline & \\
\hline & \\
\hline & \\
\hline Date of Resolution: & $7 / 8 / 9$ \\
\hline Test Director signature: & \\
\hline Project Engineer signature: & n \\
\hline
\end{tabular}




\section{TANIKI FARM ACCEPTANCE TEST PROCEDURE}

\section{ATTACHMENT 2 - ATP TEST EXCEPTION REPORT}

(This page may be reproduced as necessary)

\begin{tabular}{|l|l|}
\hline ATP step number: 5.11 .27 & ATP Exception Log Number: \\
\hline \hline Description of Exception: Procedural deficiency. Positioned MPZ-1 to OFF in \\
\hline step 5.11.25. Need to turn back on before step 5.11 .28 can be performed. \\
\hline \\
\hline
\end{tabular}

Resolution of Exception: Insert step after 5.11.27, "Position MPZ-1 to ON."

\begin{tabular}{|r|c|}
\hline Date of Resolution: & $7 / 8 / 88$ \\
\hline Test Director signature: & \\
\hline Project Engineer signature: & 010 \\
\hline
\end{tabular}




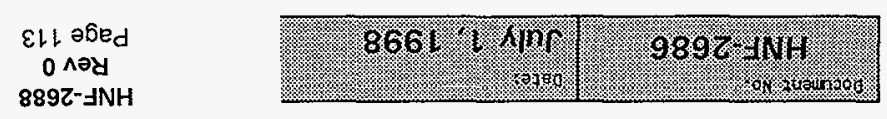

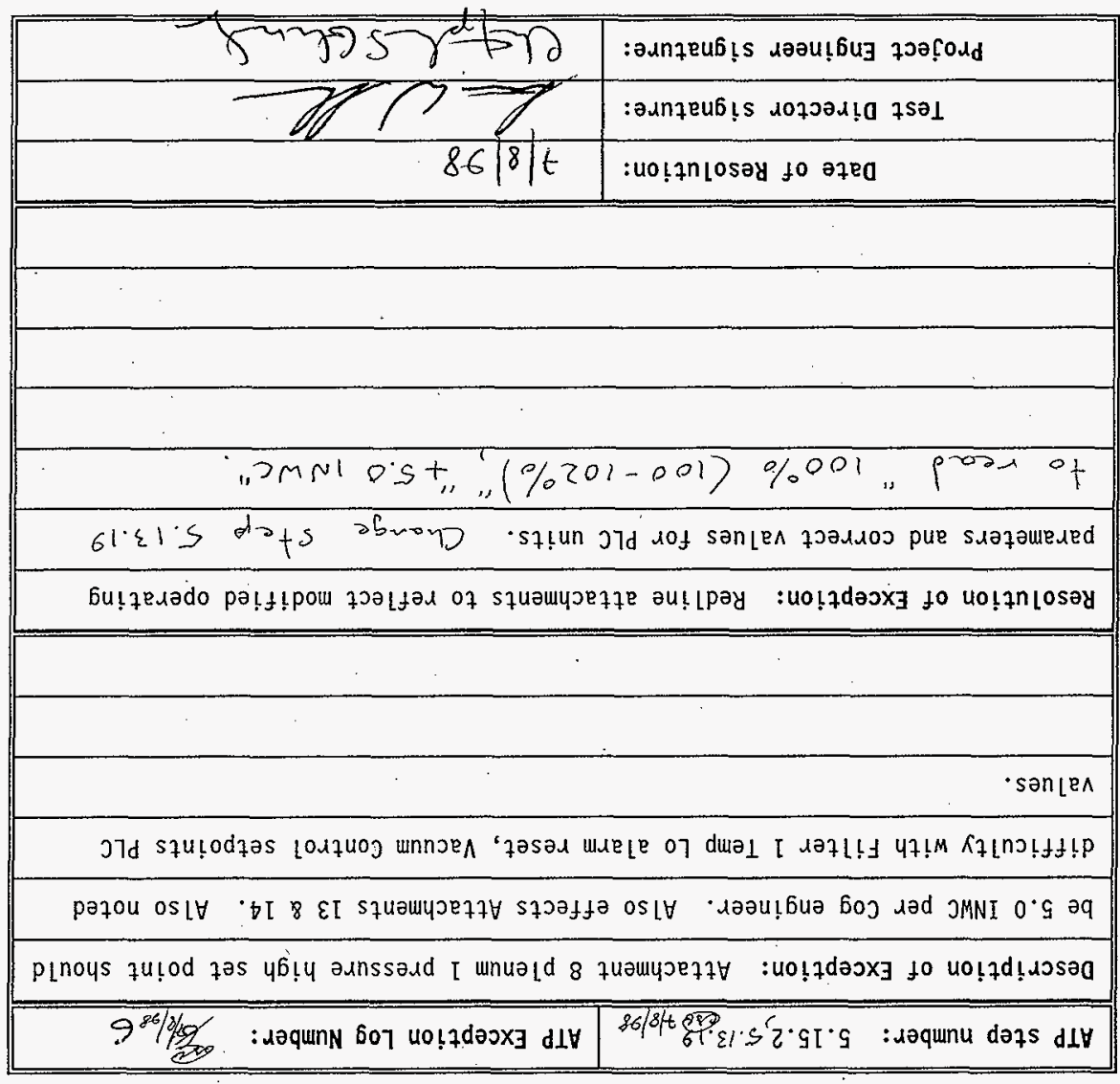

(Kuessasau se pasnposdas aq Kell abed s!41)

$\perp$ YOd $\exists y$ NOILd $\exists$ X $\exists \perp S \exists \perp d \perp \forall-Z \perp N \exists W H O \forall \perp \perp \forall$ 


\section{TANK FARM ACCEPTANCE TEST PROCEDURE}

\section{ATTACHMENT 2 - ATP TEST EXCEPTION REPORT \\ (This page may be reproduced as necessary)}

ATP step number: 5.11 .30

ATP Exception Log Number: 7

Description of Exception: Procedural deficiency. MPZ-1 not switched off at

the end of Section 5.11

Resolution of Exception: Add step prior to 5.11.31:

"POSITION MPZ-1 to OFF"

\begin{tabular}{|r|r|}
\hline Date of Resolution: & $7 / 8 / 98$ \\
\hline Test Director signature: & Project Engineer signature:
\end{tabular}




\section{TANK FARM ACCEPTANCE TEST PROCEDURE}

\section{ATTACHMENT 2 - ATP TEST EXCEPTION REPORT}

(This page may be reproduced as necessary)

\begin{tabular}{l|l|l|}
\hline ATP step number: 5.12.1 & ATP Exception Log Number: 8 \\
\hline
\end{tabular}

Description of Exception: Thermocouple simulator had a setting higher than

high temp setpoint. Caused alarm, prevented glycol heater and pump from operating.

Resolution of Exception: Add one step, one note prior to 5.12.1:

Step: "ENSURE MPZ-I is OFF"

Note: "Set thermocouple simulator to $100 \mathrm{~F}$ prior to connecting to termocoupte." input fermingts e86: 7/8/98

\begin{tabular}{r|c|} 
Date of Resolution: & $7 / 8 / 98$ \\
Test Director signature: & Project Engineer signature:
\end{tabular}

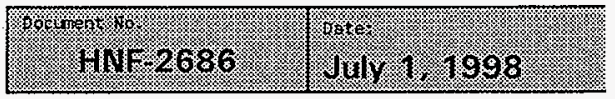


ATTACHMENT 2 - ATP TEST EXCEPTION REPORT

(This page may be reproduced as necessary)

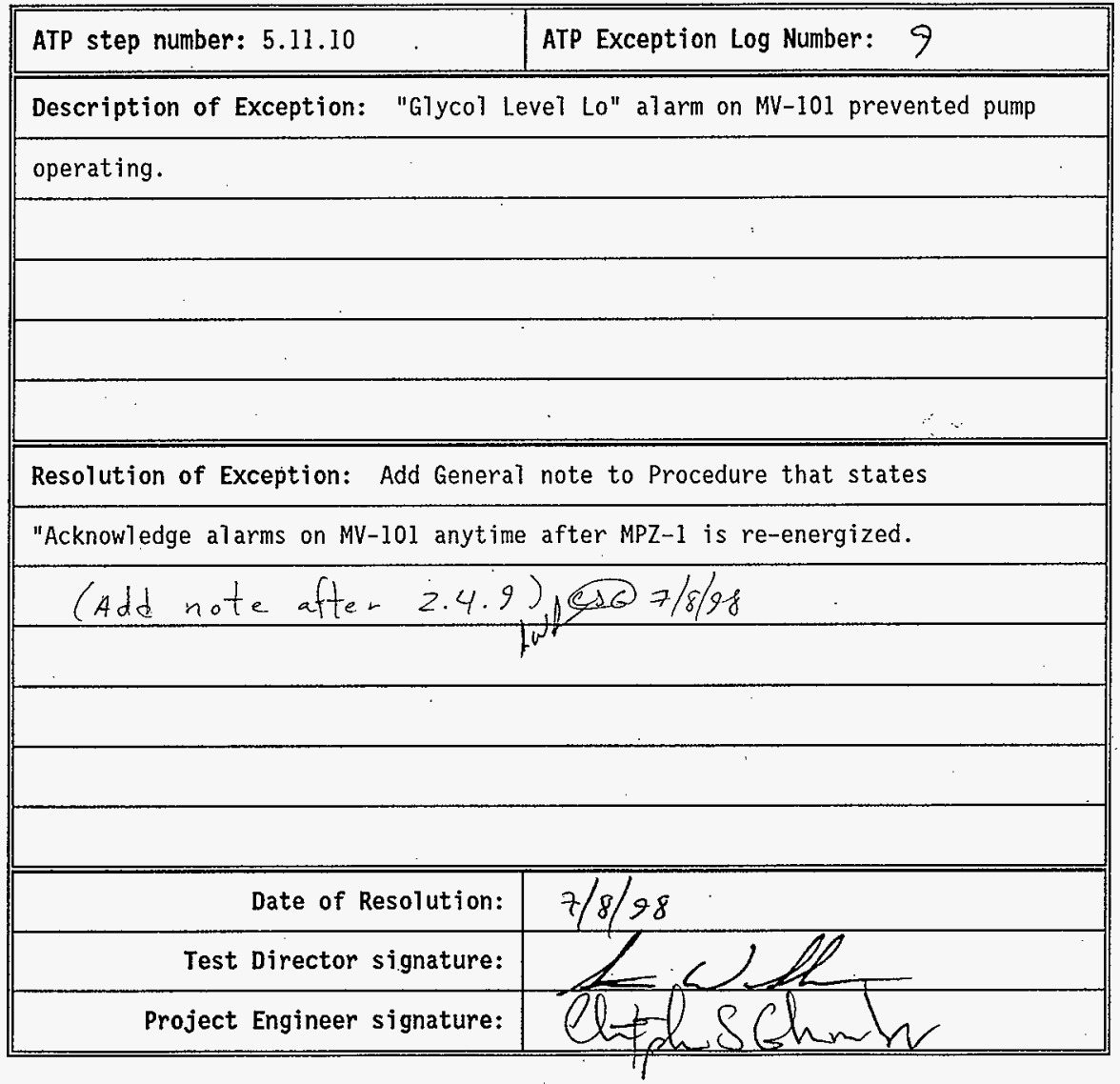


TANK FARM ACCEPTANCE TEST PROCEDURE

ATTACHMENT 2 - ATP TEST EXCEPTION REPORT

(This page may be reproduced as necessary)

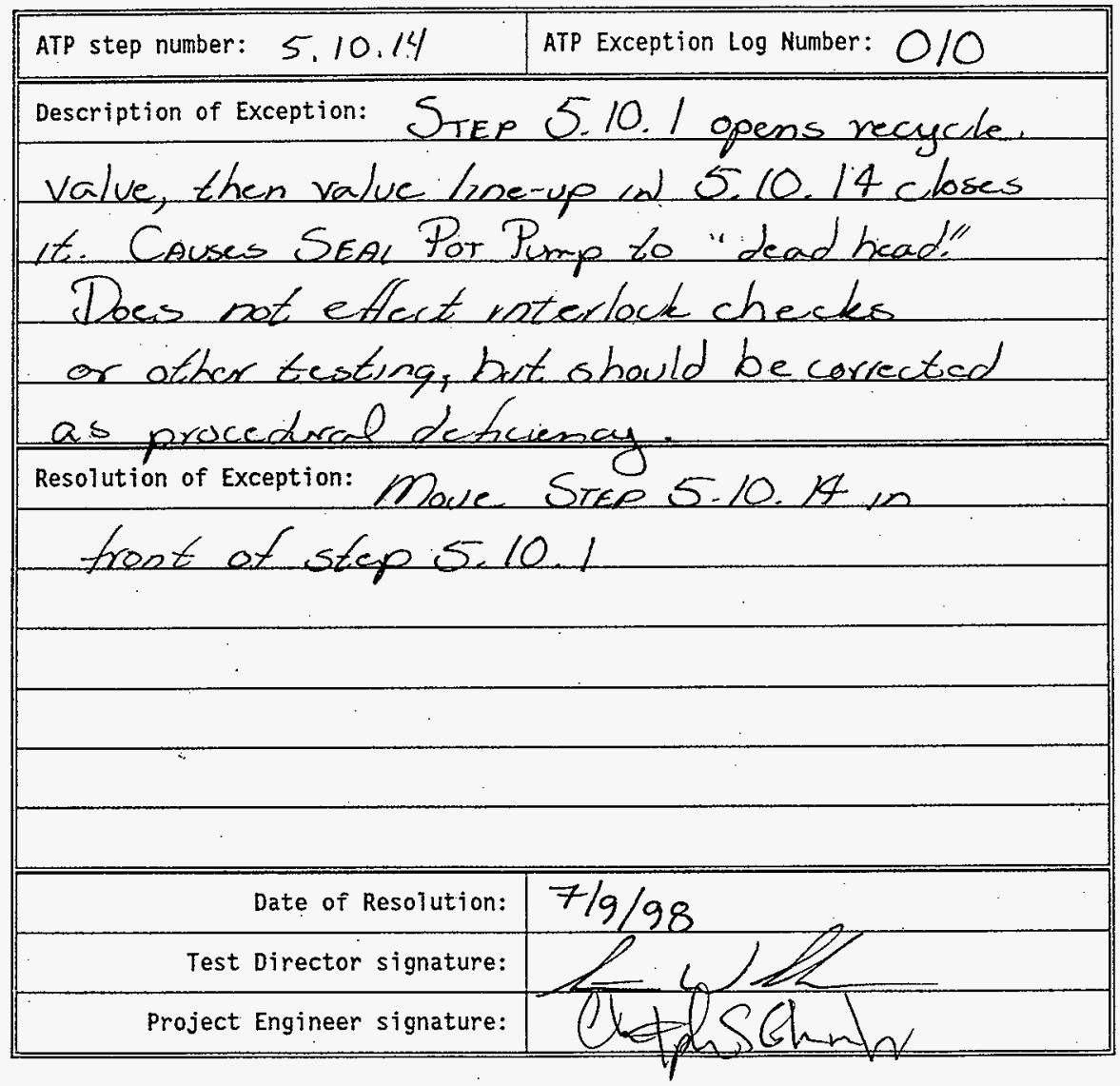

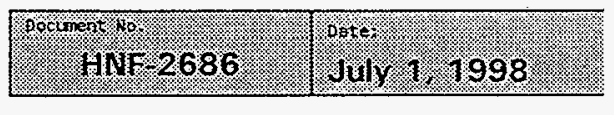

HNF-2688

Rev 0

Page 117 


\section{ATTACHMENT 2 - ATP TEST EXCEPTION REPORT}

(This page may be reproduced as necessary)

दा 7 th STET

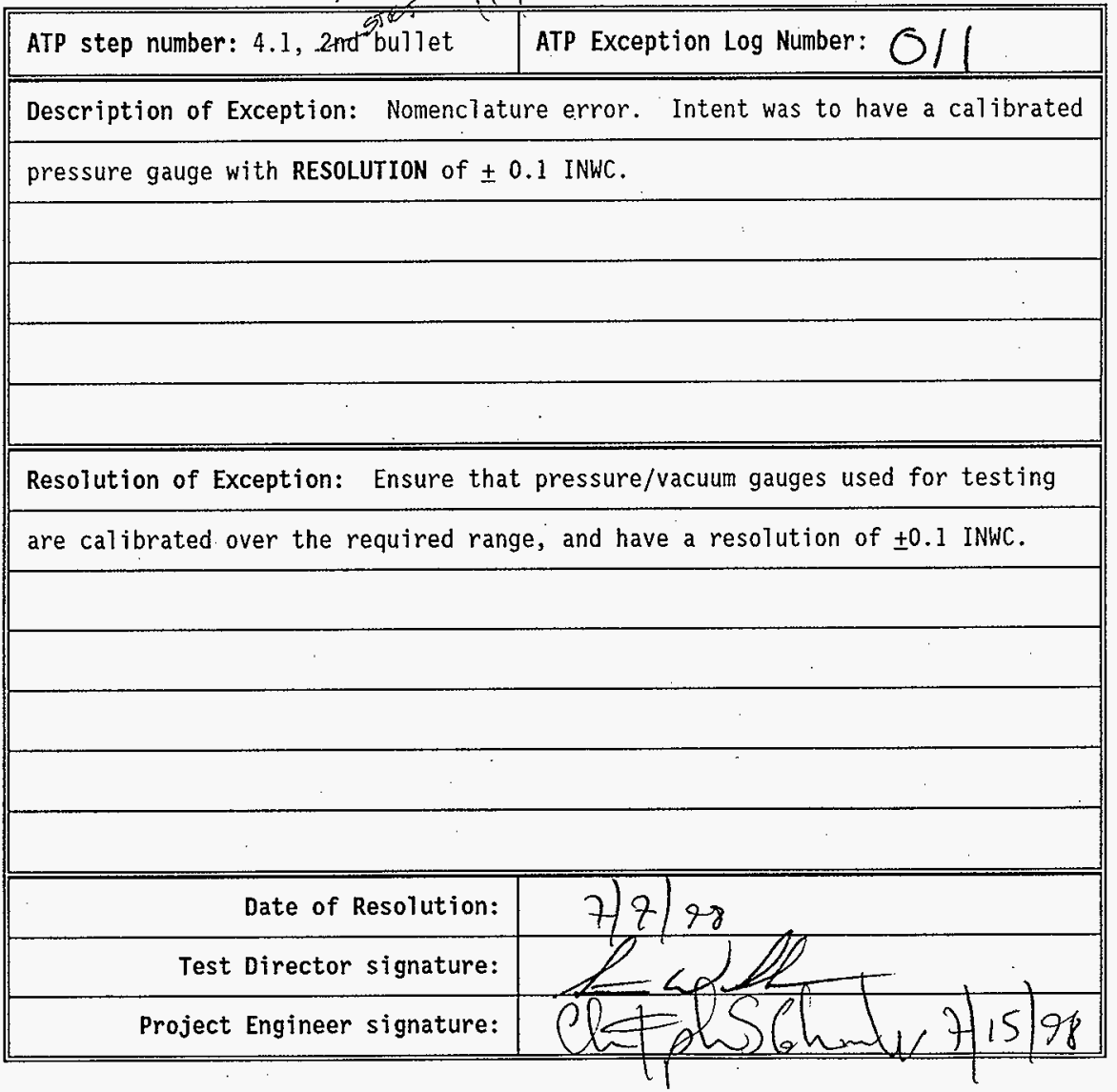

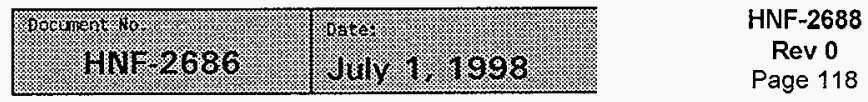




\section{ATTACHMENT 2 - ATP TEST EXCEPTION REPORT (This page may be reproduced as necessary)}

\begin{tabular}{|l|l|}
\hline ATP step number: 5.19 .1 & ATP Exception Log Number: $0 / 2$ \\
\hline \hline
\end{tabular}

Description of Exception: Test Step requires connection to a portable inlet station. However, cannot reach 1000 CFM through the inlet station with out exceeding the allowable 3.5 INWC inlet vacuum at the exhauster.

Resolution of Exception: Remove the lid from the G-1 filter station and place the roughing filter over the 12 " opening to the damper/hose assembly. Purpose of filter/damper assembly is to mimic tank operation by establishing a partial vacuum at the exhauster inlet. This can be accomplished using the damper EW-1, without flowing air through the HEPA filter. Note that tank inlet filter stations consist of HEPA filter banks (2 or more HEPAs) and will not have similarly large pressure drops at similar flow rates at the test article.

\begin{tabular}{|r|c|}
\hline Date of Resolution: & $7 / 15 / 98$ \\
\hline Test Director signature: & \\
\hline Project Engineer signature: & 1 \\
\hline
\end{tabular}

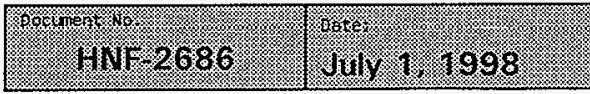




\section{OZL ә6еd \\ 0 nөy \\ $889 Z^{-}-\mathrm{NH}$}

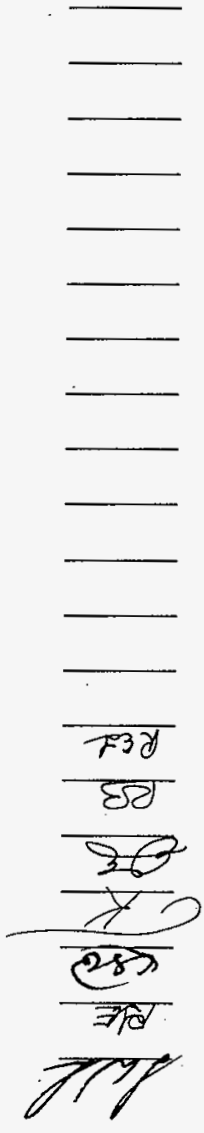

STVIIINI

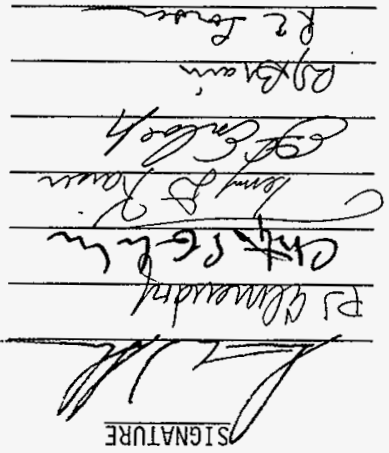

उष्पाHNजIS

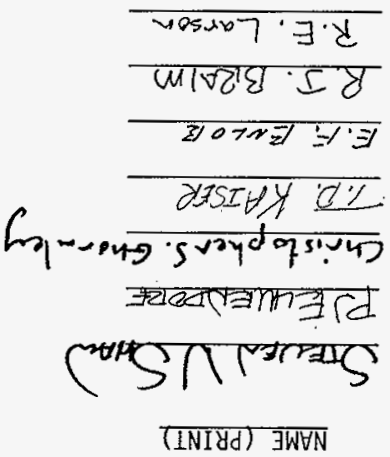

(INIYd) $3 W \forall N$

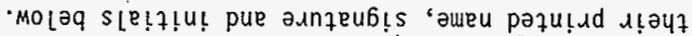

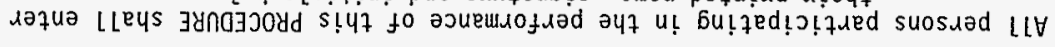




\section{TANK FARM ACCEPTANCE TEST PROCEDURE}

\section{ATTACHMENT 4 - ATP INITIAL ELECTRICAL LINEUP}

\begin{tabular}{|c|c|c|c|}
\hline COMRONENII: & DEscriptTON & POSTITOU: & mitrass \\
\hline 8 ro $15-18$ & 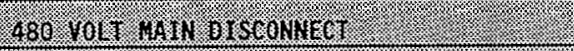 & 006 & 5 \\
\hline$\sqrt{17}=05.10$ & EWHEUST TRN TOTOR DISCONMES & 80 & GK \\
\hline $\log 0 \mathrm{~s}-201$ & 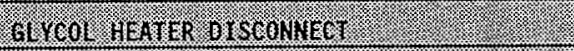 & 80 & $C K$ \\
\hline 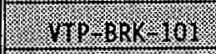 & WIZ PRMMARY BREAKER THIN. & .00 & $c k$ \\
\hline$M E=B R=-102$ & 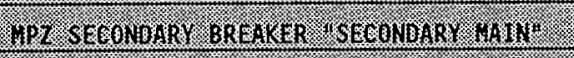 & (015: & $G$ \\
\hline $2.120 \%$ & 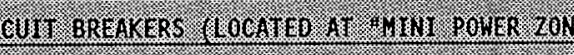 & 18 & \\
\hline $912-1$ & 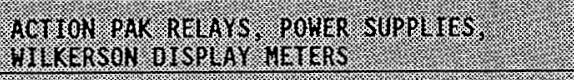 & orf & $\sigma k$ \\
\hline $192=2$ & 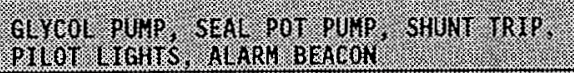 & $0 \%$ & $C R$ \\
\hline $902-3$ & 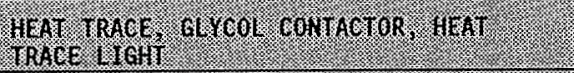 & 4 & GK \\
\hline 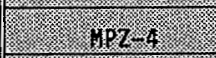 & 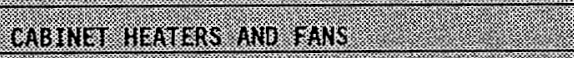 & $00 \mathrm{~F}$ & GR \\
\hline $402-5$ & 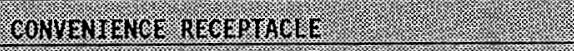 & ofer: & 6,5 \\
\hline$\sqrt{152-6}$ & GEES - GEF' (SPARE) & 0,8 & $C$ \\
\hline$\frac{8,27: 2}{20}$ & ANS.9 :GEE: (SPRRE): & on & $C K$ \\
\hline$\sqrt{132-8}$ & FLAMMABLE GAS TOMIVIOR (SPRER) & 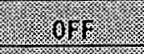 & GE \\
\hline-102 & $($ sPaPG) & 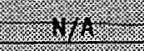 & $-N / A$ \\
\hline+1 & $(s R A R E)$. & Na & $-N / A$ \\
\hline & 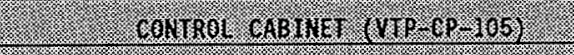 & 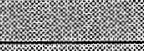 & \\
\hline VIr: $/ \mathrm{HS}: 103$ & EAr constrai & 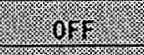 & $c k$ \\
\hline VIP.15-102 & GAYGOL PUAP & orf & 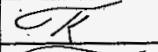 \\
\hline 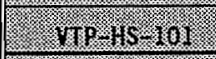 & SEUL DOT BUHE CONTROL & auro & $K K$ \\
\hline TP+15-105 & CONTROL CABINAT HEAT/COOL & 028 & GK \\
\hline 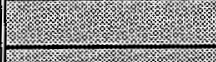 & 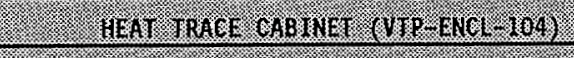 & & \\
\hline 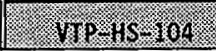 & HEAT TRECE CABIMG HEAT COQL & 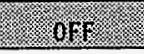 & 5 \\
\hline
\end{tabular}

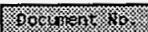

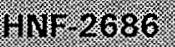

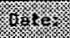

July J 1998
HNF-2688

Rev 0

Page 121 


\section{TANK FARM ACCEPTANCE TEST PROCEDURE}

\section{ATTACHMENT 5 - ATP INITIAL VALVE LINEUP}

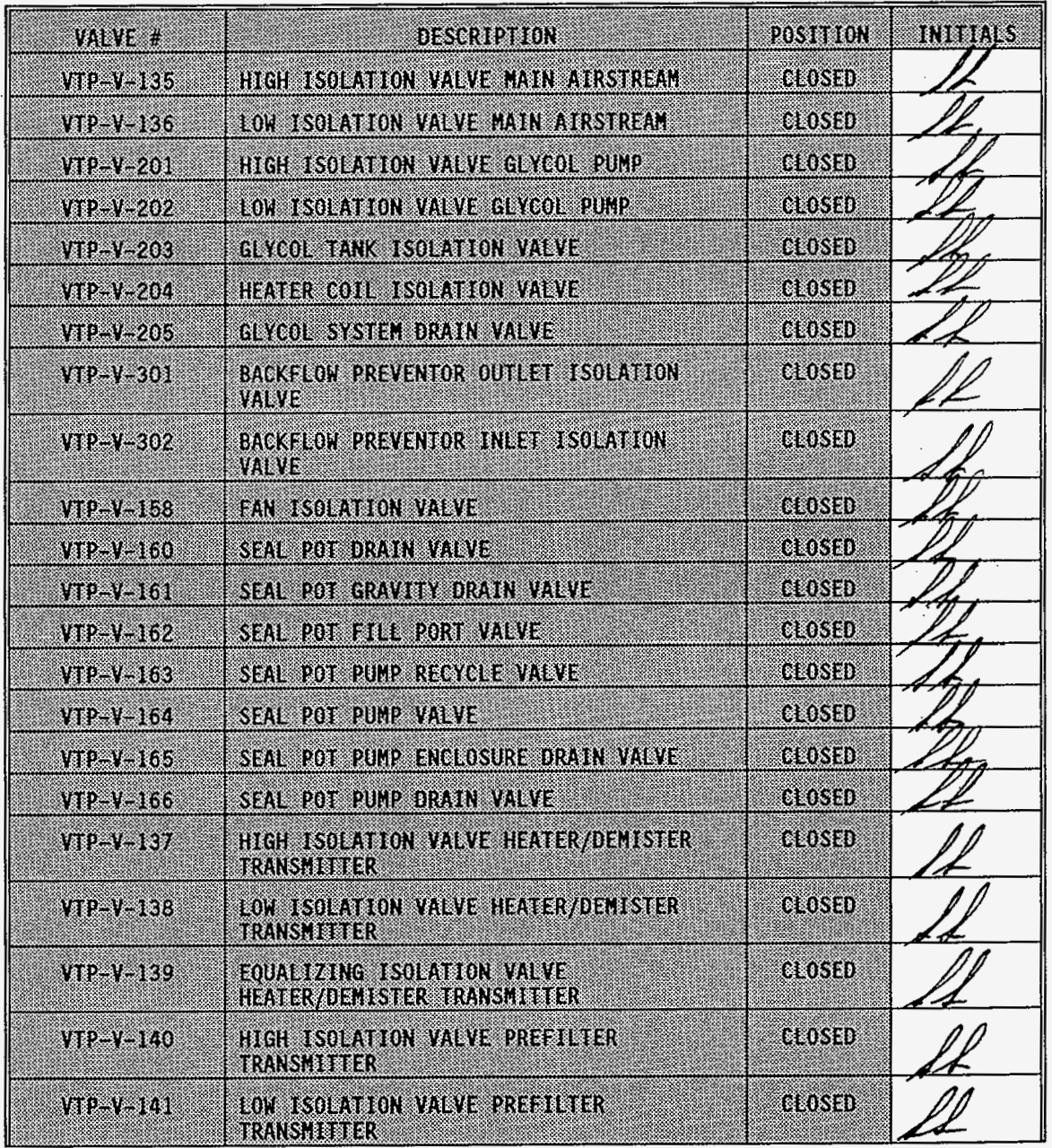

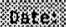

Julv 1.1998
HNF-2688

Rev 0

Page 122 


\section{TANK FARM ACCEPTANGE TEST PROCEDURE}

\section{ATTACHMENT 5 - ATP INITIAL VALVE LINEUP}

\begin{tabular}{|c|c|c|c|}
\hline 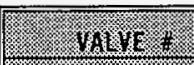 & 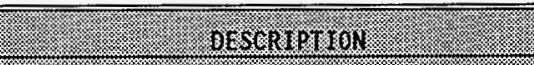 & $80541640 \%$ & matury \\
\hline Hoxy & 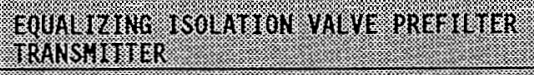 & 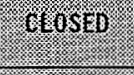 & \\
\hline W10. & 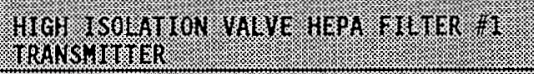 & (40S10 & \\
\hline 1) & 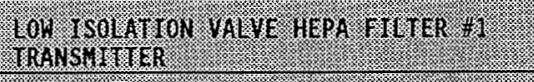 & Mosigy & \\
\hline 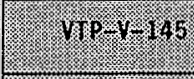 & 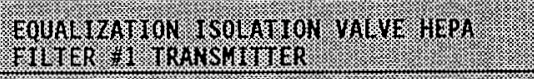 & 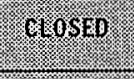 & \\
\hline How & 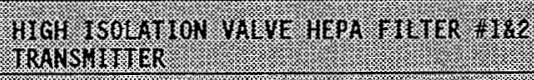 & 40S10 & \\
\hline 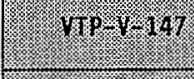 & 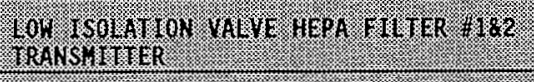 & CWOSE3 & \\
\hline Hor. & 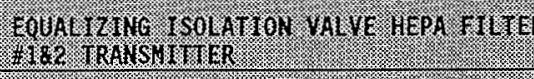 & atosta & \\
\hline 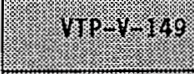 & 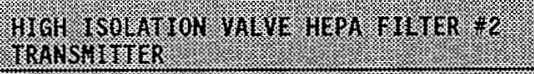 & (x) & \\
\hline Hin & 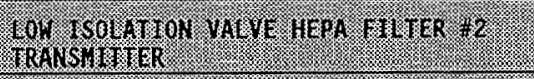 & (6) & \\
\hline 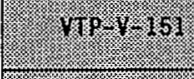 & 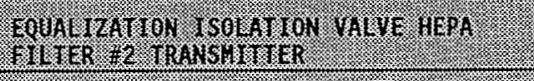 & arosta & \\
\hline $\log =125$ & 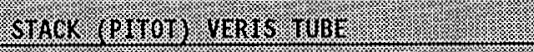 & opdin & *N/A \\
\hline 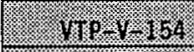 & (n) & (3) & ${ }^{*} N / A$ \\
\hline $19.1 \%$ & 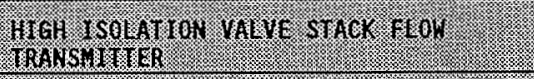 & Most & \\
\hline 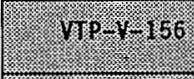 & Oon & grasin & \\
\hline How & 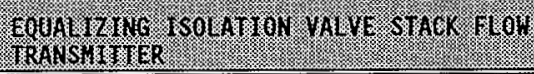 & grasso & \\
\hline
\end{tabular}

"Stack (pitot) veris tube valves have already been positioned to open.

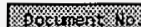

낸. 2686

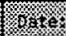

Jivit $1,19.88$
HNF-2688

Rev 0

Page 123 


\section{TANK FARM ACCEPTANCE TEST PROCEDURE}

ATTACHMENT 6 - VTP-FT-184 FIVE POINT CHECK

\begin{tabular}{|c|c|c|c|c|}
\hline 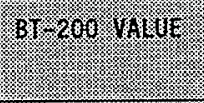 & 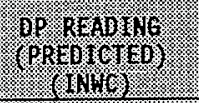 & $\begin{array}{l}\text { op ReApur } \\
\text { (g) }\end{array}$ & 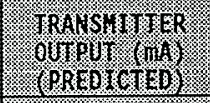 & 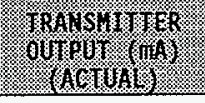 \\
\hline 8 & 0.0 & 0,000 & & 4.00 \\
\hline & (3) & 1.000 & 8 & 8.00 \\
\hline $60 \%:=$ & 2.2 .0 & 2.000 & 12 & 12.00 \\
\hline (1) & 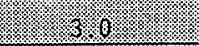 & 3.000 & 8180 & 16.00 \\
\hline & 4.8. & 4.000 & \&at & 19.99 \\
\hline
\end{tabular}

All actual values are with $+/-5 \%$ of predicted values.

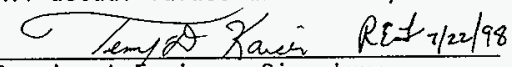

CognizantEngineer Signature

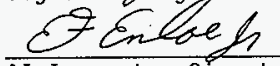

AI Inspector Signature

$\underbrace{}_{7 \rightarrow-98}$ $\frac{9}{\text { QC Inspector sighature }}$

Test Director Signature
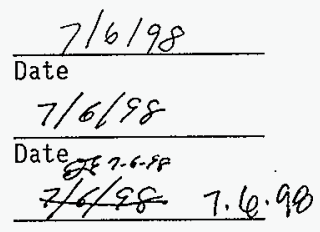

$\frac{7 / 6 / 90}{\text { Date }}$ 


\section{TANK FARM ACCEPTANCE TEST PROCEDURE}

\section{ATTACHMENT 7 - VTP-PDT-170 [0-(-20) INWC] FIVE POINT CHECK}

\begin{tabular}{|c|c|c|c|c|}
\hline 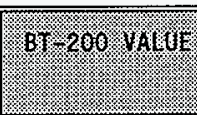 & 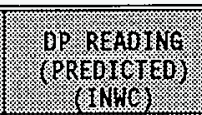 & 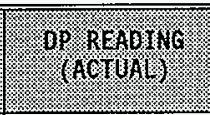 & 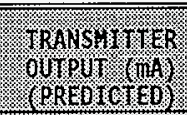 & 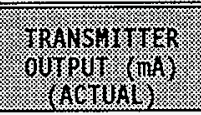 \\
\hline & $f_{1}$ & 0,00 & (1) & 4,00 \\
\hline & $3 x$ & -5.00 & & 8.00 \\
\hline & 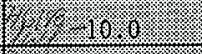 & -10.00 & 19. & 12.00 \\
\hline 158 & 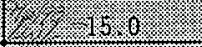 & $-15,00$ & 3.76 & 16.00 \\
\hline (180\% & 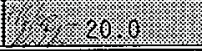 & -20.00 & ( & 19.99 \\
\hline
\end{tabular}

All actual values are with $+/-5 \%$ of predicted values.

lem/ $\$$ Kanse RE\$7/22/98

Cognizant fngineer Signature

67 En ae h

P) Glunessalon

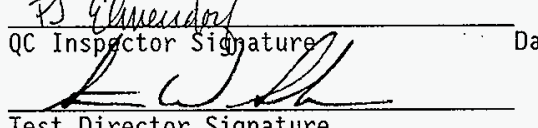

Test Director Signature
$7 / 6 / 98$

Date

$\frac{7 / 6 / 98}{\text { Date }}$

$\frac{7.6 \cdot 98}{7 / 6 / 98}$ 


\begin{tabular}{|c|c|c|c|}
\hline$\unlhd 0 b$ & Ob & LNIOd LJS $07 \mathrm{dW} \exists \perp$ l $\quad \mathrm{d} \exists 17 \mathrm{I}\rfloor$ & $8 I: 6$ IN \\
\hline$\rfloor 06 \mathrm{~T}$ & $06 \mathrm{I}$ & INIOd $1 \exists S$ IH dW $\exists \perp$ I $y \exists 17 I\rfloor$ & $9[: 6$ IN \\
\hline$\% 09$ & IE86 & $077 \exists \wedge \exists 7700 \times 79$ & $\mathrm{GI}: 6 \mathrm{IN}$ \\
\hline JMNI $t^{\circ} \mathrm{g}$ & $\varepsilon L O G I$ & INIOdLJS IHIH dQ Z/[ SyJ17II & $\varepsilon I: 6 I N$ \\
\hline JMNI $O I \cdot 0$ & S6tE & LNIOd $1 \exists S$ o] d0 $2 /[$ SVIIIIJ & $2 I: 6 I N$ \\
\hline JMNI $Z \cdot \varepsilon$ & $\angle 920 \mathrm{I}$ & INIOd $1 \exists S$ IH dO 2 y $\exists \perp 7 I J$ & II.6IN \\
\hline JMNI $\angle \cdot \varepsilon$ & 09EI I & $\perp$ NIOd $1 \exists S$ IHIH dO $z$ y $\exists \perp 7 I J$ & $0 I * 6 I N$ \\
\hline JMNI OT'O & $966 \varepsilon$ & INIOd $1 \exists S$ o7 dO $Z$ y & $6: 6[N$ \\
\hline JMNI $9^{\circ} t$ & $\overline{\mathrm{G} \angle \mathrm{I} 6}$ & INIOd L $1 \exists S$ IH dO [ $\quad 8 \exists \perp 7 I J]$ & $8: 6[N$ \\
\hline JMNI $b^{*} g$ & SGEOI & INIOd IJS IHIH dO I $8 \exists \perp 7 I\rfloor$ & $\angle: 6 \mathrm{IN}$ \\
\hline JMNI OI'O & $806 \varepsilon$ & INIOd $1 \exists S$ dO 07 [ y $317 I \exists$ & $9: 6$ IN \\
\hline $\begin{array}{l}\text { W」วS } \\
00^{\circ} 00[\mathrm{I}\end{array}$ & 25262 & INIOd LIS IH MOT! Xכ甘IS & $G: 6[N$ \\
\hline WJJS $00^{\circ} 0 \angle b$ & 9609 I & INIOd LAS 07 MOTJ XJVIS & $6: 6[N$ \\
\hline JMNI I & T\&86 & INIOd LIS IH dO $\mathrm{y} \exists \perp 7 I \exists-3 \mathrm{dd}$ & $\varepsilon: 6[N$ \\
\hline$J M N I \xi^{\cdot} \varepsilon^{-}$ & $0+29$ & INIOd L & $Z: 6 I N$ \\
\hline$\% \mathrm{SL}$ & $\angle O I E T$ & 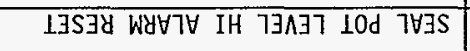 & $02: 8[\mathrm{~N}$ \\
\hline$\% \mathrm{GE} \mathrm{M}^{4}$ & $8518 / t \quad 798 L$ & 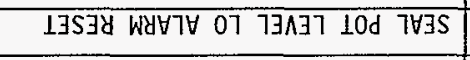 & $6 I: 8[N$ \\
\hline Ist broing & Nond St & 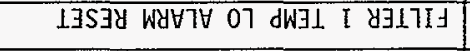 & $8 I: 8[N$ \\
\hline$\perp 09 \mathrm{I}$ & $09 I$ & 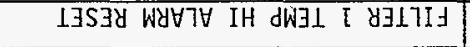 & $9[: 8[N$ \\
\hline$\% 26.6 L$ & GLtOT: & 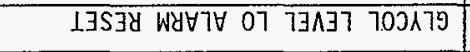 & $9 \mathrm{I}: 8[\mathrm{IN}$ \\
\hline JMNI $\quad t \varepsilon \cdot L$ & Gโ96 & 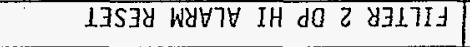 & $I I: 8 I N$ \\
\hline JMNI $O S^{\circ} 9$ & $8[98$ & LЗSJy W'Q & $8: 8 I N$ \\
\hline JMNI $\varepsilon 8 * \hbar$ & O9SOI & 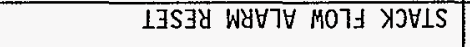 & $\mathrm{S}: 8 \mathrm{IN}$ \\
\hline JMNI $00^{\circ} I$ & โع86 & 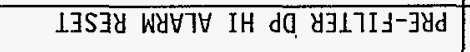 & $\varepsilon: 8 I N$ \\
\hline 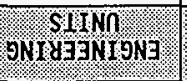 & $97 d$ & No: Idryos & ssagaqu \\
\hline
\end{tabular}

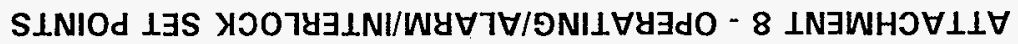




\begin{tabular}{|c|c|c|c|}
\hline \multicolumn{4}{|c|}{ ATTACHMENT 8 (cont) } \\
\hline ADDRESS & DESCRIPTION & PLC & $\begin{array}{c}\text { ENGINEERING } \\
\text { UNITS }\end{array}$ \\
\hline N19: 19 & SEAL POT LEVEL LO SET POINT & 7209 & $30 \%$ \\
\hline N19:20 & SEAL POT LEVEL HI SET POINT & 13763 & $80 \%$ \\
\hline $\mathrm{N} 19: 25$ & INLET VACUUM LOW & $\mathrm{N} / \mathrm{A}$ & N/A \\
\hline N19:26 & INLET VACUUM HIGH & $\mathrm{N} / \mathrm{A}$ & N/A \\
\hline$N 19: 27$ & PLENUM 2 PRESSURE HIGH SETPOINT & .5243 & -3.5 INWC \\
\hline $\mathrm{N} 19: 36$ & FILTER 1 ROC SET POINT & 655 & $0.50 \mathrm{INWC}$ \\
\hline $\mathrm{N} 19: 37$ & FILTER 2 ROC SET POINT & 655 & 0.50 INWC \\
\hline $\mathrm{N} 19: 39$ & PLENUM I PRESSURE HI SETPOINT* & 14417 per Exes & $65.3,5$ INWC \\
\hline & & -9t7|e & $98) \sqrt{17}$ \\
\hline F8:6 & FLOW CONTROL SETPOINT & $\begin{array}{r}27152 \text { Exymw } \\
\quad 718190 \\
\end{array}$ & Wl $\begin{array}{r}1000.00 \\
\text { SCFM }\end{array}$ \\
\hline F8.7 & VACUUM CONTROL SETPOINT & $\mathrm{N} / \mathrm{A}$ & INWC \\
\hline
\end{tabular}
Bypass these alarms under vacuum controt. 
TANK FARM ACCEPTANCE TEST PROCEDURE

ATTACHMENT 9 - DATA ACQUISITION FOR LEAK RATE CALCULATION

(This page may be reproduced as necessary)

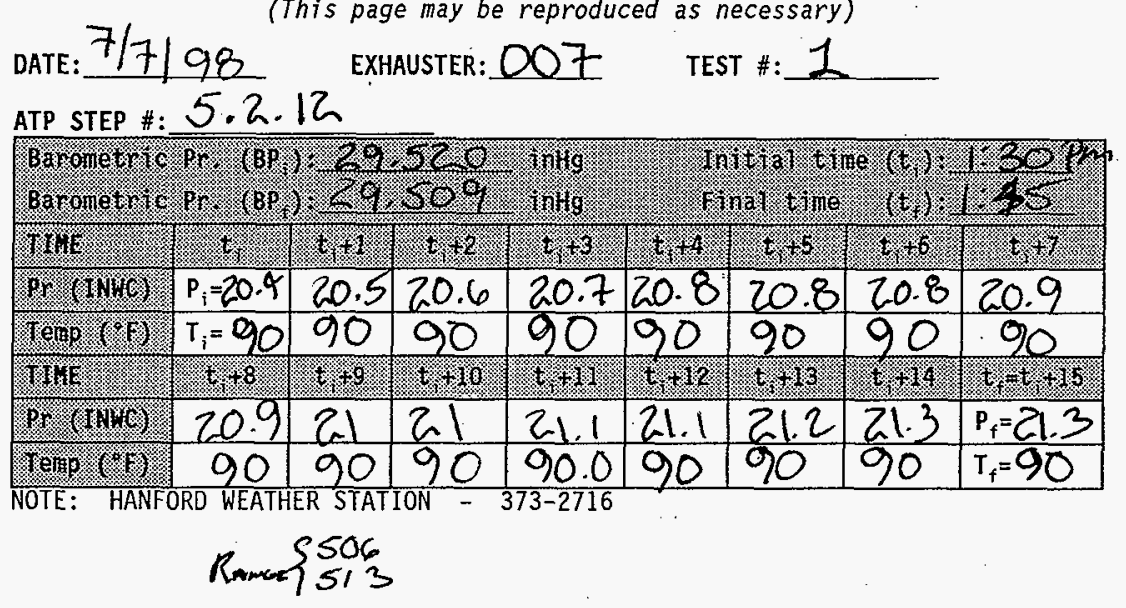

Pressure Gauge: Wallace $\xi_{1}$ Terran CaL Serial : 646-31-04-085 Expiration Date: 10/8/98

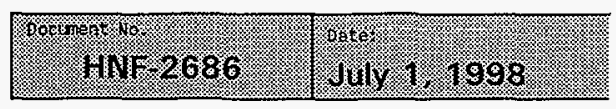

HNF-2688

Rev 0

Page 128 
TANK FARM ACCEPT ANE TEST PROCEDURE

ATTACHMENT 9 - DATA ACQUISITION FOR LEAK RATE CALCULATION

(This page may be reproduced as necessary)

DATE: $7 / 7 / 98$ EXHAUSTED: 02 TEST : $: 2$ ATP STEP \#: $5,2.23$

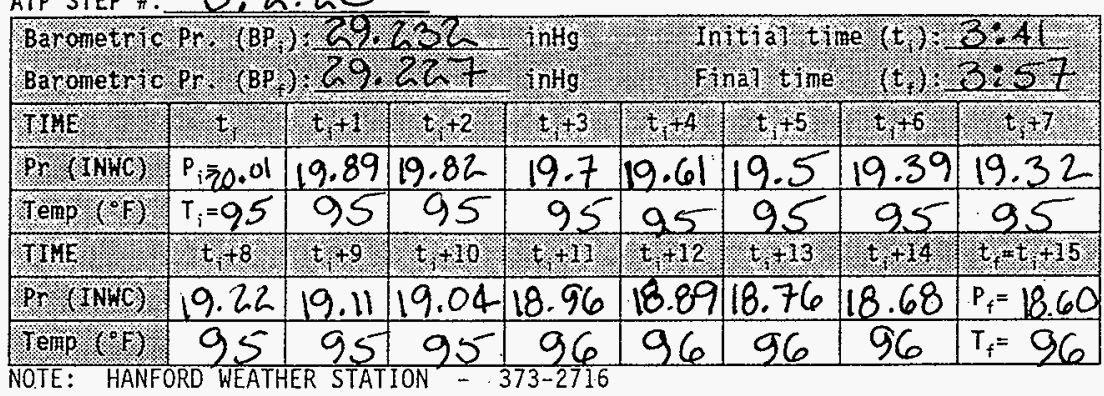

Pressure Gauge Manuf: Rochester Instrument SYSTEMS

CaL Serial t: 778-31-04-036

Expiration) Date: $2 / 23 / 99$

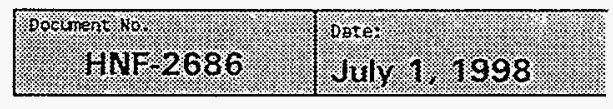

HNF-2688

Rev 0

Page 129 
ofl әбed

0 nəิ

$889 Z-\unlhd N H$

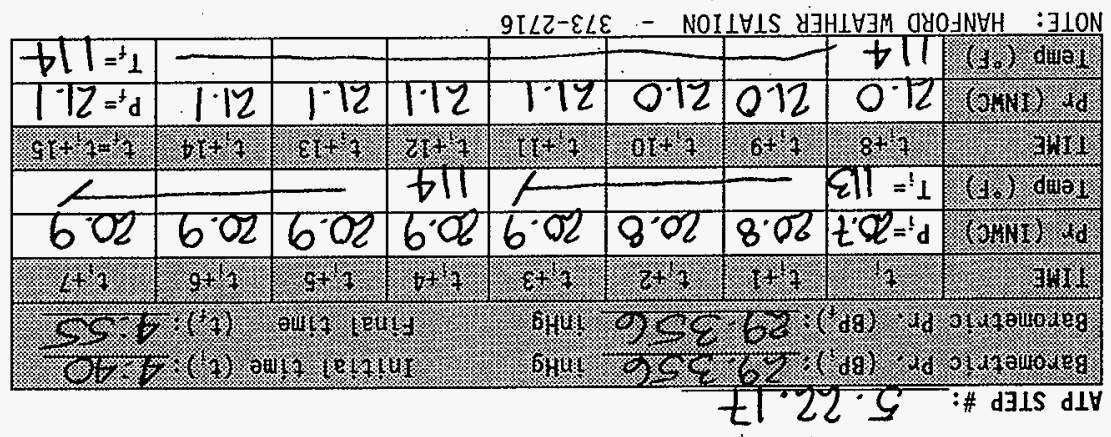

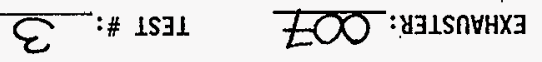

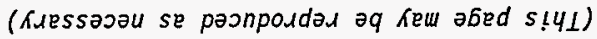 \\ $86 /$ SI/t : $: 170$

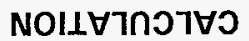

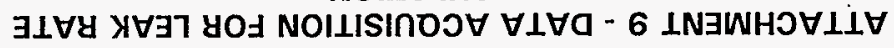


TANK FARM ACCEPTANCE TEST PROCEDURE

ATTACHMENT 9 - DATA ACQUISITION FOR LEAK RATE CALCULATION

(This page may be reproduced as necessary)

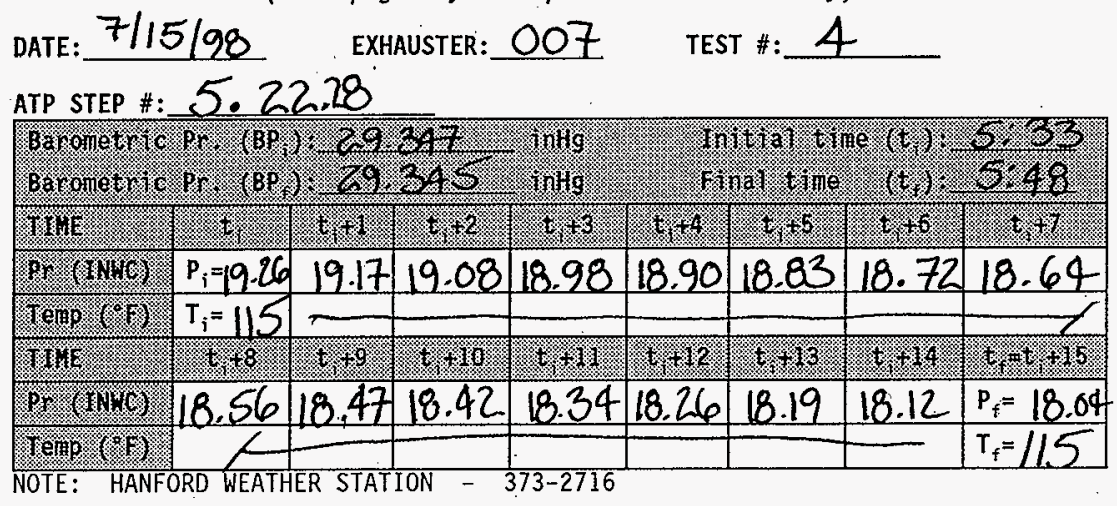

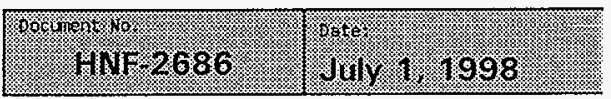

HNF-2688

Rev 0

Page 131 
- TANK FARM ACCEPTANCE TEST PROCEDURE

ATTACHMENT 10 - LEAKAGE RATE CALCULATION

(This page may be reproduced as necessary) DATE: $7 / 7 / 98$

EXHAUSTER:007 TEST* \#:

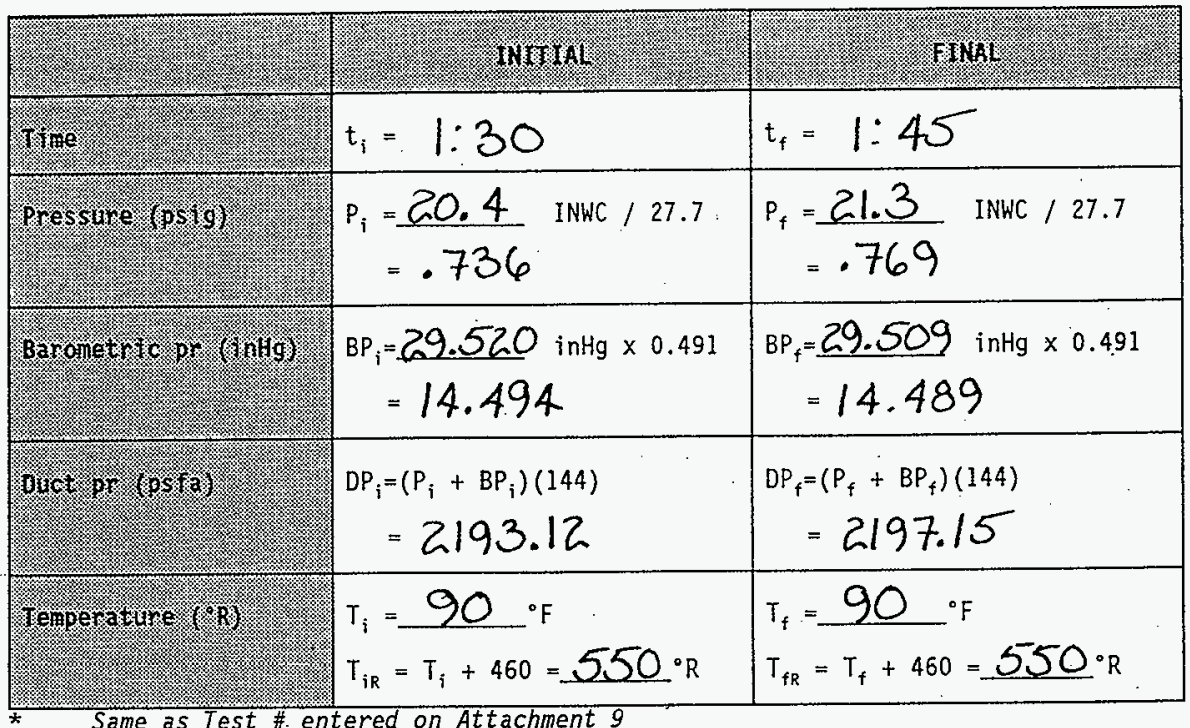

Same as Test \#. entered on Attachment 9

Test Volume: $\quad V=55.7$ cubic feet

Gas constant: $\quad R=53.35 \mathrm{ft} 1 \mathrm{~b} /(1 \mathrm{~b} * \operatorname{deg} R)$

Test Duration: $\Delta t=\left(t_{f}-t_{i}\right)=15$ minutes

$Q=\left(D_{i} / T_{j k} / D P_{f} / T_{f R}\right) V /(R \times \cdot \Delta t \times 0.075)=\varnothing$ SCFM

$Q$ is the Average total leak rate per ASME N510-1989, Section 6.5.3.9, in standard $\mathrm{ft}^{3} / \mathrm{min}$ (SCFM).

$\mathrm{L}_{\mathrm{s}}=$ Allowable Leak Rate $=0.3 \mathrm{SCFM}$

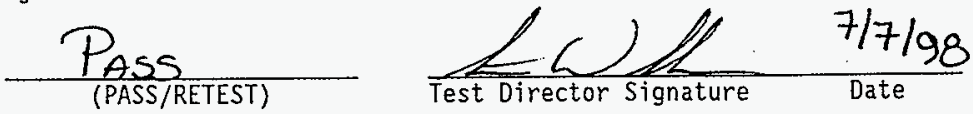

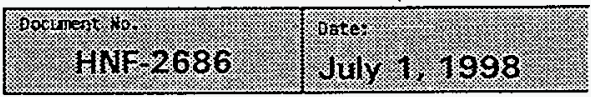

HNF-2688

Rev 0

Page 132 
TANK FARM ACCEPTANCE TEST PROCEDURE

ATTACHMENT 10 - LEAKAGE RATE CALCULATION

(This page may be reproduced as necessary) DATE: $7 / 7 / 98$

EXHAUSTER: 007

TEST $^{*}: 2$

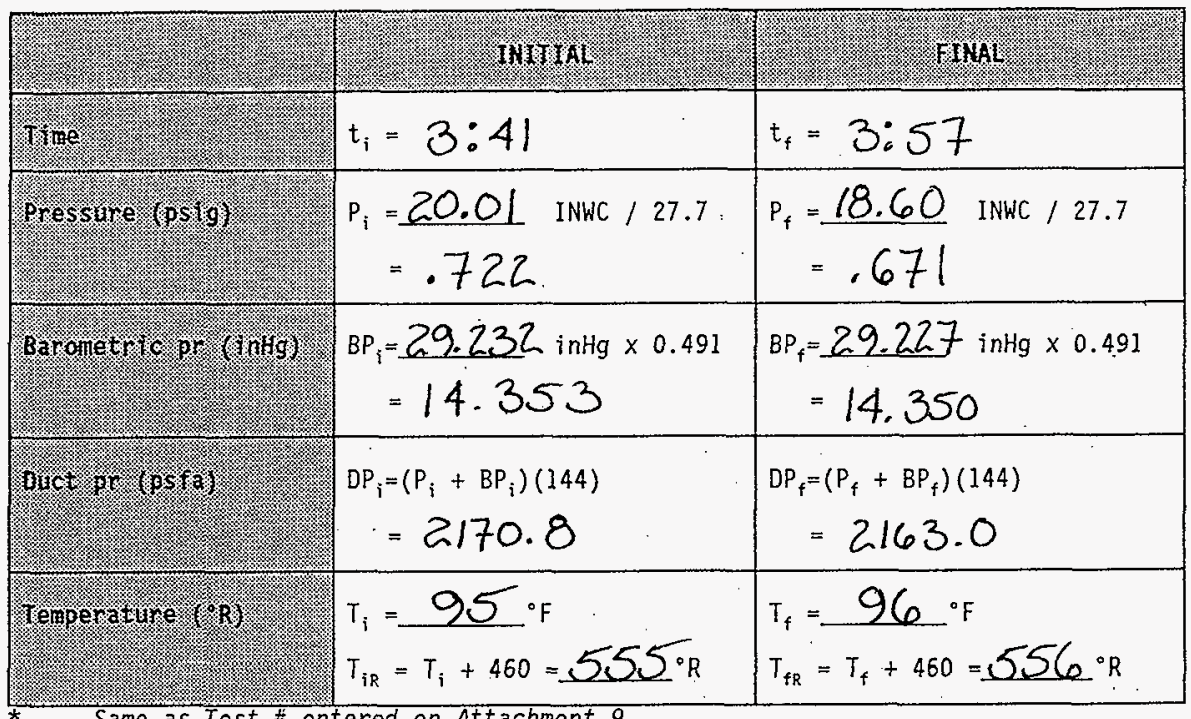

Same as Test \# entered on Attachment 9

Test volume: $\quad V=55.7$ cubic feet

Gas constant: $\quad R=53.35 \mathrm{ft} 7 \mathrm{~b} /(1 \mathrm{~b} * \operatorname{deg} R)$

Test $\frac{\text { Duration: }}{3.9}, \quad \Delta .9 \mathrm{~g}=\left(\mathrm{t}_{\mathrm{f}}-\mathrm{t}_{\mathrm{i}}\right)=\frac{16}{6}$ minutes

$\mathrm{Q}=\left(\mathrm{DP} \mathrm{P}_{\mathrm{i}} / \mathrm{T}_{\mathrm{i},} / \mathrm{DP}_{\mathrm{f}} / \mathrm{T}_{\mathrm{fR}}\right) \mathrm{V} /(\mathrm{R} \times \Delta \mathrm{t} \times 0.075)=-\bigotimes_{\text {SCAM }}$

$Q$ is the Average total leak rate per ASME N510-1989, Section 6.5.3.9, in standard $\mathrm{ft}^{3} / \mathrm{min}$ (SCFM).

$L_{s}=$ Allowable Leak Rate $=0.3$ SCFM
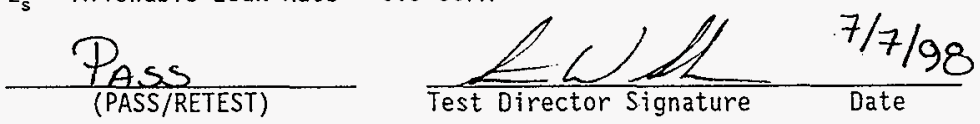

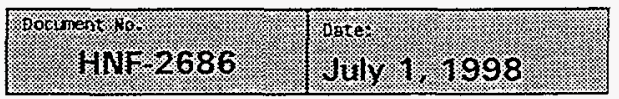

HNF-2688

Rev 0

Page 133 
TANK FARM ACCEPTANCE TEST PROCEDURE

ATTACHMENT 10 - LEAKAGE RATE CALCULATION

(This page may be reproduced as necessary)

DATE: $7 / 7 / 98$ EXHAUSTER:DO 7 TEST* \#:

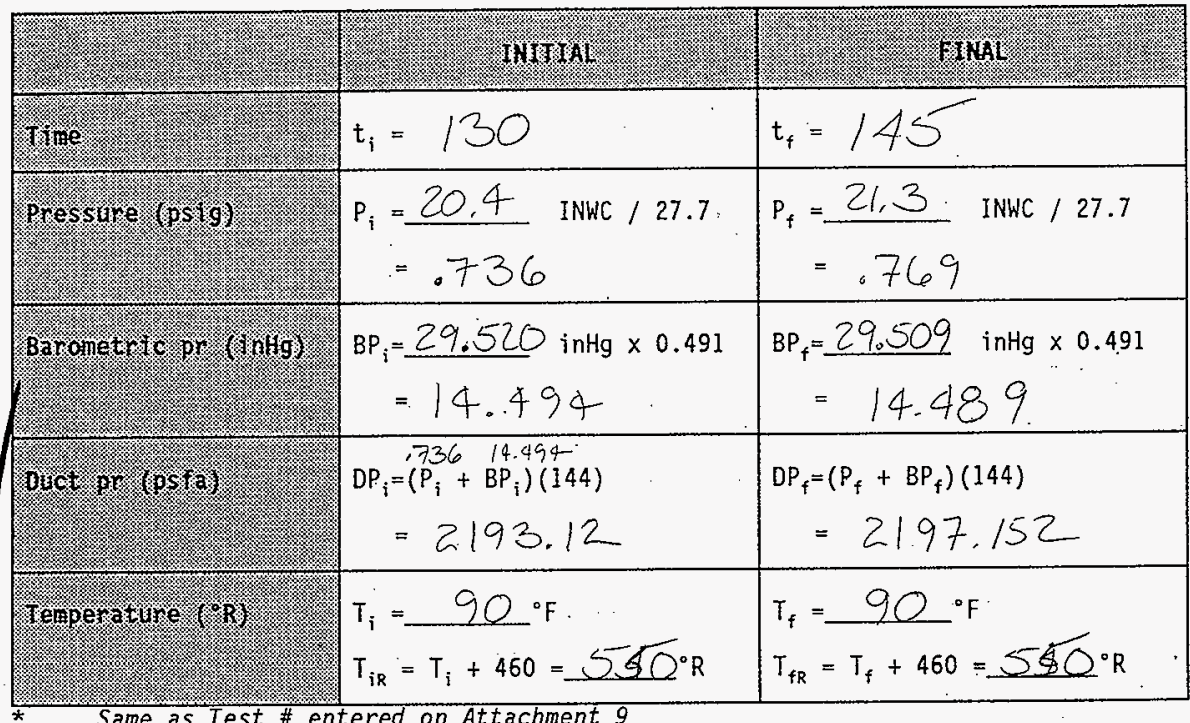

Same as Test \# entered on Attachment 9

Test Volume: $\quad V=55.7$ cubic feet

Gas constant: $\quad R=53.35 \mathrm{ft} 1 \mathrm{~b} /\left(1 b^{\star} \operatorname{deg} R\right)$

Test Duration: $\Delta t=\left(t_{f}-t_{i}\right)=15$ minutes If firs tim $3.987 \quad 3.994 \quad\left(t_{f}-t_{i}\right)=1 / 5 \times 1 /$

$Q=\left(D P_{i} / T_{i R}-D P_{f} / T_{f R}\right) V /(R \times \Delta t \times 0.075)=$ SCFM thar approx

$Q$ is the Average total leak rate per ASME N510-1989, section $0.0=Q$ 6.5.3.9, in standard $\mathrm{ft}^{3} / \mathrm{min}$ (SCFM).

$L_{s}=$ Allowable Leak Rate $=0.3 \mathrm{SCFM}$

(PASS/RETEST)

Test Director Signature

Date

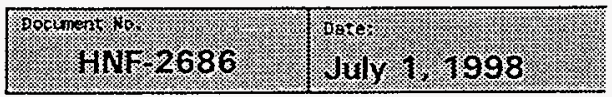

HNF-2688

Rev 0

Page 134 
TANK FARM ACCEPTANCE TEST PROCEDURE

ATTACHMENT 10 - LEAKAGE. RATE CALCULATION

(This page may be reproduced as necessary) DATE: EXHAUSTER: 007 TEST $^{*} \#$ Z 2

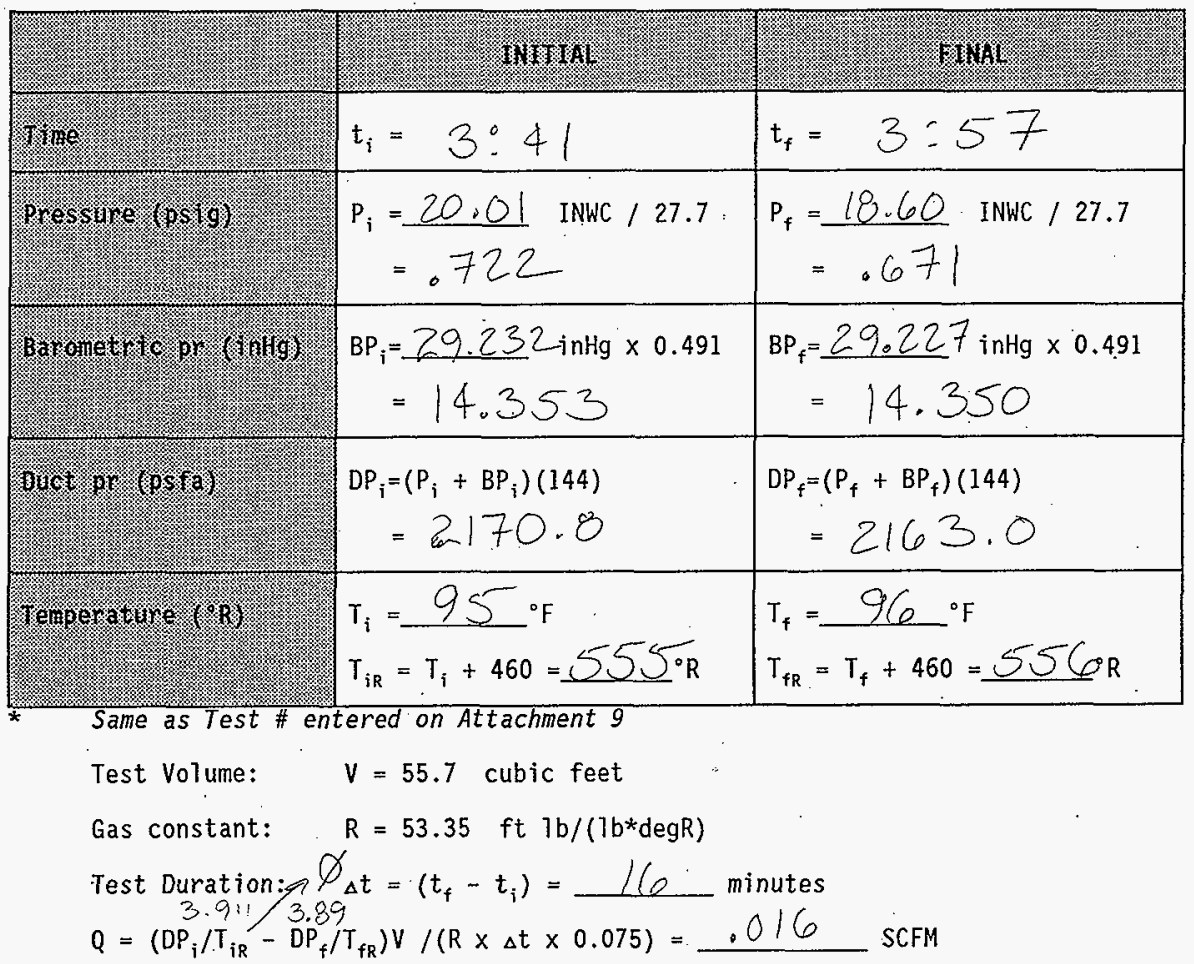

$Q$ is the Average total leak rate per ASME N510-1989, Section 6.5.3.9, in standard $\mathrm{ft}^{3} / \mathrm{min}$ (SCFM).

$L_{s}=$ Allowable Leak Rate $=0.3$ SCFM

(PASS/RETEST)

Test Director Signature

Date

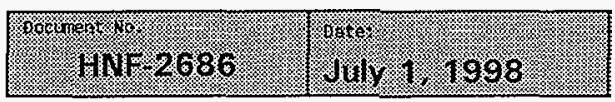

HNF-2688

Rev 0

Page 135 


\section{TANK FARM ACCEPTANCE TEST PROCEDURE}

\section{ATTACHMENT 10 - LEAKAGE RATE CALCULATION}

DATE: $7 / 15 / 98^{\text {(This page may be reproduced as necessary) }}$ EXHaUSTER: 007 TEST* \#

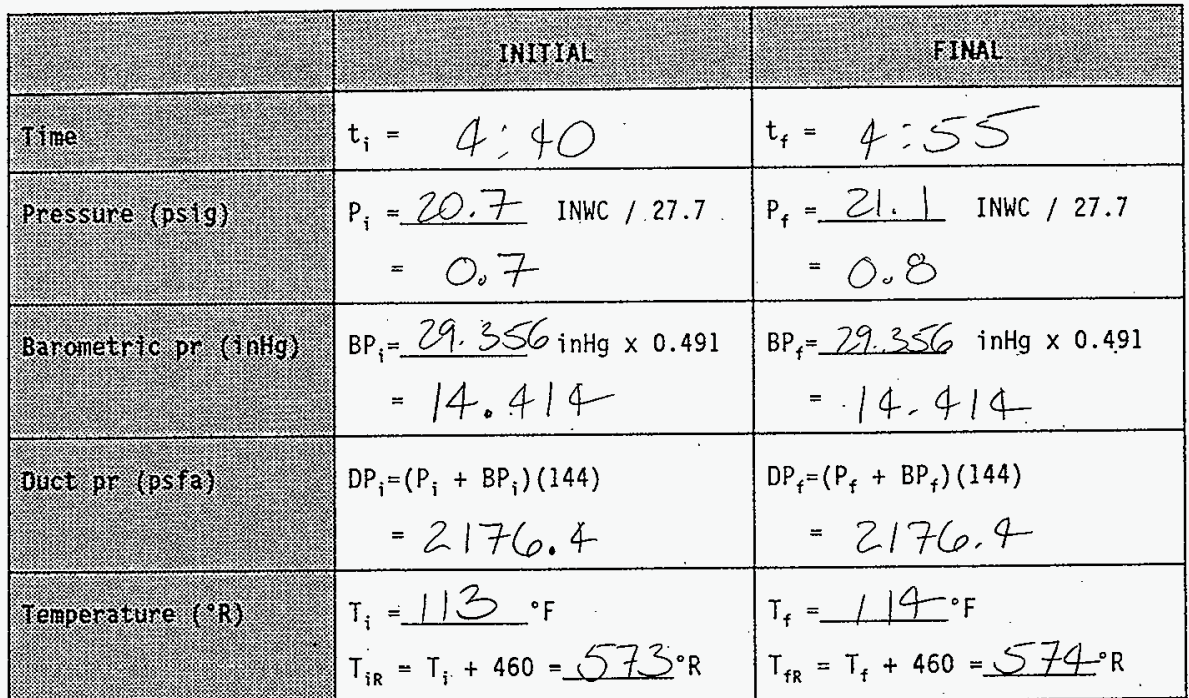

Same as Test \# entered on Attachment 9

Tešt Volume: $\quad V=55.7$ cubic feet

Gas constant: $\quad R=53.35 \mathrm{ft} 1 \mathrm{~b} /(1 \mathrm{~b} *$ degR)

Test Duration: $\Delta_{0}^{\Delta t}=\left(t_{f}-t_{i}\right)=15$ minutes

$Q=\left(\mathrm{DP}_{\mathrm{i}} / \mathrm{T}_{\mathrm{i} D} / \mathrm{DP}_{\mathrm{f}} / \mathrm{T}_{\mathrm{fR}}\right) \vee /(\mathrm{R} \times \Delta \mathrm{t} \times 0.075)=\circlearrowright$ SCFM

$O Q$ is the Average total leak rate per ASME N510-1989, Section

6.5.3.9, in standard $\mathrm{ft}^{3} / \mathrm{min}$ (SCFM).

$L_{s}=$ Allowable Leak Rate $=0.3$ SCFM

(PASS/RETEST)

Test Director Signature Date 


\section{TANK FARM ACCEPTANCE TEST PROCEDURE}

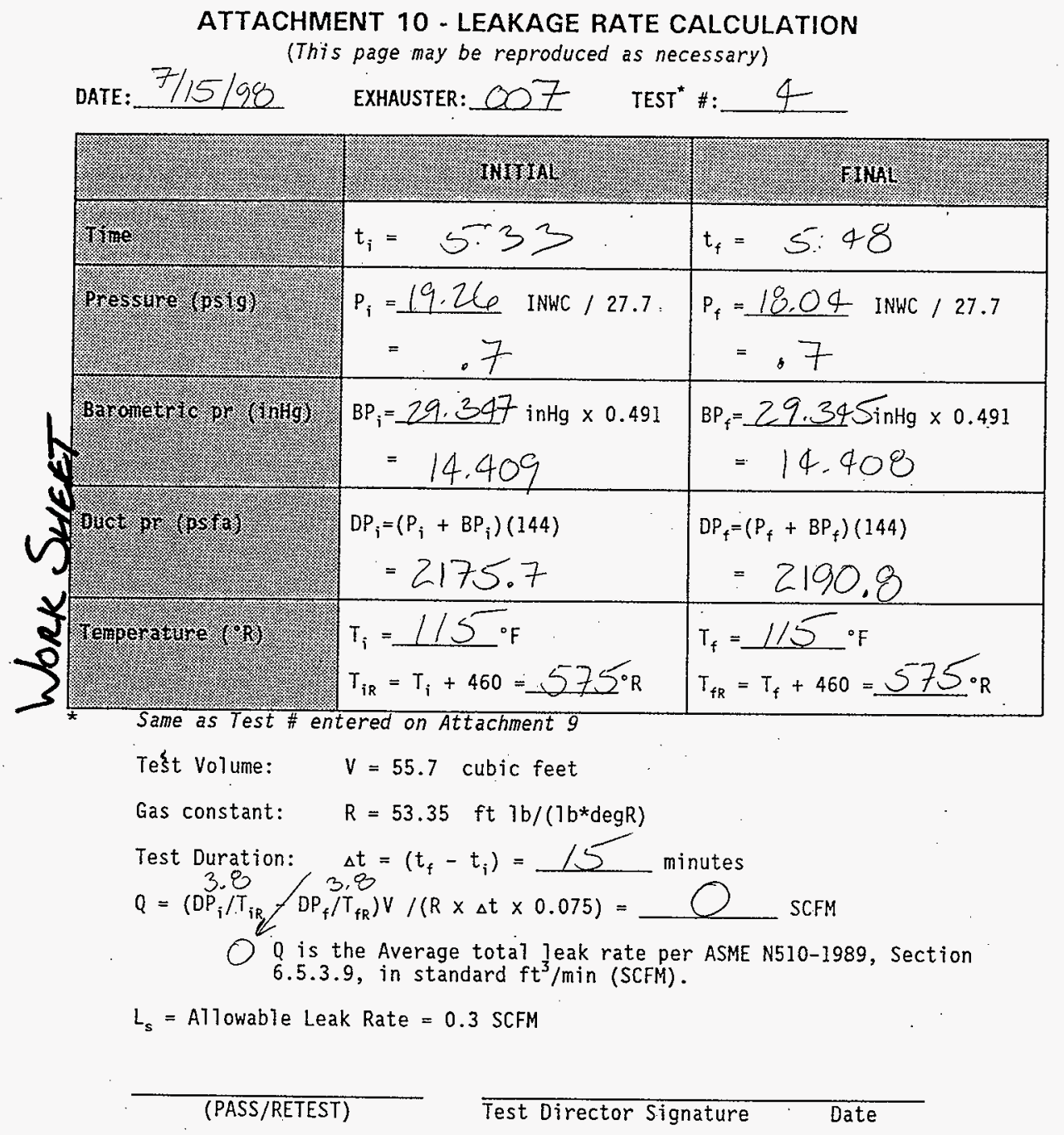

\begin{tabular}{|c|c|}
\hline \% & 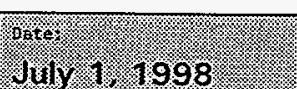 \\
\hline
\end{tabular}


TANK FARM ACCEPTANCE TEST PROCEDURE

ATTACHMENT 10 - LEAKAGE RATE CALCULATION

(This page may be reproduced as necessary)

DATE: $7 / 15 / 98$ EXHAUSTER:007 TEST ${ }^{*}$ :

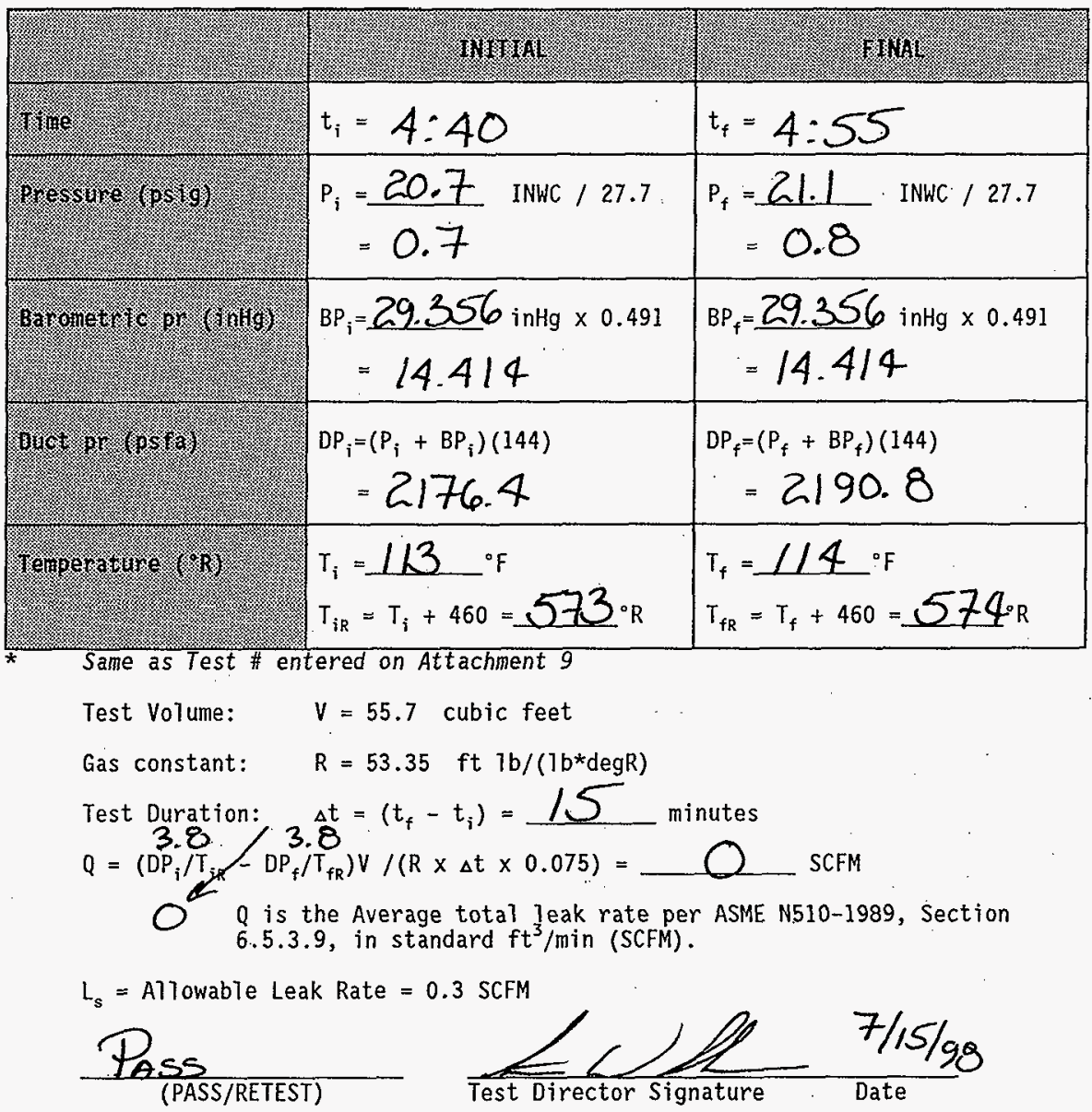

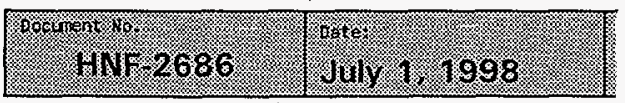

HNF-2688

Rev 0

Page 138 


\section{$6 \varepsilon$ วิธed \\ $0 \wedge$ ^əу \\ $889 Z^{-}-\mathrm{NH}$}
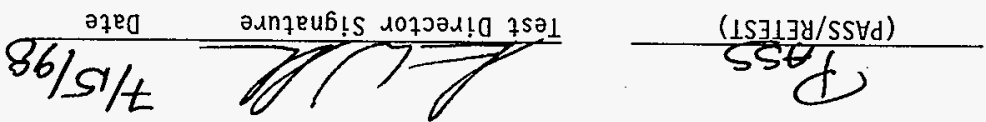

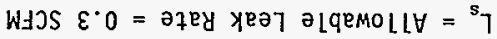

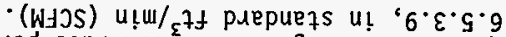

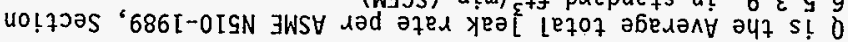

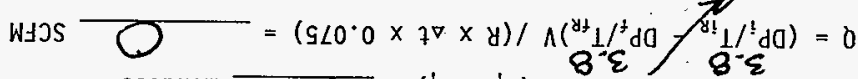

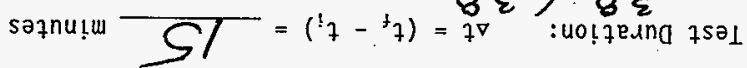

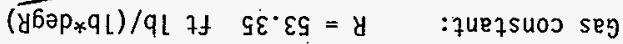

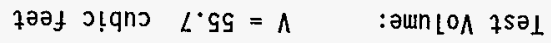

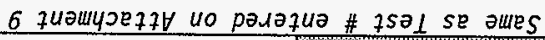

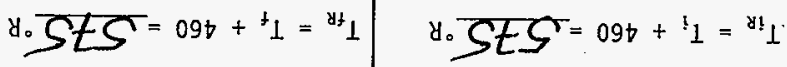

$$
\begin{aligned}
& \text { t. } 5 /={ }^{+} 1 \\
& \text { 1. } 5 \%=! 1
\end{aligned}
$$

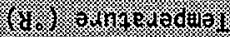

$$
\begin{aligned}
& 9 \cdot 5 t 12= \\
& +5+12=
\end{aligned}
$$

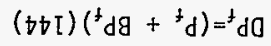

$$
\begin{aligned}
& (t+\tau)(! d g+t d)=! d a \\
& 806^{\circ} 61= \\
& 606^{-61}=
\end{aligned}
$$

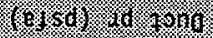

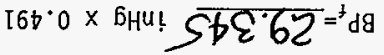

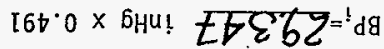

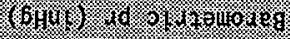

$$
t^{\prime}=
$$

$\angle \angle 2 /$ JMNI $\overline{70^{\circ} 8 I}=*^{+9}$

$\angle \cdot L Z /$ TMNI $9261=! d$

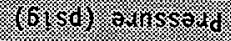

$$
86: 5={ }^{+7}
$$

$$
\varepsilon \varepsilon: S=!_{7}
$$

$10111 \%$

$$
\text { 10.1.14 }
$$

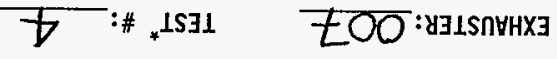

(КАessasau se pasnpoudas aq kell abed s!41)

86/S1/t :3170

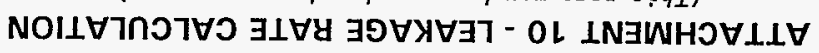




\begin{tabular}{|c|c|c|c|}
\hline Whas: & BESTRESTH & 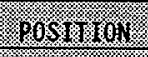 & \\
\hline 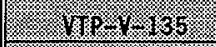 & 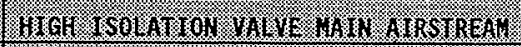 & Opp EL & \\
\hline 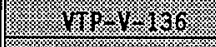 & 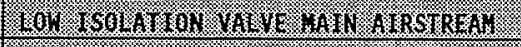 & 00 ats & \\
\hline MII & 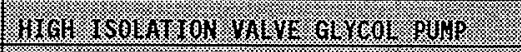 & . 0 eteN & \\
\hline 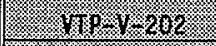 & 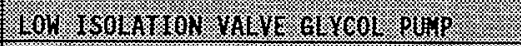 & OREA & \\
\hline$=17 \mathrm{l}=1.203$ & 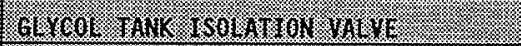 & obea & \\
\hline 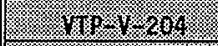 & 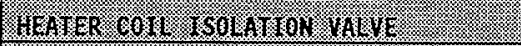 & $.0 \mathrm{pgs}$ & \\
\hline $\ln 1-3-205$ & 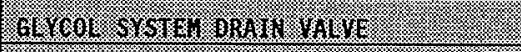 & CLGSER. & \\
\hline 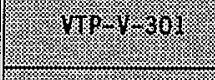 & 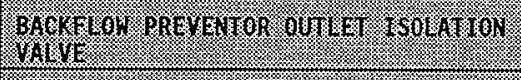 & 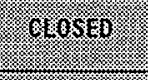 & \\
\hline $\lim =1802$ & 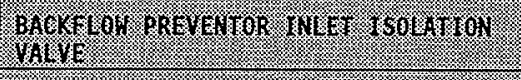 & (1.058 & \\
\hline $110.7+68$ & 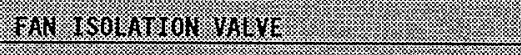 & 10080 & \\
\hline 180.760 & 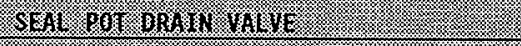 & (G) BSEa & \\
\hline $140.1 \times 16$ & 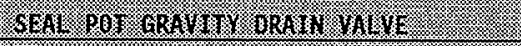 & atusEB & \\
\hline$\sqrt{30.1262}$ & 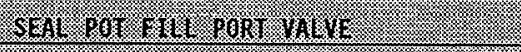 & $80.05 \mathrm{seg}$ & \\
\hline 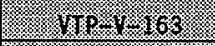 & 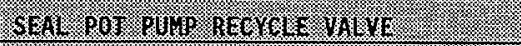 & U.6.6SB & \\
\hline 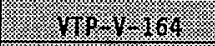 & 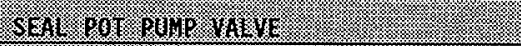 & op gy & \\
\hline 1.10 .4 .165 & 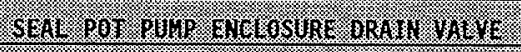 & $.08 \mathrm{gu}$ & \\
\hline 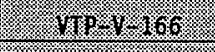 & 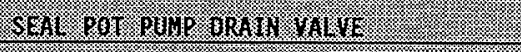 & $.8 \operatorname{sen}^{2}$ & \\
\hline int? & 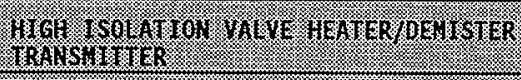 & 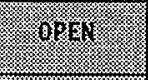 & \\
\hline 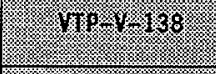 & 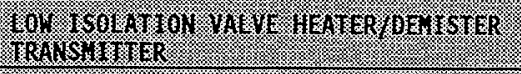 & 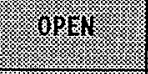 & \\
\hline $189=1.139$ & 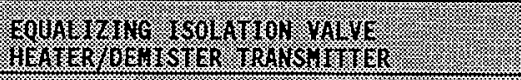 & 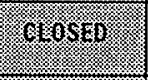 & \\
\hline 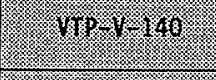 & 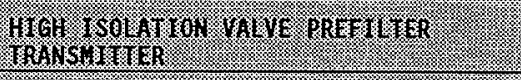 & $00 \mathrm{NEN}$ & \\
\hline $\ln 9.96$ & 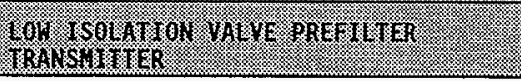 & OPE: & \\
\hline
\end{tabular}

ATTACHMENT 11 - FUNCTIONAL TEST VALVE LINEUP

1505

(1)
HNF-2688

Rev 0

Page 140 


\section{TANK FARM ACCEPTANCE TEST PROCEDURE}

\begin{tabular}{|c|c|c|c|}
\hline 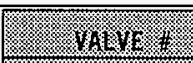 & 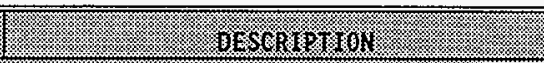 & 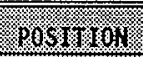 & MW WALS \\
\hline & 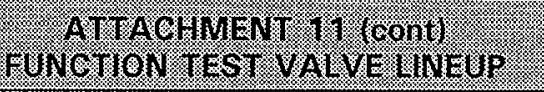 & & \\
\hline $19 \div-142$ & 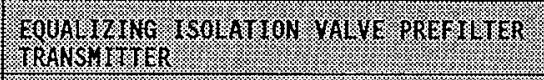 & (4. & $\theta x$ \\
\hline 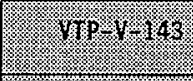 & 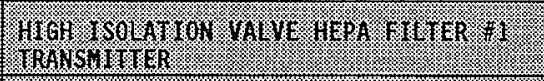 & OrEA. & 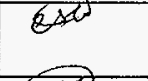 \\
\hline 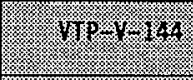 & 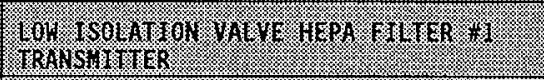 & 8PEI & $\operatorname{ces} \theta$ \\
\hline$\pi n=1+145$ & 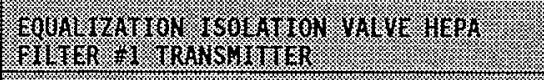 & gessto. & 5 \\
\hline 169.96 .96 & 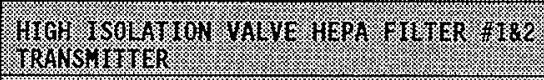 & ologer & $8 \times 6$ \\
\hline 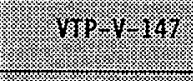 & 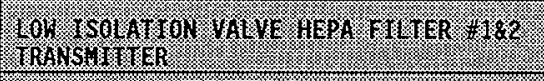 & $8.0 \% 14$ & Qs.S \\
\hline 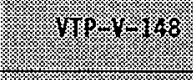 & 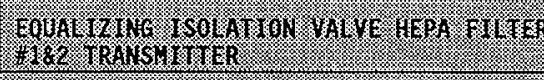 & CEosED & 88 \\
\hline $119=1.949$ & 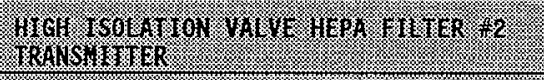 & 00 & \\
\hline 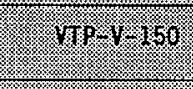 & 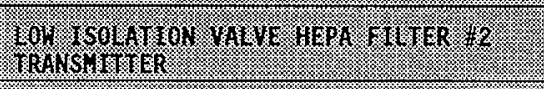 & (9p) & esse \\
\hline 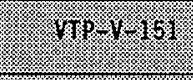 & 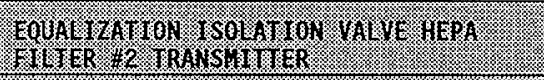 & 8205629 & Ese \\
\hline 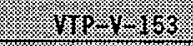 & 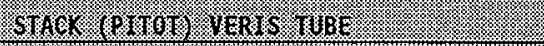 & 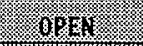 & ${ }^{*} \mathrm{~N} / \mathrm{A}$ \\
\hline 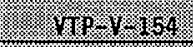 & 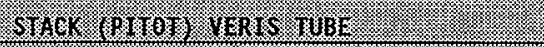 & (0) & *N/A \\
\hline $170-1.965$ & 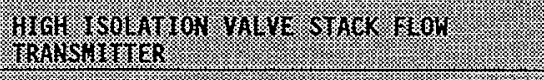 & OPE: & 58 \\
\hline$\sqrt{17} \div y=166$ & 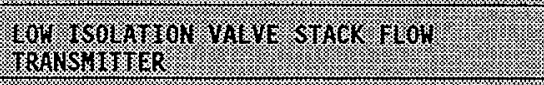 & Oper. & $8 \leqslant$ \\
\hline $\ln =1.157$ & 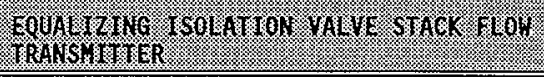 & Cyasto & a\&. \\
\hline
\end{tabular}

*Stack (pitot) veris tube valves have already been positioned to open.

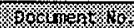

$4 N F-2686$
10

Iiviv 13.998
HNF-2688

Rev 0

Page 141 


\section{TANK FARM ACCEPTANCE TEST PROCEDURE}

\section{ATTACHMENT 12 - FUNCTIONAL TEST ELECTRICAL LINEUP}

\begin{tabular}{|c|c|c|c|}
\hline COMPONERT I I : & 3ESCR HOM IGN & 20ST r. & \\
\hline ThPOBS- & 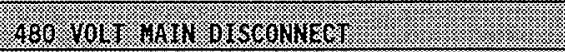 & 010 & \\
\hline nir. Ds & 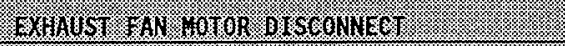 & ON. & \\
\hline 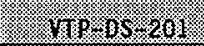 & 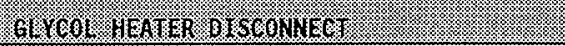 & (n) & \\
\hline $\operatorname{ser} \cdot \operatorname{BnR}-1 \mathrm{~g}$ & 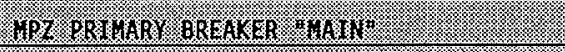 & ON & \\
\hline $\ln 2=8 \mathrm{BR}-102$ & YR7 SECQNBARY OREAKGR SECONBARY IAU & 1010 & \\
\hline 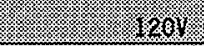 & 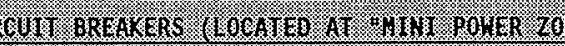 & rom & \\
\hline 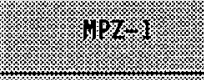 & 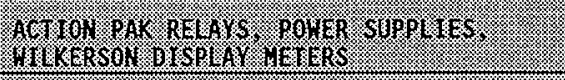 & 018. & \\
\hline $4192=2$ & 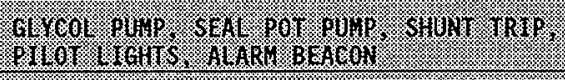 & or. & \\
\hline 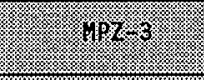 & 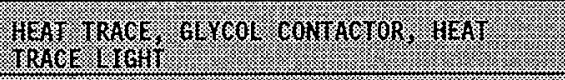 & on & \\
\hline 182.4 & 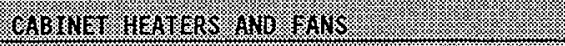 & 04 & \\
\hline $\operatorname{list-2.5}$ & 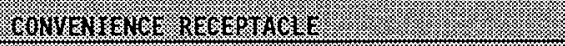 & 01 & \\
\hline 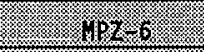 & 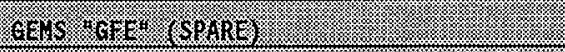 & (8) & \\
\hline (1) & 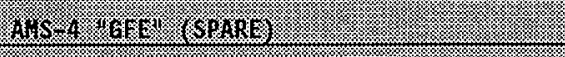 & 600 & \\
\hline 882.8 & 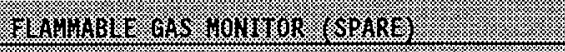 & $0 N$ & \\
\hline $182=9$ & (SPARR) & No & $N / A$ \\
\hline $192=10$ & $(\sin 2)$ & 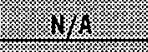 & $N / A$ \\
\hline 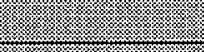 & 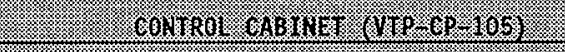 & & \\
\hline $\operatorname{lng}=15.103$ & and conirol & (0) & \\
\hline$-125.15-102$ & GICOL pinp & 06 & \\
\hline & 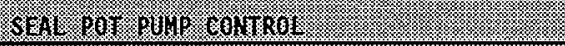 & $\sin 10:$ & \\
\hline 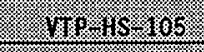 & 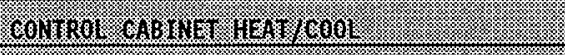 & 8) & \\
\hline 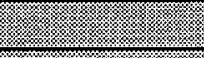 & 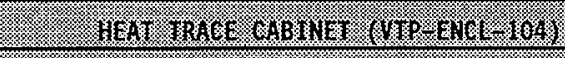 & (3.s. & \\
\hline $\operatorname{lng} \cdot 18.104$ & 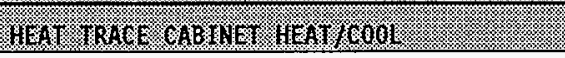 & .012 & \\
\hline
\end{tabular}

\% 0001010

MiN 2686
8.:5:

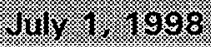

HNF-2688

Rev 0

Page 142 


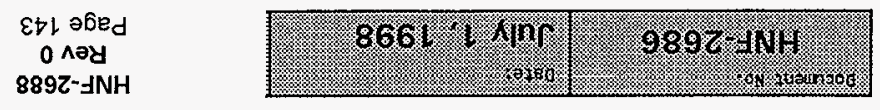

\begin{tabular}{|c|c|c|c|}
\hline$\% 0 \varepsilon$ & $602 L$ & INIOd $13 \mathrm{~S} 0773 \wedge \exists 7$ 10d $7 \forall \exists S$ & $6[: 6[N$ \\
\hline$\exists 0 t$ & ot & INIOd LJS 07 dW $\exists \perp$ [ y $\exists \perp 7 I d$ & $8[: 6[N$ \\
\hline$\exists 06 I$ & $06 \mathrm{I}$ & INIOd LIS IH dWJI [ \&JL7IJ & $9[: 6$ IN \\
\hline$\% 0 \mathrm{~S}$ & โ£86 & $0773 \wedge 37703 \times 79$ & $\mathrm{SI}: 6 \mathrm{IN}$ \\
\hline 2MNI $07^{\circ} \mathrm{G}$ & $\varepsilon \angle 09 \mathrm{I}$ & INIOdLJS IHIH dO Z/[ SYZITIJ & $\varepsilon I: 6 I N$ \\
\hline JMNI $0 I^{\circ} 0$ & S6bE & INIOd $13 S$ of dO $2 /[$ SצJITIJ & $2 T: 6 T N$ \\
\hline JMNI $Z^{\cdot} \varepsilon$ & $\angle 920 \mathrm{I}$ & INIOd $1 \exists S$ IH dO 2 y $317 I\rfloor$ & II'6[N \\
\hline JMNI $L^{\circ} \varepsilon$ & 09EII & LNIOd $1 \exists S$ IHIH dO 2 y $3 \perp 7 I$ & $0[\cdot 6$ IN \\
\hline JMNI. OI ${ }^{\circ} 0$ & 967ह & INIOd $1 \exists S 07$ dO 2 y $3 \perp 7 I J$ & $6: 6$ [N \\
\hline $3 M N I \quad 09^{\circ} t$ & GLI6 & INIOd $\perp \exists S$ IH dO I $\mathrm{Y} \exists \perp 7 I\rfloor$ & $8: 6$ IN \\
\hline JMNI Ot*G & SGEOI & INIOd LJS IHIH dO [ y $\exists \perp 7 I\rfloor$ & $\angle: 6[\mathrm{IN}$ \\
\hline JMNI OI'O & $806 \varepsilon$ & LNIOd $\perp \exists S$ dO 07 I y & $9: 6[N$ \\
\hline $\begin{array}{l}\text { WJJS } \\
00^{\circ} 000 \mathrm{I}\end{array}$ & ZSLLZ & INIOd $1 \exists S$ IH MOT」 XJVIS & $9: 6$ IN \\
\hline WIJS $00^{\circ} G \angle 9$ & $99 \varepsilon 02$ & INIOd $1 \exists S$ OT MOT」 XJ甘LS & $6: 6$ IN \\
\hline JMNI I & โદ86 & INIOd $1 \exists S$ IH dO $\mathrm{y} 3 \perp 7 \mathrm{I}\rfloor$-3yd & $\varepsilon: 6$ IN \\
\hline JMNI $\mathcal{G}^{\circ} \varepsilon^{-}$ & ObZG & 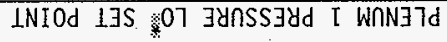 & $Z: 6$ IN \\
\hline$\% G L$ & $\angle O I E I$ & 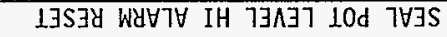 & $02: 8[N$ \\
\hline$\% 9 \varepsilon$ & $798 L$ & 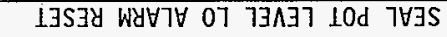 & $6[: 8[N$ \\
\hline $196 \quad 86 / 8 / t_{9}$ & PYo sh tOKEE & 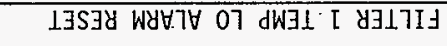 & $8[: 8 I N$ \\
\hline$\rfloor 09 \mathrm{I}$ & 09 I & 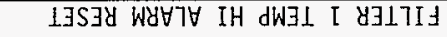 & $9[: 8 I N$ \\
\hline$\% 26^{\circ} 6 L$ & GLbOL & 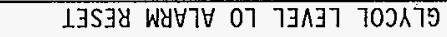 & $G[: 8[N$ \\
\hline JMNI $\nabla \varepsilon^{\circ} L$ & Gโ96 & 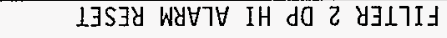 & {$[I: 8 I N$} \\
\hline JMNI OS.9 & $8[98$ & $1 \exists S \exists y$ WyYרV IH d0 [ $y \exists \perp 7 I\rfloor$ & $8: 8 \mathrm{IN}$ \\
\hline JMNI $\varepsilon 8^{\circ} b$ & O9G0I & 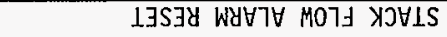 & $\mathrm{G}: 8[\mathrm{~N}$ \\
\hline JMNI $00^{\circ} I$ & {$[\varepsilon 86$} & 1.S & $\varepsilon: 8[N$ \\
\hline 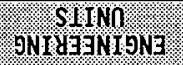 & 3) & NOILIYSSIO & ss Jidag \\
\hline
\end{tabular}

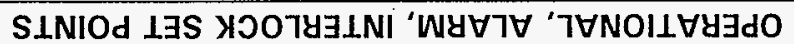

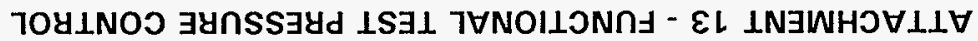




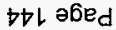 \\ 0 ^әу \\ 889Z-JNH}

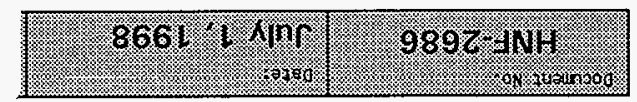

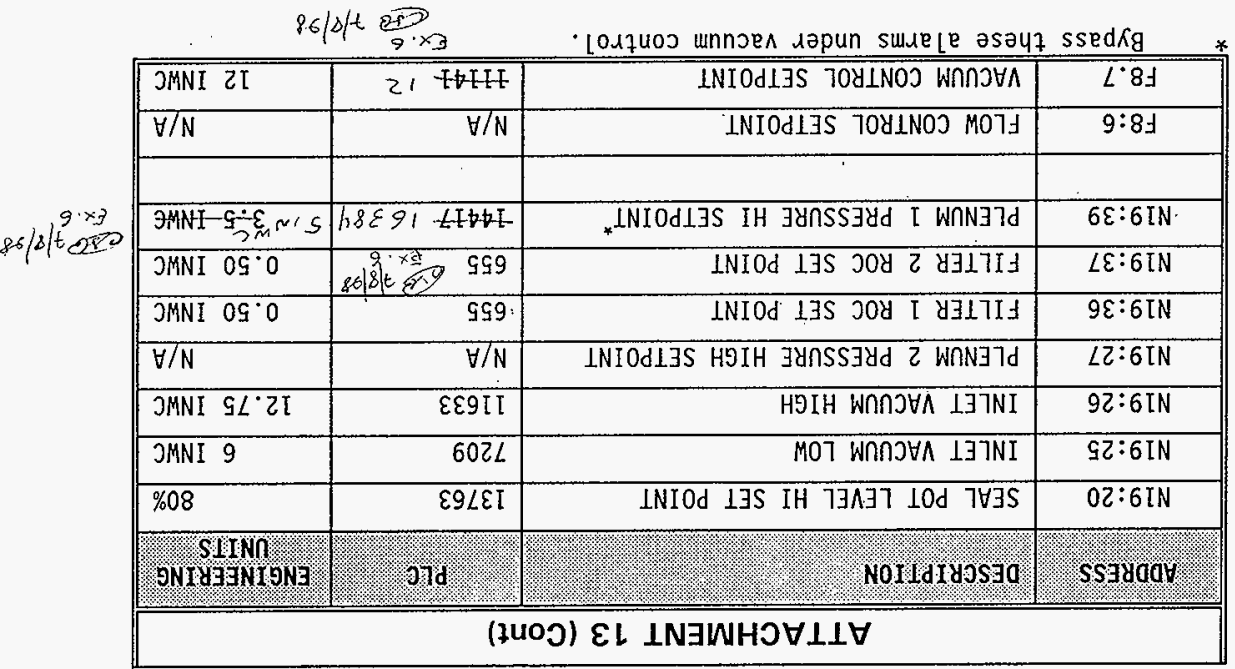




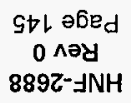

\begin{tabular}{|c|c|c|c|}
\hline$\% 0 \varepsilon$ & 6021 & LNIOd LJS $077 \exists A \exists 7$ LOd TVJS & $6[: 6 \mathrm{IN}$ \\
\hline $50 t$ & ot & INIOd $13 S 07$ dWJI I $y \exists \perp 7 I$ & $8[: 6 \mathrm{LN}$ \\
\hline$\rfloor 06 \tau$ & 06I & INIOd $1 \exists S$ IH dW $I$ I $y \exists L I I$ & $9[\div 6 \mathrm{IN}$ \\
\hline$\% 09$ & โह86 & $0773 \wedge \exists 7703 \wedge 79$ & $9 I: 6$ IN \\
\hline JMNI ot ${ }^{\circ} \mathrm{s}$ & $\varepsilon \angle O G \mathrm{I}$ & INIOdLJS IHIH dO Z/I SyヨLIId & $\varepsilon[\div 6: \mathrm{TN}$ \\
\hline JMNI OI ${ }^{\circ} 0$ & $96 \nabla \varepsilon$ & INIOd $1 \exists S$ o7 dO $2 /[$ sy $\exists I 7 I J$ & $2[: 6 \mathrm{IN}$ \\
\hline JMNI $Z \cdot \varepsilon$ & $\angle 920 \mathrm{I}$ & INIOd $13 \mathrm{~S}$ IH d0 2 y & II $I^{\circ} 6 \mathrm{IN}$ \\
\hline JMNI $L^{\circ} \varepsilon$ & 09EI I & INIOd $13 S$ IHIH dO 2 y $317 I d$ & $0 I^{\circ} 6 \mathrm{IN}$ \\
\hline JMNI OI'0 & $\overline{96 t \varepsilon}$ & INIOd $13 S$ O 1 da 2 y & $6: 6 \mathrm{IN}$ \\
\hline JMNI $O g^{\circ} \bullet$ & SLI6 & INIOd $13 S$ IH.d0 [ y & $8: 6 \mathrm{IN}$ \\
\hline JMNI Ot 9 & פGEOI & INIOd LIS IHIH da I Y & $\angle \because 6[N$ \\
\hline JMNI $O I^{*} 0$ & $80+\varepsilon$ & INIOd $1 \exists S$ dO 07 I y]ITIJ & $9: 6 \mathrm{IN}$ \\
\hline W」JS 000I & 29LL2 & INIOd $1 \exists S$ IH MOTJ XOY $\triangle S$ & $\mathrm{G}: 6 \mathrm{IN}$ \\
\hline WJJS $00^{\circ} \subseteq \angle 9$ & $99 \varepsilon 02$ & 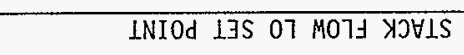 & $7: 6 \mathrm{IN}$ \\
\hline JMNI I & โع86 & INIOd $1 \exists S$ IH dO $y \exists \perp 7 I J-\exists y d$ & $\varepsilon: 6[N$ \\
\hline JMNI $G^{\cdot} \varepsilon^{-}$ & 0429 & 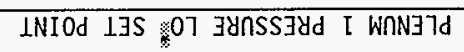 & $2: 6 \mathrm{IN}$ \\
\hline$\% 9 L$ & LOIEI & 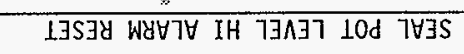 & $02: 8 \mathrm{IN}$ \\
\hline$\% \varsigma \varepsilon$ & $798 L$ & 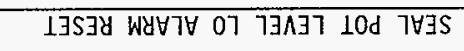 & $6[: 8 \mathrm{IN}$ \\
\hline $\pm 9 t \quad 86 / 8 / t$ & $x a y^{S h}$ tOEEF & $\perp \exists S 3 Y$ WY & $8[: 8 \mathrm{IN}$ \\
\hline J $09 I$ & 09[ & 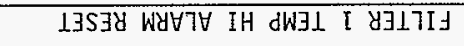 & $9[: 8 \mathrm{IN}$ \\
\hline$\% 26.6 L$ & $\mathrm{G} \angle \mathrm{b} 0 \mathrm{I}$ & 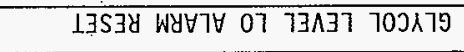 & GI:8IN \\
\hline JMNI $\quad b \varepsilon^{\circ} L$ & Sโ96 & 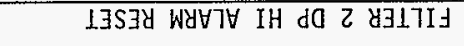 & II:8IN \\
\hline JMNI $0 g^{\circ} 9$ & 8 8โ8 & 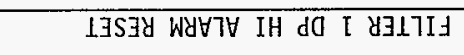 & $8: 8[N$ \\
\hline JMNI $\varepsilon 8^{\circ} \succsim$ & 0950I & 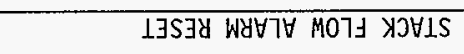 & $G: 8 \mathrm{IN}$ \\
\hline TMNI $00^{\circ} \mathrm{I}$ & โ£86 & 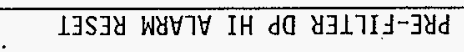 & $\varepsilon: 8 \mathrm{IN}$ \\
\hline 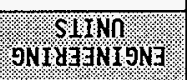 & 2010: & Norldoryosjo & sszyocay \\
\hline
\end{tabular}



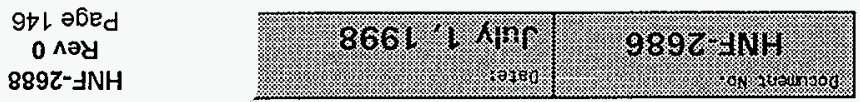

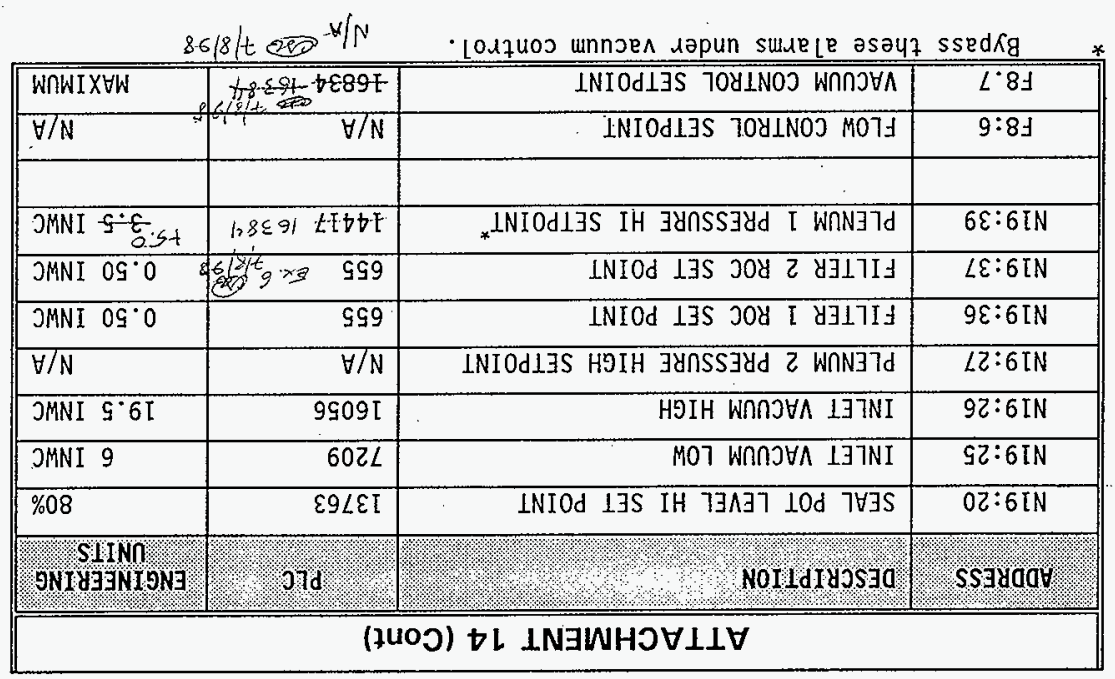




\section{TANK FARM ACCEPTANCE TEST PROCEDURE}

\section{ATTACHMENT 15 - ATP FINAL VALVE LINEUP}

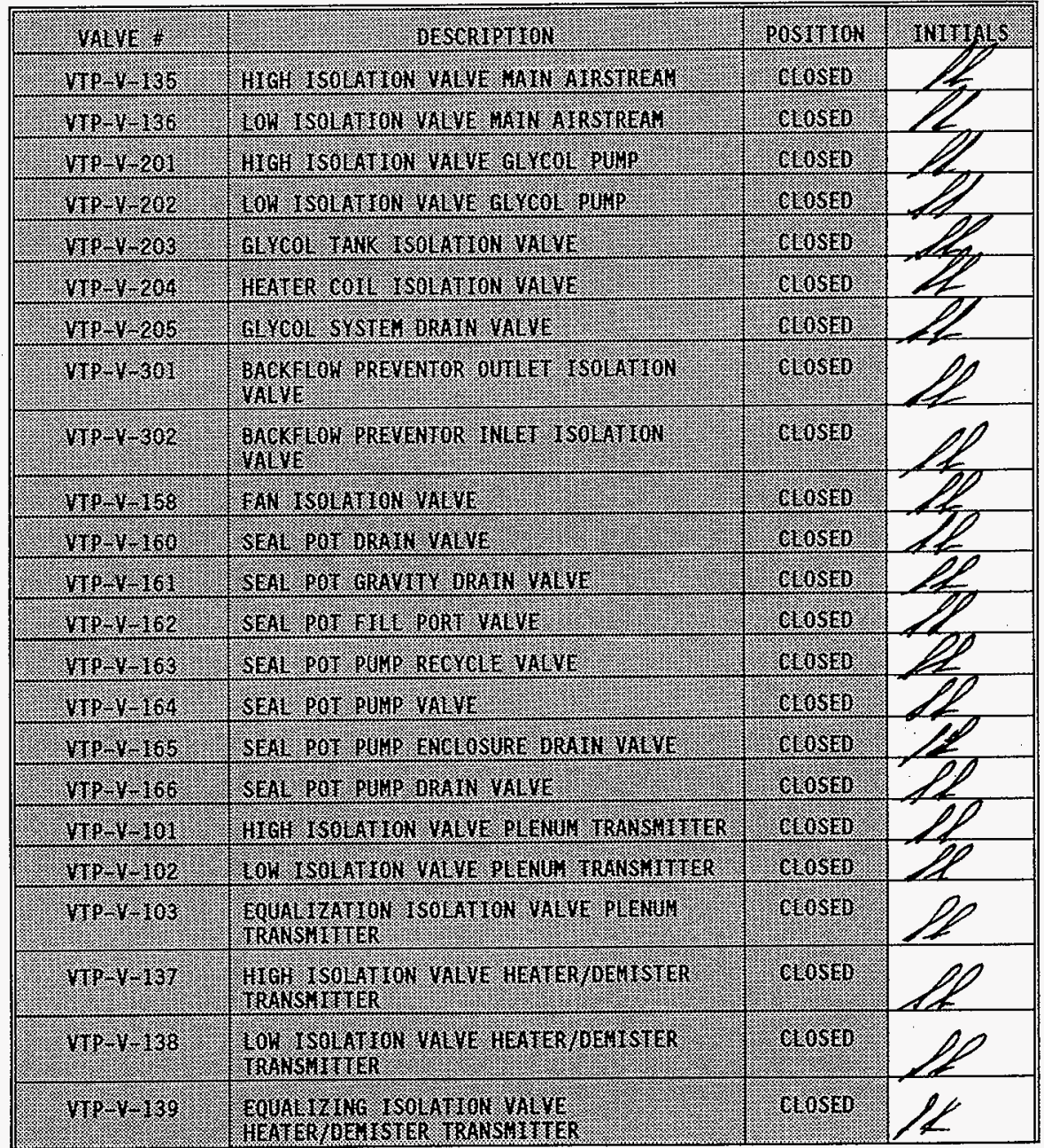




\section{TANK FARM ACCEPTANCE TEST PROCEDURE}

\begin{tabular}{|c|c|c|c|}
\hline Valvir: & BESCRR PT TI ON & pos Thos & WIYKIIS \\
\hline 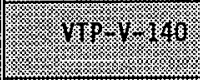 & 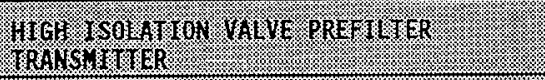 & 480580 & \\
\hline 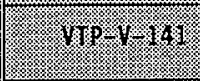 & 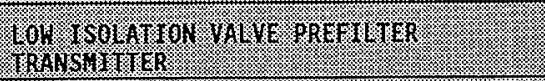 & $4.68 \mathrm{sg}$ & \\
\hline $419=1.192$ & 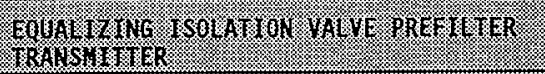 & y.oswo. & \\
\hline 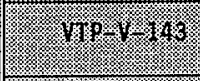 & 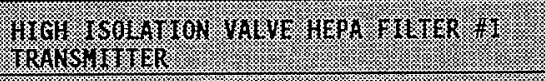 & $9.058 \mathrm{~m}$ & \\
\hline 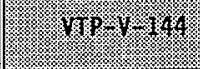 & 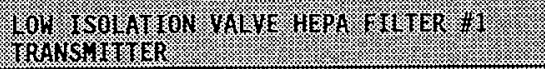 & C.OSGEU & \\
\hline 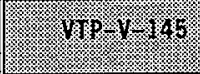 & 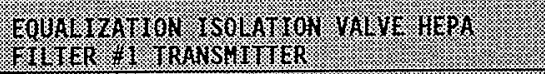 & C.oses & \\
\hline 19. & 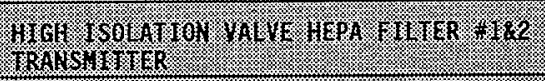 & 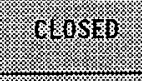 & \\
\hline $419=12$ & 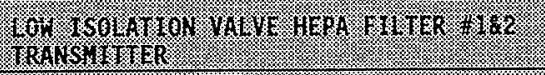 & (c) & \\
\hline$\sqrt{19} \cdot 128$ & 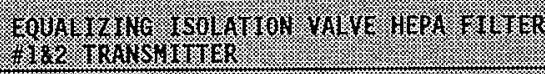 & 4 & \\
\hline$\sqrt{13}=1.499$ & 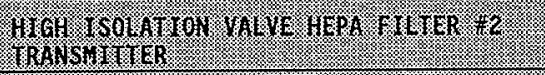 & (c) & \\
\hline$\sqrt{17} \cdot \sqrt{1 / 50}$ & 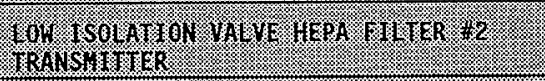 & CE(ESE) & \\
\hline 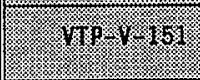 & 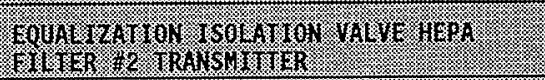 & CESSEO & 7 \\
\hline $17 \mathrm{p}-1.163$ & STIAEK (PIOU) VERTS WUB: & $80 \mathrm{EN}$ & ${ }^{*} \mathrm{~N} / \mathrm{A}$ \\
\hline 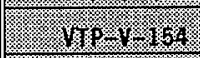 & 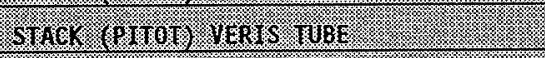 & (1) & *N/A \\
\hline 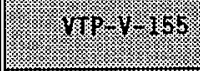 & 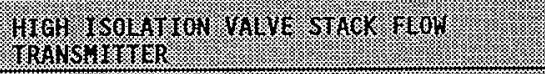 & gesfor & \\
\hline 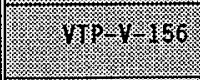 & 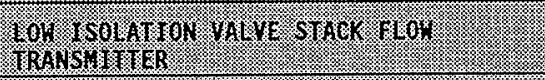 & 840560 & \\
\hline 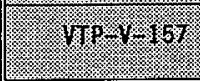 & 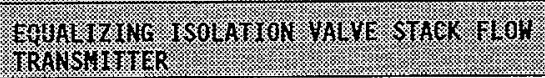 & (1) 1095 & \\
\hline
\end{tabular}

*Stack (pitot) veris tube valves have already been positioned to open.

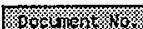

11112.2086
桜

July 1,1998
HNF-2688

Rev 0

Page 148 


\section{ATTACHMENT 16 - ATP FINAL ELECTRICAL LINEUP}

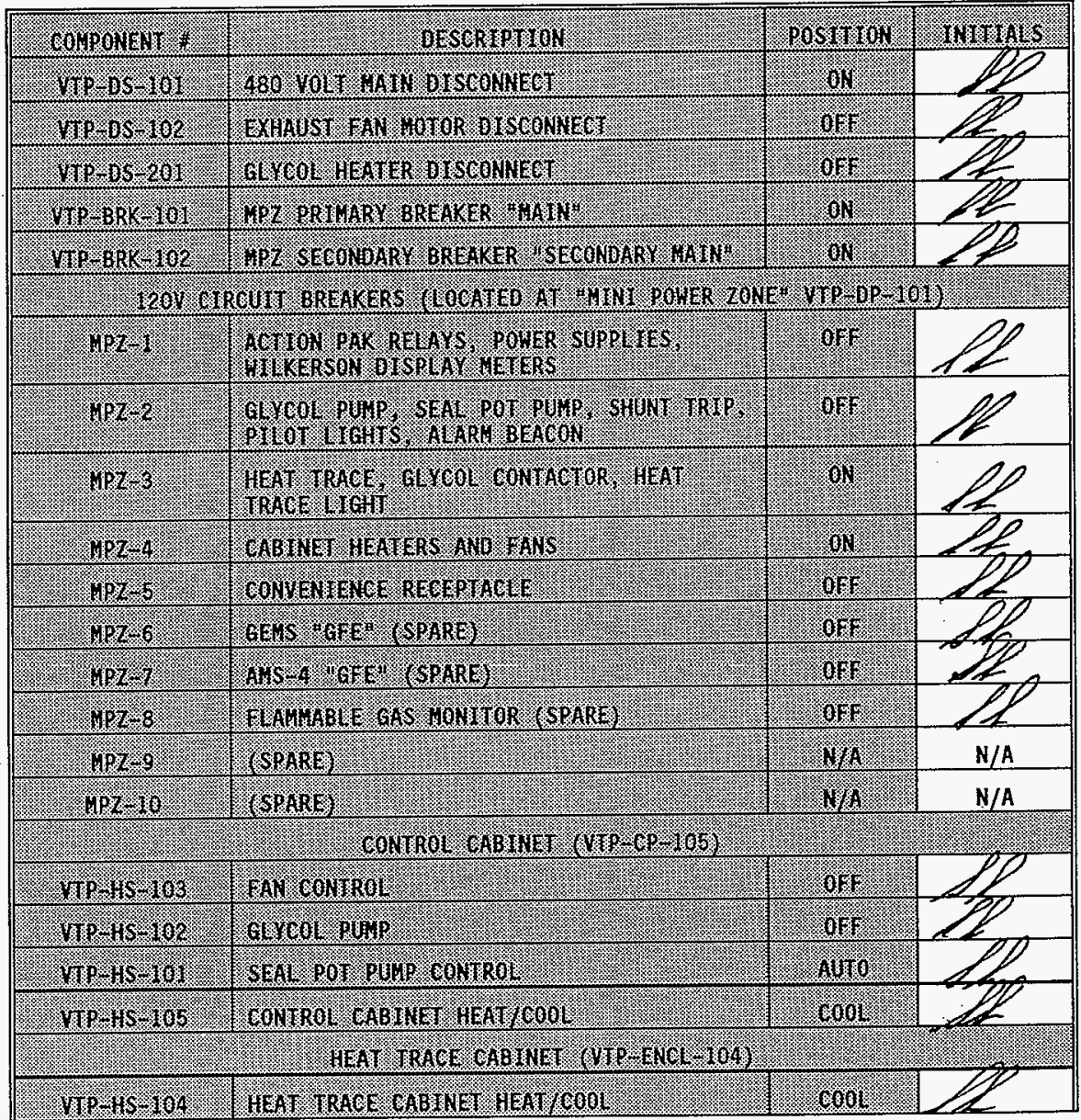




\section{ATTACHMENT 17}

\section{NOISE LEVEL TEST DATA}




\section{ATTACHMENT 18}

\section{SYSTEM PERFORMANCE TEST DATA}




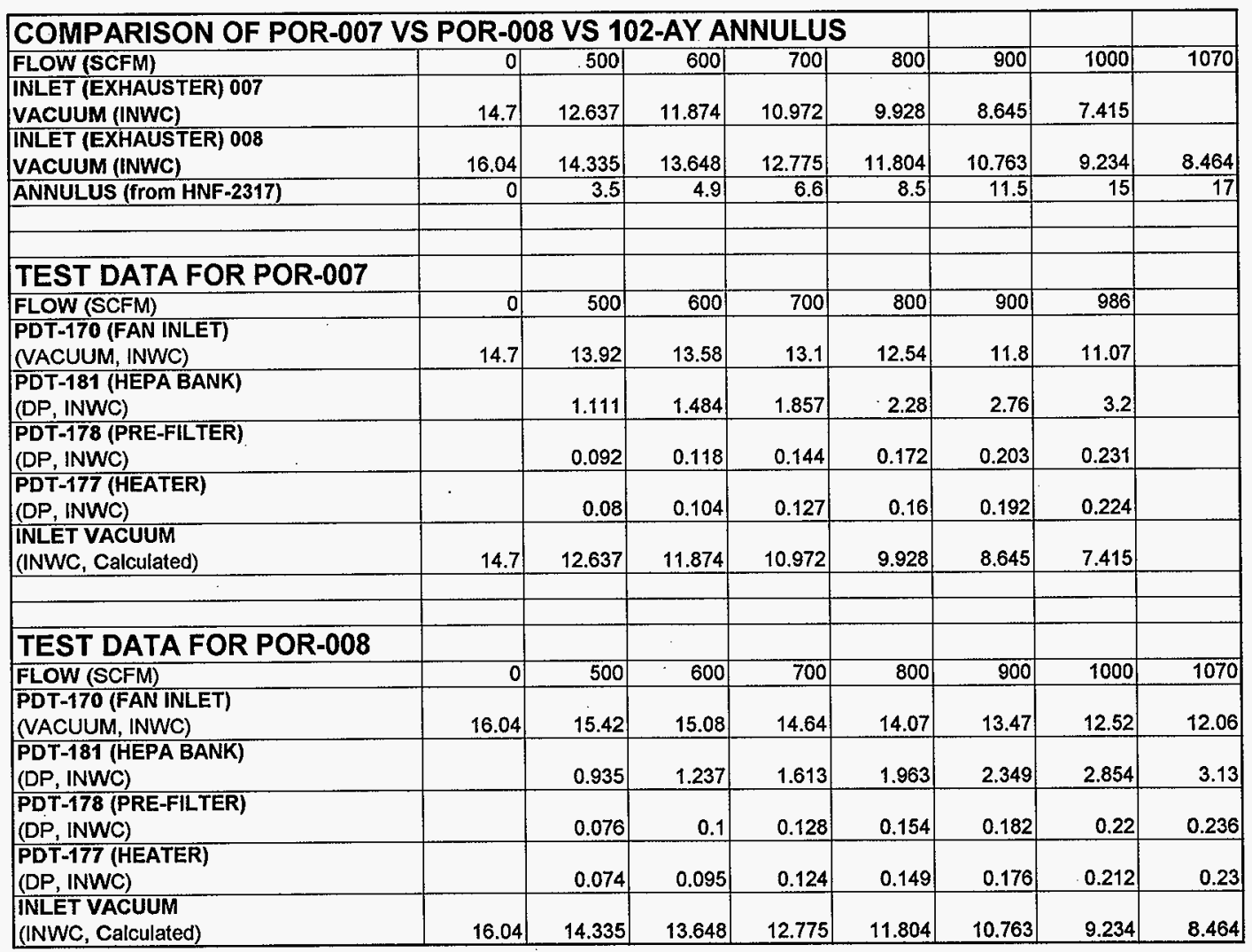

HNF-2688

Rev 0

Page 153 


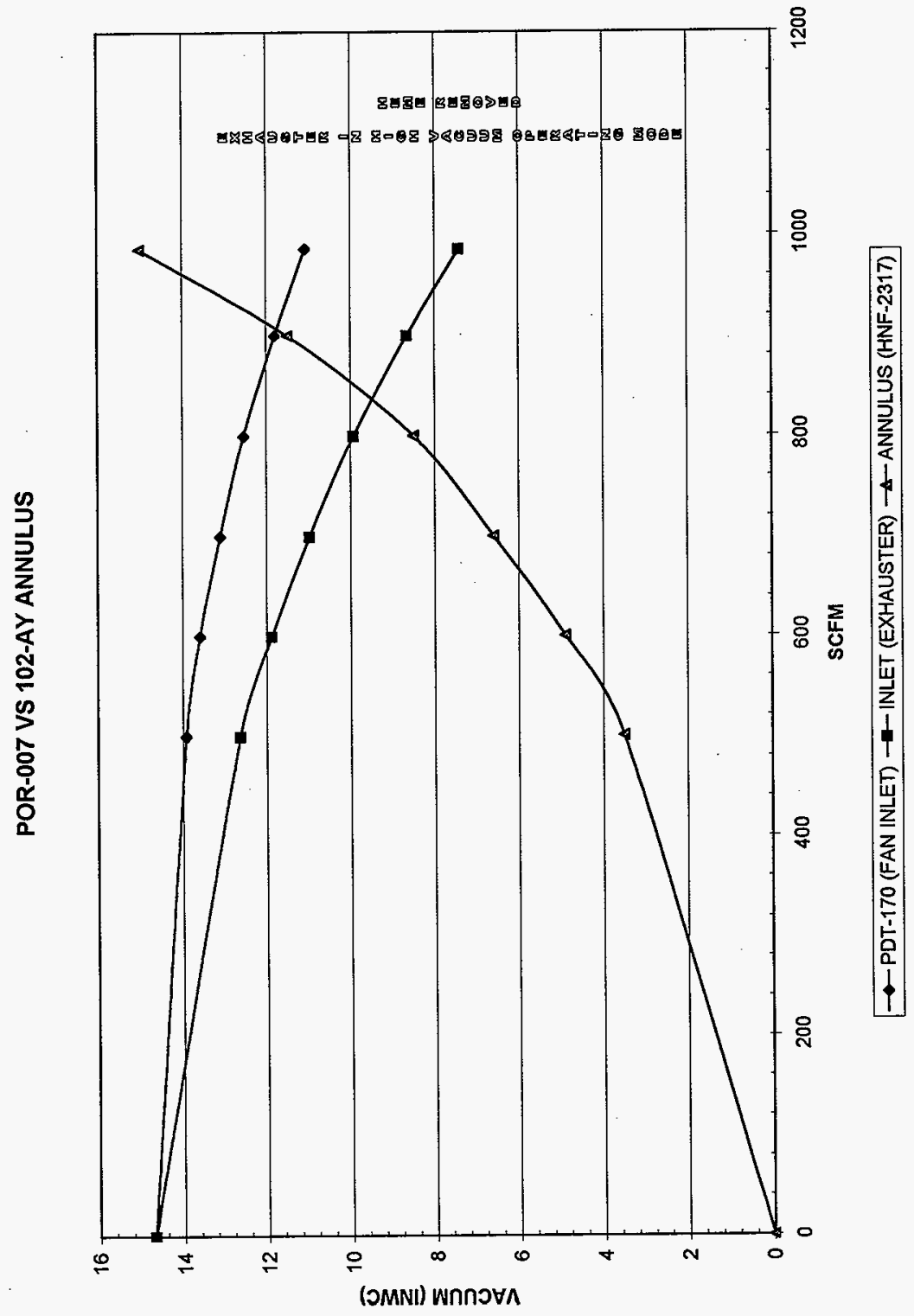

HNF-2688

Rev 0

Page 154 


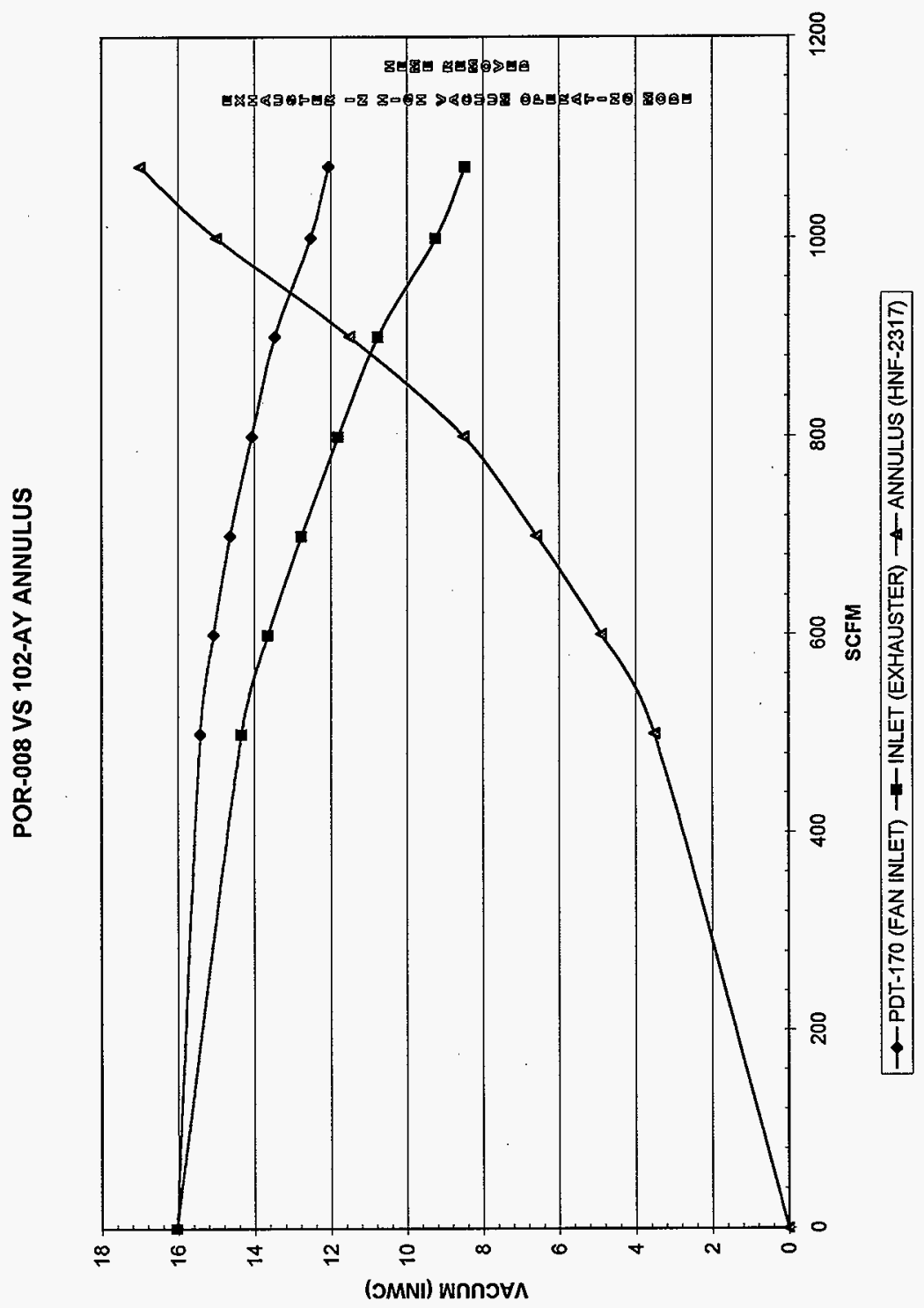

HNF-2688

Rev 0

Page 155 
PORTABLE EXHAUSTER COMPARISON

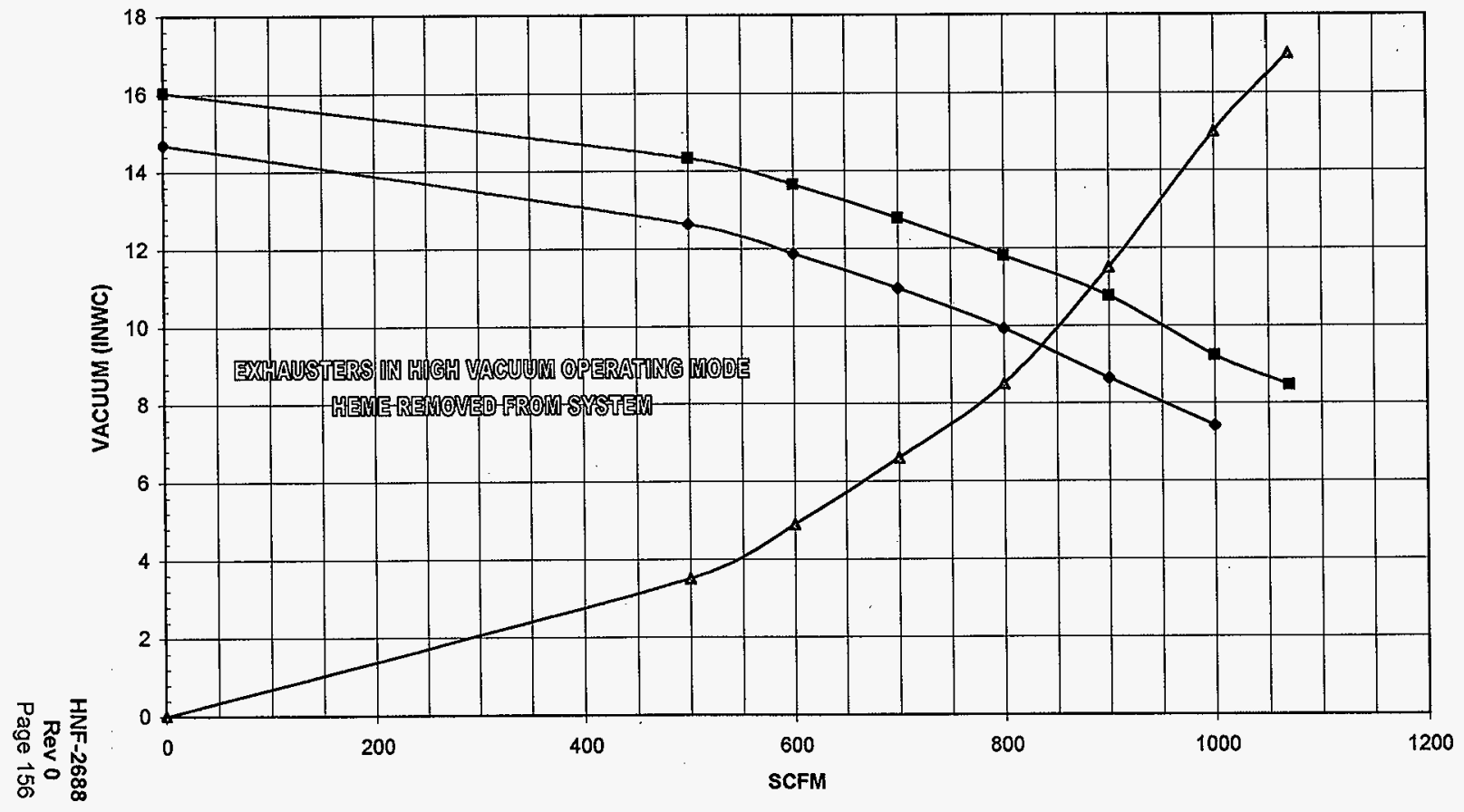

$\rightarrow$ INLET (EXHAUSTER) $007 \rightarrow-$ INLET (EXHAUSTER) $008 \rightarrow$ A ANNULUS (HNF-2317) 